\title{
MARK THOMAZ UGLIARA BARONE
}

\section{CICLO VIGÍLIA/SONO EM PORTADORES DE DIABETES MELLITUS TIPO 1}

Tese apresentada ao Programa de Pós-Graduação em Fisiologia Humana do Instituto de Ciências Biomédicas da Universidade de São Paulo, para obtenção do Título de Doutor em Ciências. 
MARK THOMAZ UGLIARA BARONE

\section{CICLO VIGÍLIA/SONO EM PORTADORES DE DIABETES MELLITUS TIPO 1}

Tese apresentada ao Programa de Pós-Graduação em Fisiologia Humana do Instituto de Ciências Biomédicas da Universidade de São Paulo, para obtenção do Título de Doutor em Ciências.

Área de concentração: Fisiologia Humana

Orientador: Prof. Dr. Luiz Silveira Menna Barreto

Versão Original 
DADOS DE CATALOGAÇÃO NA PUBLICAÇÃO (CIP)

Serviço de Biblioteca e Informação Biomédica do

Instituto de Ciências Biomédicas da Universidade de São Paulo

(C) reprodução total

Barone, Mark Thomaz Ugliara.

Ciclo vigília/sono em portadores de diabetes mellitus tipo 1 / Mark Thomaz Ugliara Barone. -- São Paulo, 2011.

Orientador: Luiz Silveira Menna Barreto.

Tese (Doutorado) - Universidade de São Paulo. Instituto de Ciências Biomédicas. Departamento de Fisiologia e Biofísica. Área de concentração: Fisiologia Humana. Linha de pesquisa: Cronobiologia.

Versão do titulo para o inglês: Sleep/wake cycle in individuals with type 1 diabetes mellitus.

Descritores: 1. Diabetes mellitus tipo 1 2. Ciclo vigília/sono 3. Melatonina 4. Sono 5. Cronobiologia I. Barreto, Luiz Silveira Menna II. Universidade de São Paulo. Instituto de Ciências Biomédicas.

Programa de Pós-Graduação em Fisiologia Humana III. Titulo. 
Candidato(a):

Título da Tese:

Orientador(a):
Mark Thomaz Ugliara Barone.

Ciclo vigília/sono em portadores de diabetes mellitus tipo 1.

A Comissão Julgadora dos trabalhos de Defesa da Tese de Doutorado, em sessão pública realizada a I... ... considerou

\title{
( ) Aprovado(a)
}

( ) Reprovado(a)

\begin{abstract}
Examinador(a): Assinatura:
Nome:

Instituição:

Examinador(a): Assinatura:

Nome:

Instituição:

Examinador(a): Assinatura:

Nome:

Instituição:

Examinador(a): Assinatura:

Nome:

Instituição:

Presidente: Assinatura:

Nome:

Instituição:
\end{abstract}




\section{PARECER 873/CEP}

Prezado Senhor,

Atendendo sua solicitação, a Comissão de Ética em Pesquisas com Seres Humanos do ICB, em sua $91^{\circ}$ reunião realizada em 09.12 .08 , analisou o projeto de sua responsabilidade intitulado: "Ciclo vigília/sono em portadores de diabetes mellitus tipo $1 "$.

Informo a V.Sa. que, após análise e discussão, o referido projeto foi aprovado por esta Comissão.

Lembramos que cabe ao pesquisador elaborar e apresentar a este Comitê, relatórios anuais (parciais ou final), de acordo com a resolução 196/06 do Conselho Nacional da Saúde, item IX.2 letra c.

O primeiro relatório deverá ser encaminhado à Secretaria deste CEP em 09 de dezembro de 2009.

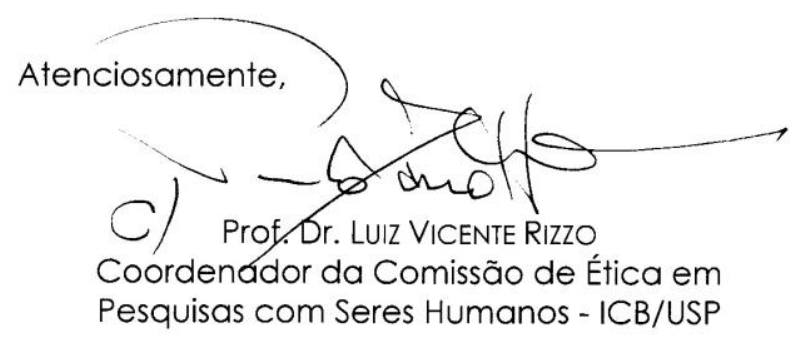

IImo. Sr.

MARK THOMAZ UGLIARA BARONE Departamento de Fisiologia e Biofisica Instituto de Ciências Biomédicas -USP 
Dedico este trabalho às milhares de pessoas que vivem saudáveis com diabetes e seus familiares. Às pessoas que fazem do controle diário da glicemia mais uma daquelas atividades de rotina que não são esquecidas e, assim, não se privam de realizarem seus sonhos e serem felizes. 


\section{AGRADECIMENTOS}

Agradeço a todos aqueles que, direta ou indiretamente, me apoiaram na realização deste trabalho. Felizmente são muitos e seria impossível mencionar todos os nomes. Mas vocês sabem o quanto foram importantes em meu caminho. Deixo registrada minha eterna gratidão.

Pelo constante apoio e incentivo, agradeço toda minha família, em especial minha mãe, Mirian Ugliara Barone, meu pai, Francisco Barone, meu irmão, Fernando Barone, meus avós, Alice e Salvador Ugliara, meus tios, Liane e Pedro Rasmussen, e minha prima, Cinthya Ugliara.

Aproveito para agradecer todos os ótimos professores, educadores e mestres, que tive durante toda minha vida, por suas incansáveis buscas pelo conhecimento e imensa preocupação em ensinar o que é preciso que se saiba e, com isso, fazer a diferença na vida de seus alunos. Agradeço ainda meus alunos, que me motivam diariamente a aprender mais.

Agradeço com destaque o meu orientador, Prof. Luiz Menna-Barreto, pelos ensinamentos, dedicação e incentivo constante.

Agradeço os membros da banca de qualificação, Prof. José Cipolla-Neto, Profa. Sandra Ferreira-Vivolo e Dra. Sonia Togeiro, pelas sugestões que possibilitaram o enriquecimento do presente trabalho.

Agradeço os que foram parceiros diretos para a execução deste estudo: Denise Franco e toda a equipe da ADJ; Prof. Geraldo Lorenzi, Fabíola Schorr, Maria Vanderlea e a ótima equipe de técnicos do Laboratório do Sono do InCor-FMUSP; Mario Carra, Karla Melo e Márcia Nery do HC-FMUSP; Fernando Fonseca e André Gonçalves da FMABC; Daniela Wey, Mario Miguel, Clarissa Bueno, Leila Affini, Eduardo Santos do GMDRB; e Lucy Aihara, Juliana Baptista, Cinthya Ugliara, e especialmente aos 27 voluntários.

Aos membros do GMDRB que me acolheram tão bem há muitos anos, ou que integraram o grupo mais tarde, e que apesar dos caminhos dificultarem os reencontros, a amizade permanece: Ana Amélia Fracalossi, Andrea Ferrari, Caroline Araújo, Clarissa Bueno, Daniela Wey, Eduardo Santos, Eugênia Mesquita, Fernanda Torres, Flávio Back, Hadassa Batinga, José Ricardo Lopes, Juliana Tonsmann, Leandro Duarte, Leila Affini, Márcia Braz, Maria Raquel de Carvalho, Mario Miguel, 
Prof. Mario Pedrazzoli, Roberta Áreas, Rodrigo Tambelli, Valéria Oliveira, e também aos que vieram antes ou estão chegando agora.

Não poderia deixar de agradecer ainda o José Maria Rodrigues Junior e a Paloma Cañipa pelas orientações durante todo o doutorado.

E à FAPESP pelo apoio financeiro (processo número: 2008/11026-2).

Muito obrigado! 
Para atingir o sonho impossivel, tente ir dormir. Joan Klempner

To achieve the impossible dream, try going to sleep. Joan Klempner 


\section{RESUMO}

Barone MTU. Ciclo vigília/sono em portadores de diabetes mellitus tipo 1 [Tese (Doutorado em Fisiologia Humana)]. São Paulo: Instituto de Ciências Biomédicas da Universidade de São Paulo; 2011.

Associações entre diabetes mellitus e controle glicêmico com aspectos do sono têm chamado a atenção da comunidade científica ultimamente. Nosso objetivo, no presente estudo, foi avaliar possíveis relações entre o diabetes mellitus tipo 1 e controle glicêmico, e o ciclo vigília/sono. Para isso recrutamos 18 voluntários portadores de diabetes mellitus tipo 1 (DM1) (idade: $26,3 \pm 5,1$ ), sem complicações crônicas, não obesos, não usuários de medicamentos que alteram o sono, não trabalhadores noturnos ou em turnos, e sem diagnóstico prévio de distúrbio do sono. Recrutamos também 9 voluntários para o grupo controle (idade: $28,8 \pm 5,3$ ), com as mesmas características, porém não portadores de diabetes. Os dados foram coletados através de: diário de sono e de glicemia, de actímetria (Tempatilumi) durante 10 dias consecutivos, polissonografia, dosagem de 6-sulfatoximelatonina (6SMT) na urina noturna de $12 \mathrm{~h}$, e questionário de sonolência de Epworth. Os voluntários DM1 tiveram a glicose monitorada durante o exame de polissonografia através de sensor subcutâneo (equipamento $\mathrm{CGMS}^{\circledR}$, Medtronic). Destacamos os seguintes resultados: a) níveis significativamente mais elevados de 6-SMT no grupo controle, comparado ao grupo de indivíduos DM1 com a média da glicemia alta (>154 mg/dl); b) correlação negativa entre a média da glicemia dos indivíduos com a média da glicemia baixa (<154 mg/dl) e a média da qualidade do sono; c) correlação positiva entre a média da latência do sono e a média da glicemia e a variabilidade glicêmica; d) a privação de sono durante a semana foi maior no grupo DM1 que no grupo controle; e) correlação positiva entre o número de despertares completos e microdespertares e a hemoglobina glicada; f) correlação negativa entre a média da glicemia dos indivíduos DM1 com a média da glicemia baixa (<154 mg/dl) e a média da duração do repouso noturno. A associação entre controle glicêmico e o ciclo vigília/sono é evidenciada no presente estudo. A duração inadequada, a baixa qualidade, a fragmentação do sono e a secreção reduzida de melatonina, possivelmente, favoreceram um pior controle glicêmico em DM1. Por outro lado, entendemos que indivíduos DM1, com melhor controle em termos de média e variabilidade glicêmica, podem se beneficiar de maior secreção de melatonina 
noturna e menor fragmentação e latência do sono. Esse controle mais adequado, além de regularizar o ciclo vigília/sono, potencialmente, previne ou retarda o desenvolvimento de complicações crônicas, aumentando a qualidade de vida desses indivíduos.

Palavras-chave: Diabetes mellitus tipo 1. Ciclo vigília/sono. Melatonina. Sono. Cronobiologia. 


\begin{abstract}
Barone MTU. Sleep/Wake cycle in individuals with type 1 diabetes mellitus [Ph.D. Thesis (Human Physiology)]. São Paulo: Instituto de Ciências Biomédicas da Universidade de São Paulo; 2011.
\end{abstract}

Associations of diabetes mellitus and glycemic control with sleep have been attracting the attention of the scientific community. Our goal in this study was to evaluate the relationship of type 1 diabetes mellitus and glycemic control with the sleep/wake cycle. For this purpose we recruited 18 volunteers with type 1 diabetes mellitus (T1DM) (age: 26.3 \pm 5.1 ), non-obese, free of diabetes chronic complications and of drugs that affect sleep, non-night or -shift workers and without previous diagnostic of sleep disorder. We also recruited nine volunteers for the control group (age: $28.8 \pm 5.3$ ), with the same characteristics, but without diabetes. Data were collected through: sleep and blood glucose diaries and actigraphy (Tempatilumi) for 10 consecutive days, polysomnography, measurement of 6-sulphatoxymelatonin (6$\mathrm{SMT}$ ) in $12 \mathrm{~h}$ night urine, and the Epworth sleepiness questionnaire. The T1DM volunteers had the glucose monitored during polysomnography through subcutaneous sensor (CGMS $\AA$, Medtronic). Our main results are: a) significantly higher levels of 6-SMT in the control group, compared with the T1DM group of individuals with high glycemic mean (> $154 \mathrm{mg} / \mathrm{dl}$ ), b) negative correlation between the mean glycemia of subjects with low mean glycemia $(<154 \mathrm{mg} / \mathrm{dl})$ and the mean sleep quality, c) a positive correlation between the mean latency sleep and the mean glycemia and the glycemic variability, d) sleep deprivation during the week was higher in T1DM group comparing to the control group, e) positive correlation of the number of full awakenings and arousals with glycated hemoglobin, f) negative correlation between mean glycemia of T1DM individuals with low mean glycemia $(<154 \mathrm{mg} / \mathrm{dl})$, and mean duration of nocturnal rest. The association between glycemic control and the sleep/wake cycle is evidenced in this study. The inadequate duration, poor quality, fragmented sleep and reduced secretion of melatonin are possibly favoring a worse glycemic control in T1DM. On the other hand, we understand that T1DM individuals with better glycemic control in terms of mean glycemia and glycemic variability may benefit from increased nocturnal melatonin secretion and less sleep fragmentation and latency, which also regulate the sleep/wake cycle potentially facilitate the maintenance of a good glycemic control, preventing or 
delaying the development of chronic complications and improving life quality of these individuals.

Keywords: Type 1 diabetes mellitus. Sleep/wake cycle. Melatonin. Sleep. Chronobiology. 


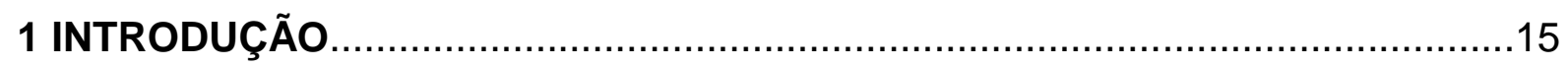

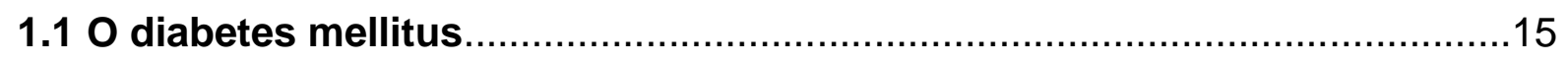

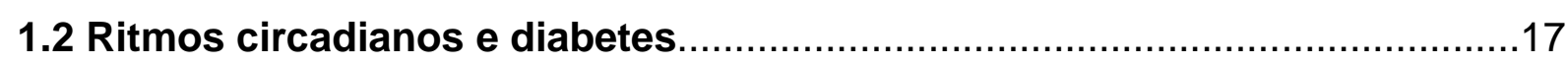

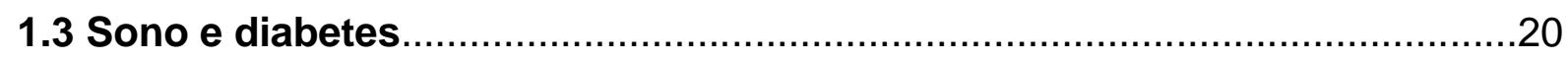

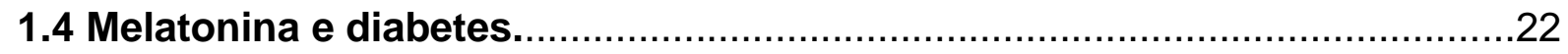

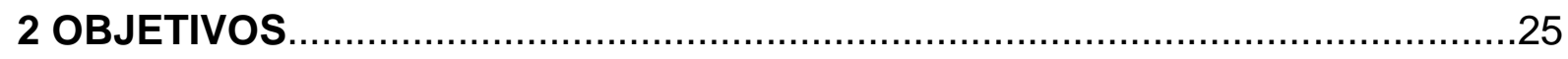

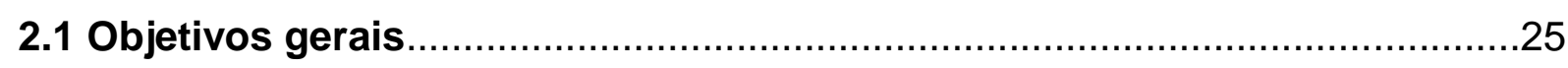

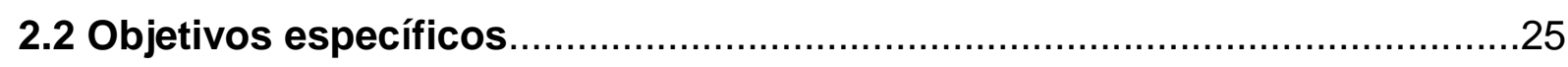

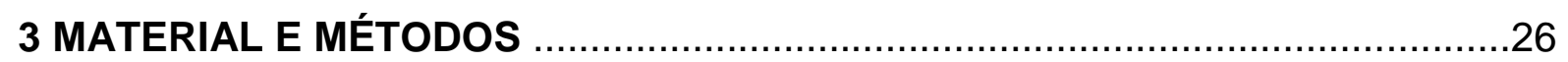

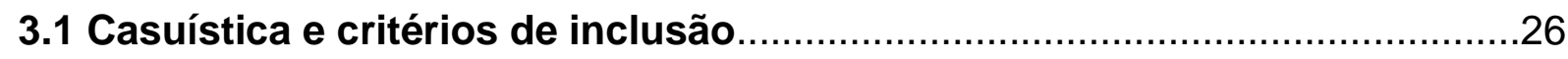

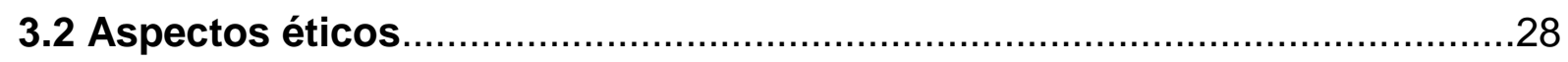

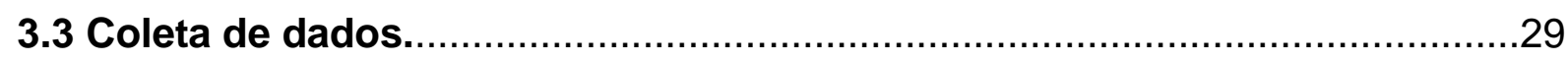

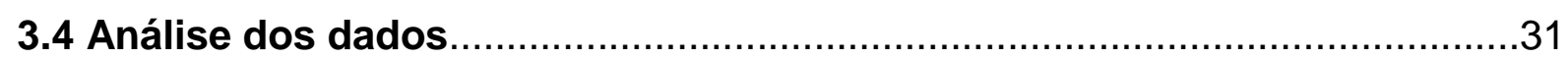

4 RESULTADOS

4.1 Melatonina

4.2 Sono

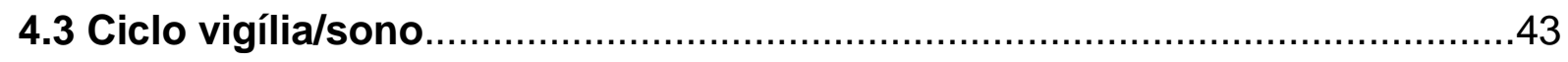

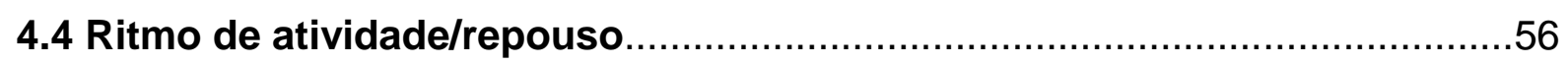

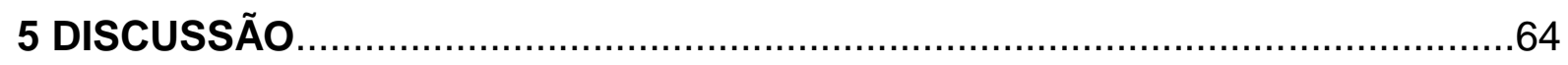

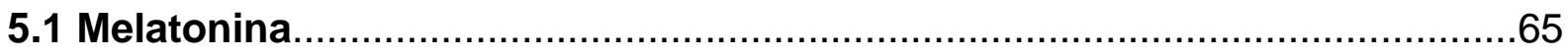

5.2 Sono

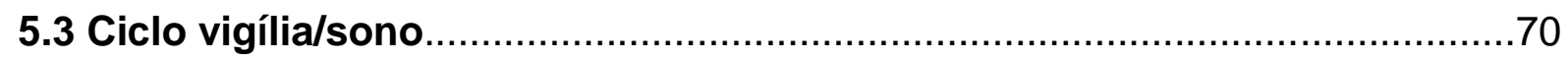

5.4 Ritmo de atividade/repouso

5.5 Limitações do presente estudo..............................................................77

6 CONCLUSÃO 
APÊNDICE A - Relatório médico para seleção ou exclusão de voluntários do grupo DM1 .90

APÊNDICE B - Protocolo de triagem para avaliação de neuropatia e retinopatia.....92 APÊNDICE C - Correlação entre dados do diário de sono e do Tempatilimi (actímetro)

ANEXO A - Termo de consentimento para realização dos procedimentos para triagem, avaliação de complicações.

ANEXO B - Parecer da Comissão de Ética em Pesquisa com Seres Humanos do Instituto de Ciências Biomédicas da USP 98

ANEXO C - Parecer da Comissão de Ética do Hospital das Clínicas da Faculdade de Medicina da Universidade de São Paulo. .99

ANEXO D - Carta da Comissão Científica do Instituto do Coração da Faculdade de Medicina da Universidade de São Paulo. 100

ANEXO E - Carta da Associação de Diabetes Juvenil. 101 ANEXO F - Termo de consentimento livre e esclarecido apresentado aos voluntários do HC-FMUSP 102

ANEXO G - Termo de consentimento livre e esclarecido apresentando aos voluntários da ADJ e aos do grupo controle. 105

ANEXO H - Escala de sonolência de Epworth. 107

ANEXO I - Diário de Sono .108

ANEXO $\mathbf{J}$ - Tempatilumi. 110

ANEXO K - Diário de Glicemia 


\section{INTRODUÇÃO}

\subsection{0 diabetes mellitus}

O diabetes mellitus (DM), grupo de disfunções metabólicas caracterizadas por hiperglicemia, resultante de defeito na secreção de insulina, na ação deste hormônio, ou ambos (American Diabetes Association, 2011), tem chamado a atenção das autoridades por estar aumentando em prevalência de forma pandêmica. Estima-se que em 2010 o diabetes tenha afetado, no mundo todo, 285 milhões de pessoas, com idade entre 20 e 79 anos (6,4\% das pessoas nessa faixa etária). Em 20 anos, portanto em 2030, estima-se que $7,7 \%$ da população mundial (aproximadamente 439 milhões de pessoas) seja afetada por diabetes (Sicree et al., 2009). O diabetes mellitus do tipo 2 (DM2), caracterizado pela combinação da resistência à ação da insulina e resposta compensatória da secreção de insulina inadequada (American Diabetes Association, 2011), é responsável por $85-95 \%$ de todos os casos (Sicree et al., 2009). Apesar de todos os grupos serem vulneráveis, a incidência de DM2 tem sido ainda maior em minorias étnicas e povos nativos (Acton et al., 2002). É interessante notar que o DM2, considerado no passado uma doença de idosos, tem acometido cada vez mais crianças, adolescentes e adultos jovens (Wahi et al., 2009). O aumento da prevalência do DM2 no mundo é atribuído principalmente aos seguintes fatores: aumento da expectativa de vida e, portanto, da idade da população, alimentação não saudável, sobrepeso e obesidade, e sedentarismo (Sicree et al., 2009; Keiss et al., 2003).

Já o diabetes mellitus tipo 1 (DM1), apesar de não ter seu desenvolvimento associado a um estilo de vida favorecedor do desenvolvimento de resistência à ação da insulina e de alterações metabólicas que levam à lenta e progressiva incapacidade de produção suficiente de insulina, também tem tido sua prevalência aumentada (International Diabetes Federation, 2010). Em 2010 o DM1 atingia 479,6 mil crianças entre 0 e 14 anos no mundo, e sua incidência se mostra em franca ascensão de $3 \%$ ao ano (IDF, 2010). A maior parte dos casos de DM1 é atribuída à destruição autoimune das células beta pancreáticas, levando à falência das mesmas 
e consequente deficiência secretória absoluta de insulina (American Diabetes Association, 2011). Sabe-se que há predisposição genética ligada à destruição autoimune das células beta pancreáticas, assim como fatores ambientais desencadeadores. Porém, estes fatores ainda são pouco conhecidos e estão sendo investigados (American Diabetes Association, 2011).

Enquanto se busca desvendar os fatores ambientais que estariam levando ao aumento da prevalência do DM1, as autoridades, aos poucos, têm se mobilizado para educar a população e tentar reduzir o aumento da incidência de DM2, que tanto onera os cofres públicos. Pelos motivos que discutiremos adiante, entendemos que, apesar dos componentes genéticos associados ao desenvolvimento de ambos os tipos de diabetes e os fatores ambientais que favorecem o desenvolvimento do DM2, o sono adequado pode ser um fator tanto para a redução da incidência de DM2 quanto para a manutenção do bom controle glicêmico em ambos os tipos de diabetes (Barone e Menna-Barreto, 2010). Entendemos que o sono seria visto de forma incompleta caso não se considerasse a vigília. E, anormalidades no ciclo vigília/sono poderiam retratar, em portadores de diabetes, um controle glicêmico inadequado.

A instabilidade glicêmica, frequente em muitos portadores de DM, e fator desencadeante de hiperglicemias e hipoglicemias, produz sintomas como: fadiga, cansaço, sonolência, diminuição do nível de atenção, entre outros. Estes sintomas indicam uma possível influência da glicemia sobre o ciclo vigília/sono, e têm chamado a atenção de pesquisadores que relatam que variações nos níveis de glicemia contribuem para o aumento do risco de acidentes em pessoas que exercem profissões que exigem atenção e alerta constantes, como motoristas de caminhão (Moreno et al., 2003).

Sabe-se bem que as graves complicações, tanto agudas quanto crônicas do DM, podem ser evitadas ou postergadas com um controle adequado da glicemia. Dessa forma, orientações sobre sono de qualidade e duração adequada, devem ser incorporadas às demais orientações clínicas para o controle glicêmico do DM, já que podem contribuir para um melhor controle glicêmico. 


\subsection{Ritmos circadianos e diabetes}

Entre os ritmos circadianos mais estudados, na espécie humana, estão: o ciclo vigília/sono, o ritmo de temperatura central e periférica, e o ritmo de secreção de muitos hormônios, entre os quais se destacam a melatonina, o cortisol e o hormônio de crescimento. Apesar de a literatura, muitas vezes, utilizar os termos ritmo circadiano e ritmo diário como sinônimos, já que ambos tem período de $24 \mathrm{~h} \pm$ $4 \mathrm{~h}$, formalmente o ritmo só pode ser considerado circadiano quando além exibir essa periodicidade, tenha sido medido com o organismo isolado de pistas temporais do ambiente (Halberg et al., 1977). Por esse motivo, muitos dos ritmos mencionados neste trabalho serão denominados ritmos diários.

A existência de ritmos biológicos talvez tenha sido notada, e chamado a atenção dos seres humanos, desde o surgimento dos Homo sapiens. Por que dormimos, por exemplo, é uma questão que comumente aparece já na infância. A observação de ritmos na natureza é encontrada em registros desde a Grécia antiga (Rotenberg et al., 2003). Os ciclos ambientas têm influência tão evidente sobre os ritmos biológicos que a compreensão de que haveriam temporozadores endógenos veio muito depois dos primeiros experimentos sobre o tema. O primeiro registro de observação de ritmo em organismo isolado é sobre o movimento periódico de folhas de uma planta do gênero Mimosa, mantida em escuro constante, feita pelo astrônomo De Mairan, em 1729 (Rotenberg et al., 2003). Nessa ocasião, os movimentos foliares regulares, mesmo em isolamento de ciclos ambientais de claro/escuro, já davam pistas da endogenicidade do fenômeno, mas ainda eram entendidos como se a planta sentisse o sol mesmo sem vê-lo.

O caráter endógeno dos ritmos observados na natureza teve muita resistência para ser aceito e, aparentemente, só em 1935 com o cruzamento de plantas de feijão, que possuíam períodos diferentes para os movimentos foliares, a determinação genética da ritmicidade biológica passou a ser aceita (Rotenberg et al., 2003). Quanto à ritmicidade dos fenômenos comportamentais e fisiológicos em seres humanos, os que mais nos interessam no presente estudo são o ciclo vigília/sono e o ritmo de atividade/repouso em indivíduos com diabetes mellitus tipo 1, além da influência do controle glicêmico sobre esses ritmos, assim como desses 
ritmos sobre o controle glicêmico. Como veremos adiante, evidências da influencia do diabetes ou do descontrole glicêmico sobre esses e outros ritmos, podendo levar a achatamento da amplitude e mudanças de fase, têm se acumulado.

Em experimentos tanto com animais, quanto com humanos, já foi indicado que os níveis glicêmicos variam diariamente (Yamamoto et al., 1987; Boden et al., 1996). Esta variação acompanha os ritmos também diários de tolerância à glicose (Van Cauter et al., 1997), de produção hepática de glicose (Cailotto et al., 2005), e de secreção de insulina (Boden et al., 1996; Merl et al., 2004). Autores têm apontado que o ritmo circadiano de secreção de insulina está em oposição de fase ao ritmo de secreção de melatonina, atingindo seus maiores valores durante o dia, em especial pela manhã (Peschke, 2008; Merl et al., 2004). Contudo, a secreção de insulina apresenta também ritmos ultradianos muito evidentes, compostos por pulsos de 5 a 10 minutos e outros de 50 a 120 minutos (Simon e Brandenberger, 2002), e passiveis de mascaramento, por consumo alimentar, por exemplo.

Ademais, o grupo da Dra. Van Cauter, entre outros, tem demonstrado que a tolerância à glicose, em portadores de ambos os tipos de diabetes, varia diariamente de forma bastante distinta da observada em indivíduos não portadores de DM (Simon, 1998; Van Cauter et al., 1997; Scheen e Van Cauter, 1998), parecendo se tratar de inversão de fase desse ritmo. Enquanto portadores de DM apresentam menor tolerância à glicose pela manhã e aumento da tolerância com o passar das horas do dia, indivíduos não acometidos apresentam maior tolerância à glicose pela manhã e diminuição dessa tolerância com o passar das horas do dia.

A amplitude de ritmos circadianos é outro elemento que merece especial atenção. Segundo Mejean et al. (1988), a grande amplitude dos ritmos circadianos de glicemia, observada em portadores de DM, poderia ser considerada como um fenômeno cronopatológico, ou seja, expressão de perturbações do sistema de temporização. De acordo com Aronson (2001), o DM está associado a anormalidades dos padrões temporais diários de diversos processos comportamentais e fisiológicos, que incluem alterações nas variações hormonais diárias, ritmo de atividade locomotora e mudanças na resposta do oscilador circadiano sensível à luz.

Autores, em estudos mais recentes, têm revelado a associação entre metabolismo e ritmos no nível molecular. Como vimos, em indivíduos com diabetes 
mellitus o ritmo de tolerância à glicose tem sua fase invertida ao de indivíduos sem DM. Isso sugere alterações no sistema de temporização. Camundongos com mutação em genes do sistema de temporização em suas ilhotas pancreáticas (no caso os genes relógio selecionados foram o Clock e o Bmal1) tiveram redução nos níveis de expressão e/ou inversão de fase de oscilação de RNA de genes envolvidos na sinalização da insulina, na sensibilidade à glicose e no crescimento e desenvolvimento das ilhotas (Marcheva et al., 2010). Nesses estudos se observou: elevação dos níveis de glicose durante todo o ciclo claro/escuro, sem aumento nos níveis de insulina; aumento da variação da glicemia, em especial no início da fase escura; $50 \%$ de redução na secreção de insulina diante de teste de tolerância à glicose; e $23 \%$ de diminuição na proliferação das ilhotas, concomitante a tendência de aumento de apoptose das mesmas. Os autores destes estudos concluíram que, pelo fato de mutação em qualquer dos dois genes, Clock e Bmal1, produzir efeitos muito semelhantes nas células $\beta$ pancreáticas, o sistema de temporização celular, incluindo sua multiplicidade de genes, tem impacto sobre o funcionamento e desenvolvimento das células $\beta$.

Assim, os genes relógios, que estão envolvidos com outras funções, como os ritmos circadianos de atividade/repouso e temperatura, têm papel importante nas células pacreáticas e, portanto, sobre metabolismo (Bass e Takahashi, 2010). Dessa forma, a coincidência entre distúrbios tanto de ritmos biológicos, como o ciclo vigília/sono, quanto do metabolismo energético, pode não ser casual mas sim envolver alterações a nível molecular, ou na expressão de genes relógio, ou mesmo resultarem do atrito entre o geneticamente programado e o comportamento. Este atrito pode se acontecer devido a:1) demandas sociais que se distanciam das características rítmicas diurnas da espécie humana; 2) trabalhos noturnos, e em longos turnos, que sabidamente favorecem o desenvolvimento de síndrome metabólica e portanto de resistência a ação da insulina e DM2 (Esquirol et al., 2009); 3) descontrole glicêmico, que pode levar ao desajuste do ritmo de secreção de hormônios, alterações do sono, e até mesmo ter efeitos sobre a transcrição gênica (Aronson, 2001; Trento et al., 2008; El-Osta et al., 2008).

Portanto, entendemos que cada vez mais evidências se acumulam demonstrando que, preponderantemente, o controle glicêmico inadequado no DM, tanto do tipo 1 quanto do tipo 2, está associado a alterações em padrões rítmicos; e 
que alterações em ritmos biológicos estão associadas a alterações metabólicas que podem favorecer o desenvolvimento de DM2 ou agravar o controle glicêmico em indivíduos já acometido por DM.

\subsection{Sono e diabetes}

Autores têm sugerido, ainda, que o DM contribui para o surgimento de distúrbios do sono (Resnick et al., 2003), que distúrbios do sono podem afetar negativamente a tolerância à glicose (Scheen et al., 1996) e que a qualidade do sono pode influir sobre a utilização da glicose (Scheen e Van Cauter, 1998), gerando, assim, um processo que se retro-alimenta (Barone e Menna-Barreto, 2011). Autores afirmam que distúrbios respiratórios, assim como qualidade e duração inadequadas do sono podem conduzir ao DM2, por estarem fortemente associados ao desenvolvimento de intolerância à glicose e resistência à insulina (Punjabi et al., 2004; Kutson et al., 2006).

Dessa forma, entendemos que DM2 e distúrbios do sono se retro-alimentam, um favorecendo o desenvolvimento e agravamento do outro. Pelo mesmo motivo, tolerância à glicose reduzida e aumento da resistência à insulina, geradas por distúrbios, privação e má qualidade de sono, afetariam negativamente o controle metabólico tanto em pessoas com DM2 quanto com DM1.

Nos Estados Unidos tem sido proposto que a alta prevalência do diabetes, $12,3 \%$ da população entre 20 e 79 anos (Sicree et al., 2009), pode estar favorecida pela privação de sono, muito característica em tal sociedade, e favorecedora do ganho de peso e da resistência à insulina (Dinsmoor, 2002). Por esse motivo, recomendações já vêm sendo feitas em relação à necessidade de duração e qualidade de sono para controle adequado do DM2 (Knutson et al., 2006; Trento et al., 2008). Mais recentemente foi demonstrado também em DM1 que a privação parcial do sono leva a redução significativa da sensibilidade à insulina (Donga et al., 2010). Por esse motivo, entendemos que essas recomendações de sono, de qualidade e duração adequada, devem ser estendidas a indivíduos com DM1, que também se beneficiarão, seja diretamente, reduzindo a resistência à insulina e 
melhorando o controle glicêmico, ou indiretamente, prevenindo o desenvolvimento de outras condições, com potencial para afetar tanto o sono quanto o controle metabólico; destacamos obesidade e apnéia obstrutiva, pressão alta, desregularão neuro-hormonal da saciedade e do metabolismo, entre outras (Barone e MennaBarreto, 2011).

Especificamente sobre DM1, autores têm evidenciado a existência de associações também entre esse tipo de diabetes e distúrbios do sono. Villa et al. (2000), ao analisar dados polissonográficos, verificou que crianças com DM1, mesmo não apresentando sinais de neuropatia diabética, apresentaram número maior de eventos de apnéia central que os indivíduos do grupo controle. O mesmo autor frisa ainda que esse distúrbio do sono, assim como o índice de apnéiahipopnéia $(\mathrm{AHI})$, é acentuado pelo controle glicêmico inadequado e pelo tempo transcorrido desde o diagnóstico do diabetes.

Em outro estudo acerca de DM1 e sono, concluiu-se que mudanças rápidas na glicemia, independente do nível absoluto de glicose, estiveram associadas a despertares noturnos (Pillar et al., 2003). Nesse mesmo trabalho, quando se compararam crianças DM1 com seus pares sem a disfunção, observou-se tendência a diminuição no tempo total de sono e na eficiência de sono, e aumento da latência de sono. Além disso, verificou-se que hipoglicemias podem aprofundar o sono e inibir respostas simpáticas e de ativação ("arousal"), dificultando que o indivíduo DM1 desperte (Pillar et al., 2003; Banarer e Cryer, 2003; Schultes et al., 2007). Esse, que é um achado de diferentes grupos, é de grande relevância, já que o não despertar durante o sono pode levar ao agravamento da hipoglicemia, potencialmente fatal (Schultes et al., 2007; Gill et al., 2009; Pires, 2010). Como observou Pillar et al. (2003) em crianças DM1, o número de indivíduos com hipoglicemia durante o sono pode ser bastante elevado, no caso 1/3 da amostra.

Recentemente foi observado ainda que indivíduos com DM1 dormem em média mais durante a semana que seus pares sem diabetes (este estudo foi realizado com adolescentes por Yeshayahu e Mahmud, em 2010); e que há alterações na arquitetura do sono de indivíduos DM1 (Jauch-Chara et al., 2008). Jauch-Chara et al. (2008) relatam que em relação ao grupo controle, os indivíduos DM1 apresentaram níveis elevados de hormônio de crescimento e adrenalina durante toda a noite, tendência à elevação no nível de cortisol e menos tempo em 
sono de ondas lentas na primeira metade da noite, e indicação de sono menos restaurador, de acordo com o questionário respondido ao despertar. Nesse trabalho os pesquisadores monitoraram a glicemia e evitaram hipoglicemias, talvez por isso não tenham encontrado maior tempo de sono de ondas lentas, como encontraram Pilla et al. (2003), associado a hipoglicemias.

\subsection{Melatonina e diabetes}

A melatonina é um hormônio lipofílico sintetizado a partir do triptofano e imediatamente liberado pela glândula pineal (Seabra e Cipolla-Neto, 2008). A melatonina além de se ligar a receptores de membrana pode atravessá-la e agir intracelularmente em células, desde o sistema nervoso central até os tecidos periféricos. A produção deste hormônio apresenta ritmo circadiano, com sua acrofase (tempo no qual acontece o valor mais elevado da variável) coincidindo com a ausência de luz. Sua produção difunde pelo organismo a mensagem de escuro ambiental.

Autores têm relacionado a ação da melatonina a diversos fenômenos. Entre eles estão: a regulação do sono, do metabolismo, da temperatura e de ritmos biológicos circadianos, já que, entre outras estruturas, os núcleos supraquiasmáticos do cérebro possuem receptores para este hormônio (Nishida, 2005). Assim, a melatonina, possivelmente, age sobre essas estruturas marcadoras de tempo endógeno sinalizando para ajustá-las ao ciclo claro/escuro ambiental. Da mesma forma, produções mais ou menos prolongadas de melatonina sinalizam para mudanças de estação, ajustando ritmos infradianos, como ritmos de hibernação e reprodução, de muitas espécies. São ainda atribuídas à melatonina importantes atividades: antioxidante (Rios et al., 2010), antitumoral, redução de colesterol sérico

e hipoglicemiante (Nishida, 2005). Correlações entre controle metabólico em portadores de diabetes e níveis de melatonina poderiam, assim, ajudar a explicar os mecanismos que estão por trás da associação entre diabetes e distúrbios do sono, ou, ainda melhor, controle da glicemia e distúrbios do ciclo vigília/sono. 
Autores têm conduzido estudos elucidativos sobre a interação entre melatonina e sistema imunológico, contribuindo com resultados sobre os mecanismos de controle metabólico exercido por este hormônio. Especialmente em animais de experimentação têm sido evidenciado que a melatonina atua como modulador de respostas inflamatórias e de respostas imunológicas (Markus et al., 2003; Nishida, 2005). Citocinas marcadoras de estado inflamatório e associadas à resistência à insulina e resistência à leptina, como o fator de necrose tumoral alfa (TNF- $\alpha$ ), tiveram seus níveis circulantes reduzidos quando da administração de melatonina exógena (Sacco et al., 1998). Há também evidências em animais de experimentação indicando que a melatonina pode ter um papel protetor sobre as células pancreáticas produtoras de insulina, células $\beta$ (Yavuz et al., 2003).

Autores têm também estudado como se dá a interação entre a produção de melatonina e insulina, já que apesar de apresentarem acrofases em fases opostas, não são todos que atribuem à insulina papel inibidor da produção de melatonina, assim como da melatonina à produção de insulina (Peschke, 2008). Há evidências apontando para efeitos da melatonina aumentando não só a sensibilidade, mas também a produção da insulina (Rodriguez et al., 1989), assim como ações da insulina potencializando a produção de melatonina (Garcia et al., 2008).

Em estudos com ratos pinealectomizados, autores observaram deficiência na secreção e ação da insulina, concomitante à redução de $40 \%$ no número de transportadores de glicose GLUT-4 em adipócitos e células musculares, levando a aumento da glicose plasmática (Rodriguez et al., 1989; Lima et al., 1998). Sabendo ainda que em seres humanos a melatonina pode facilitar o início do sono, em especial devido à redução da temperatura corporal que promove (Markus et al., 2003), podemos supor que, caso a secreção de melatonina em pessoas com diabetes esteja diminuída, tanto o início do sono quanto o controle da glicemia poderiam estar prejudicados.

Se por um lado, entende-se que em espécies diurnas, como o Homo sapiens, o aumento da secreção de melatonina sinaliza para o início do repouso, em espécies noturnas esse aumento, que também coincide com a fase escura do ciclo ambiental, sinalizaria para a fase de atividade. Com isso, em animais, a melatonina teria a função abrangente de ajuste do organismo às condições noturnas e adaptações necessárias às atividades de cada espécie (Markus et al., 2003). 
Portanto, a melatonina tem papel importante na regulação do metabolismo energético, do sono, de ritmos circadianos e infradianos, de respostas imunológicas e inflamatórias. Dessa forma, concluímos que o estudo dos níveis de melatonina em seres humanos, portadores de DM1 pode nos auxiliar no entendimento de distúrbios do ciclo vigília/sono e glicemia desses indivíduos. Levando em conta o que foi apresentado anteriormente, supomos que a possível redução nos níveis de melatonina em indivíduos com diabetes, como já foi observado em DM2 (Radziuk e Pye, 2006), em especial com controle glicêmico inadequado, pode ser resultado não só de possível glicotoxicidade sobre os pinealócitos, mas também de um sono de baixa qualidade, de duração inadequada ou fragmentado (Estrada et al., 2011; Jauch-Chara et al., 2008). Níveis reduzidos de melatonina, por sua vez, contribuiriam para: 1) piora ainda mais acentuada tanto em parâmetros do sono quanto do controle glicêmico, com possível redução no número de transportadores de glicose GLUT-4 em tecidos que armazenam esse substrato energético; 2) possível desenvolvimento de resistência à insulina e à leptina; 3) aumento na oxidação de tecidos, favorecendo o desenvolvimento de complicações crônicas.

Alguns autores, seguindo essa linha de pensamento, têm estudado os efeitos do uso de melatonina exógena no controle do diabetes, com resultados bastante promissores (Winiarska et al., 2005) . Entre eles estão: melhora da glicemia pré- e pós-prandial, da hemoglobina glicada, além de melhora da resposta tecidual ao hipoglicemiante oral de primeira escolha, metformina, e redução da microalbuminúria, em portadores de DM2 (Hussain et al., 2006; Kadhim et al., 2006).

Dessa forma, entendemos que estudar as possíveis interações entre o diabetes mellitus tipo 1 e o controle glicêmico com o ciclo vigília/sono, ampliando também para estudos do sono noturno, ritmo de atividade/repouso e níveis de melatonina, será de importância não só para se elucidar ocorrência e impacto dessas interações, mas também para que recomendações possam ser feitas, visando uma melhor qualidade de vida dessa população. 


\section{OBJETIVOS}

\subsection{Objetivos gerais}

O objetivo principal do presente trabalho é testar se indivíduos do grupo controle (não portadores de diabetes) e do grupo de portadores de diabetes mellitus do tipo 1 (DM1) adequadamente controlados (DA) têm ciclo vigília/sono (CVS) mais regular e estável, além de melhor qualidade de sono noturno, que indivíduos do grupo de portadores de DM1 com controle metabólico inadequado (DI).

\subsection{Objetivos específicos}

- Verificar se há diferença na secreção noturna total de melatonina entre os indivíduos dos grupos: controle, DA e DI.

- Verificar possíveis associações entre o controle glicêmico e o CVS, sono noturno e ritmo de atividade/repouso em portadores de DM1. 


\section{MATERIAL E MÉTODOS}

\subsection{Casuística e critérios de inclusão}

Para testar nossa hipótese recrutamos voluntários na Associação de Diabetes Juvenil de São Paulo (ADJ) e no Ambulatório de Endocrinologia do Hospital das Clínicas da Faculdade de Medicina da Universidade de São Paulo (HC-FMUSP), com as seguintes características:

- Portador de DM1

- Idade entre 20 e 40 anos

$-I M C<30 \mathrm{~kg} / \mathrm{m}^{2}$

- Não apresentar complicação crônica decorrente do diabetes

- Não apresentar outro distúrbio endócrino (exceção em relação ao hipotiroidismo)

- Não ser usuário de medicamento que altere o sono

- Não ser trabalhador noturno, nem em turnos

- Não apresentar distúrbio do sono já diagnosticado

A fim de se fazer tal seleção, solicitamos a cada indivíduo com potencial para ser voluntário do grupo DM1 que apresentasse um relatório estruturado preenchido e assinado por seu médico (APENDICE A).

Recrutamos também voluntários não portadores de diabetes, dentro da mesma faixa etária (grupo controle), com as seguintes características:

- Não ser portador de DM1, nem de qualquer outra disfunção endócrina

- Idade entre 20 e 40 anos

- IMC $<30 \mathrm{~kg} / \mathrm{m}^{2}$

- Não ser usuário de medicamento que altere o sono

- Não ser trabalhador noturno, nem em turnos

- Não apresentar distúrbio do sono já diagnosticado 
Além dos critérios descritos acima, os indivíduos do grupo controle tiveram a glicemia de jejum dosada em laboratório, a fim de nos certificarmos de não serem portadores de diabetes.

Para os sujeitos experimentais (grupo DM1) foram solicitadas avaliações padrão para detecção de complicações decorrentes do diabetes (American Diabetes Association, 2009; Sociedade Brasileira de Diabetes, 2009), incluindo: exame de fundo de olho (retina) com a pupila dilatada, realizado por oftalmologista; dosagem de microalbuminúria de 24 horas e creatinina; teste de sensibilidade periférica com microfilamento de $10 \mathrm{~g}$ e diapasão de $128 \mathrm{~Hz}$; aferição da pulsação em repouso e comparação entre a pressão arterial em repouso e 1 minuto após se levantar. Os indivíduos que já contavam com essas avaliações realizadas por sua equipe médica apresentaram declaração do médico. Caso o indivíduo não contasse com dosagem de microalbuminúria, creatinina, e exame da retina, estes foram solicitados. Para os indivíduos que não contavam com avaliação de neuropatia, oferecemos a avaliação, que foi feita pela equipe que colaborou com o projeto, seguindo protocolo anexo (APENDICE B), desde que os voluntários estivessem de acordo e assinassem termo de consentimento para tanto (ANEXO A).

Inicialmente pretendíamos não incluir na pesquisa indivíduos que tivessem outra disfunção endócrina. Porém, deparamo-nos com um grande número de portadores de diabetes com hipotireoidismo, devido ao fato de a doença autoimune de tiróide ser a mais comumente associada ao DM1 (Roldan et al., 1999). Dessa forma, a fim de aproximar a amostra da população real, optamos por também aceitar indivíduos hipotireoideos, desde que em regime de reposição hormonal e níveis de hormônio tireoidiano dentro da faixa de normalidade. Para tanto solicitamos dosagem de TSH, T3 e T4 antes e após a coleta de dados, e não aceitamos indivíduos que tivessem níveis considerados alterados pelos médicos endocrinologistas que acompanharam a pesquisa. Ao final, entre os 10 voluntários do sexo feminino do grupo DM1, quatro apresentavam hipotiroidismo.

O número de voluntários que cumpriu cada uma das principais etapas do estudo encontra-se no Quadro 1. O maior número de voluntários que conseguimos, cumprindo uma das etapas, foi de 18 do grupo DM1 e 9 do grupo controle, no preenchimento de diário de sono. Em relação ao Tempatilumi, apesar de 33 voluntários terem recebido o equipamento, apenas obtivemos os dados completos 
de actimetria de 12 indivíduos do grupo DM1 (7 do sexo feminino e 5 do sexo masculino) e de 7 indivíduos do grupo controle (3 do sexo feminino e 4 do sexo masculino). Esse fato foi atribuído a falha de registro ou de memória em alguns dos equipamentos. Falhas em equipamentos também resultaram em perdas de dados polissonográficos.

Quadro 1 - Número de coletas bem sucedidas/número total de amostras ou procedimentos realizados por grupo.

\begin{tabular}{|c|c|c|c|c|c|}
\hline & $\begin{array}{c}\text { Assinaram } \\
\text { Termo de } \\
\text { Consentimento }\end{array}$ & $\begin{array}{c}\text { Preencheram de } \\
\text { forma adequada } \\
\text { o Diário de Sono }\end{array}$ & $\begin{array}{c}\text { Sucesso na } \\
\text { coleta com o } \\
\text { Tempatilumi }\end{array}$ & $\begin{array}{c}\text { Tiverama } \\
\text { 6-sulfatoximelatonina } \\
\text { dosada }\end{array}$ & $\begin{array}{c}\text { Polissonografia } \\
\text { realizada }\end{array}$ \\
\hline $\begin{array}{c}\text { Grupo } \\
\text { DM1 }\end{array}$ & 36 & $18 / 23$ & $12 / 23$ & $15 / 20$ & $16 / 19$ \\
\hline $\begin{array}{c}\text { Grupo } \\
\text { Controle }\end{array}$ & 13 & $9 / 10$ & $7 / 10$ & $9 / 10$ & $8 / 11$ \\
\hline
\end{tabular}

Dezesseis voluntários foram desligados ou se desligaram da pesquisa durante sua execução, por um ou mais dos seguintes fatores: decisão pessoal de não continuar contribuindo; detecção de complicação decorrente do diabetes; não realização de um dos exames para detecção de complicações; presença de outra disfunção endócrina; nível de hormônio tireoidiano fora do padrão.

\subsection{Aspectos éticos}

O projeto foi aprovado pela Comissão de Ética em Pesquisa com Seres Humanos do Instituto de Ciências Biomédicas da Universidade de São Paulo (ICB), parecer 873/CEP (ANEXO B). Foi também apresentado e aprovado pela Comissão de Ética do HC-FMUSP (ANEXO C), pela Comissão Científica do InCor (ANEXO D) e pela ADJ (ANEXO E).

O contato com os indivíduos do grupo DM1 foi feito através das equipes de saúde do HC-FMUSP ou da ADJ. Nessa ocasião, os indivíduos receberam informações detalhadas sobre o protocolo de pesquisa e Ihes foi apresentado o 
termo de consentimento livre e esclarecido (ANEXO F, termo apresentado aos voluntários do HC-FMUSP; ANEXO G, termo apresentando aos voluntários da ADJ e aos do grupo controle). Tanto o pesquisador quanto o indivíduo que se prontificava a participar do protocolo assinaram o termo de consentimento; e cada um ficava com uma cópia. Mesmo após assinado o termo de consentimento, os voluntários tiveram liberdade para desistir de colaborar com a pesquisa a qualquer momento, sem necessidade de justificar sua decisão.

\subsection{Coleta de dados}

Todos os voluntários incluídos na pesquisa foram solicitados a preencher a escala de sonolência de Epworth (ANEXO H), diário de sono (ANEXO I) e usar o Tempatilumi (acelerômetro de punho brasileiro, Areas et al. (2006), ANEXO J) por 10 dias. O grupo DM1 foi solicitado ainda a realizar no mínimo 6 testes de glicemia capilar ao dia, durante os mesmos 10 dias, e anotar no diário (ANEXO K). Este período de coleta de dados referente ao ciclo vigília/sono (CVS), ritmo de atividade/repouso (RAR) e glicemia capilar, aconteceu entre os dias 26 de fevereiro e 8 de março de 2010. Para a dosagem de glicemia capilar os voluntários do grupo DM1 receberam um glicosímetro portátil da marca Performa ${ }^{\circledR}$ (Roche Diagnostics, Mannheim, Germany), 100 tiras reativas, e lancetas. Os dados armazenados na memória dos glicosímetros foram baixados utilizando o programa Accu-chek® 360ㅡ, da mesma empresa (Roche Diagnostics, Mannheim, Germany).

Apesar de ao todo terem sido realizados 30 exames de polissonografia no Laboratório do Sono do Instituto do Coração da Faculdade de Medicina da USP, apenas 24 exames puderam ser utilizados (16 do grupo DM1 e 8 do grupo controle). A perda de exames de indivíduos do grupo DM1 ocorreu em virtude de: 1 indivíduo do grupo DM1 não ter os dados registrados por problemas no equipamento e não ter aceitado refazer o exame; e outros 3 , após realização do exame, apresentarem laudos que não nos permitiam incluí-los na pesquisa (um por descontrole de hormônios tireoidianos e os outros dois por presença de alterações na retina). Em relação às polissonografias realizadas nos voluntários do grupo controle, 3 foram 
perdidas por defeito no disco rígido do computador onde estavam armazenados, no entanto, 1 foi refeita. Faz-se importante mencionar que 2 voluntários do grupo DM1 não concordaram em fazer a polissonografia.

As polissonografias foram realizadas durante a noite em um dos equipamentos do laboratório (EMBLA, Flagra hf. Medical Devices, Reykjavik, Iceland, ou ALICE 5, Philips Respironics, Murrysville, PA). A monitorização incluiu eletroencefalograma (4 canais), eletrooculograma (2 canais), eletrocardiograma, eletromiograma submentoniano e tibial anterior, oximetria de pulso, fluxo de ar (termístor oronasal e cânula de pressão), e movimentação da caixa torácica e abdominal através de cintas. Apnéia foi definida como a cessação completa do fluxo de ar por pelo menos 10 segundos. Hipopnéia foi definida como uma redução significativa (> 50\%) do fluxo por pelo menos 10 segundos associada à dessaturação de oxigênio de pelo menos 3\% ou despertar. $O$ índice de apnéiahipopnéia foi calculado como o número total de eventos respiratórios (apnéias mais hipopnéias) por hora de sono. Também foram analisados, de acordo com os parâmetros da American Academy of Sleep Medicine (2005, 2007) e eficiência do sono, índice de microdespertares e despertares completos e percentual dos estágios do sono.

Apesar de 20 sensores de glicose terem sido utilizados, contamos com a glicose continuamente monitorada durante a polissonografia de apenas 11 indivíduos. Isto ocorreu porque alguns sensores apresentaram defeito ou porque o equipamento não armazenou os resultados da glicose de 4 voluntários do grupo DM1. Em um deles utilizamos um segundo sensor, que também não funcionou. Além disso, de outros 4 voluntários que fizeram a polissonografia, concomitante à monitorização da glicose, 3 foram retirados do estudo por, tardiamente, termos descoberto não estarem dentro de algum critério de inclusão; e 1 voluntário teve a polissonografia perdida e não quis refazê-la.

Todos os voluntários coletaram urina por 12 horas, durante a noite, para dosagem de 6-sulfatoximelatonina (6-SMT), metabólito este que reflete o total de melatonina secretado durante o período de coleta (Bojkowskl et al., 1987). Tal dosagem foi gentilmente realizada pela equipe do Laboratório de Análises Clínicas da Faculdade de Medicina do ABC, utilizando o kit Bühlmann 6-SMT ELISA. 
Contudo, durante o processamento, tivemos perda de material de 3 indivíduos do grupo DM1.

O valor da hemoglobina glicada ( $\mathrm{HbA1c})$, solicitada aos participantes do grupo DM1 antes e após os 10 dias de coleta de dados, inicialmente seria utilizado para dividir os participantes em grupos. Contudo, percebemos a dificuldade em obter indivíduos com valores extremos de $\mathrm{HbA1c}$, a fim de dividi-los em dois grupos bastante distintos. Havia, entre os voluntários recrutados, diferenças pequenas de HbA1c. Dessa forma, optamos por utilizar a média das glicemias capilares e a variabilidade glicêmica, que, como será apresentado adiante, apresentaram correlação significativa com os valores da $\mathrm{HbA} 1 \mathrm{c}$ dosada.

\subsection{Análise dos dados}

A média e desvio padrão da glicemia e porcentagem de hipoglicemias e hiperglicemias foram calculados com o programa Accu-check ${ }^{\circ} 360^{\circ}$ (versão 1.1.0.3239, 2009). Para a análise do ritmo de atividade/repouso foram utilizados os seguintes recursos do programa El Temps (Díez-Noguera, 1, 209+, Barcelona):

- Actograma produz gráfico para a visualização das fases de atividade e de repouso de cada indivíduo;

- Cosinor ajusta os dados a uma curva coseno, e calcula a acrofase do ritmo estudado, a amplitude e a porcentagem rítmica do mesmo;

- Periodograma Lomb-Scargle, utilizado para se determinar o espectro de frequências do ritmo, e identificar a frequência mais significativa e sua potência;

- Teste de Rayleigh, permite que se verifique se as acrofases dos diferentes indivíduos de cada um dos grupos se agrupam.

Para se testar as hipóteses do presente estudo foram utilizados os seguintes algoritmos do programa Statistica (StatSoft, Inc., 2004, versão 6):

- Análise de Correlação de Pearson e Regressão Linear;

- Teste de normalidade de Shapiro Wilk's;

- Testes $t$ de Student para amostras independentes;

- Teste $t$ de Student para amostras dependentes; 
- ANOVA de uma via;

- U de Mann-Whitney (alternativa não paramétrica ao teste $t$ para amostras independentes);

- Wilcoxon (alternativa não paramétrica ao teste $t$ para amostras dependentes);

- Kruskal-Wallis (alternativa não paramétrica ao teste ANOVA de uma via).

Os dados obtidos a partir do registro do Tempatilumi foram, antes das análises, tratados a fim de se retirar da sequência dados referentes a fases nas quais os indivíduos não estavam usando o aparelho. As séries temporais incompletas que resultaram desse tratamento foram preenchidas com a média da atividade naqueles horários nos demais dias. No periodograma do programa El Temps optamos por utilizar a análise de Lomb-Scargle, já que o máximo de dias coletados que tínhamos era 10, o que, segundo Bueno (2010, comunicação pessoal $)^{1}$, constitui-se um número de dias muito reduzido para se utilizar o algoritmo Sokolove-Bushell. Optamos por utilizar teste $t$ ou ANOVA de uma via, e não testes não-paramétricos, para se comparar dois ou mais grupos, sempre que o $p$ do teste de normalidade de Shapiro Wilk foi maior que 0,05. Aceitamos como estatisticamente significativas correlações e diferenças entre grupos que apresentaram $p$ menor que 0,05

Como será apresentado abaixo, optamos por analisar em separado os dados obtidos a partir dos diários de sono e do actímetro (Tempatilumi). Tomamos essa decisão, ao invés de editar os dados de actímetro com base nos dados do diário de sono, por entendermos que o ciclo vigília/sono e o ritmo de atividade/repouso são ritmos distintos. Assim, considerar os dados de diário de sono ou os dados do actímetro mais precisos e confiáveis e, por isso, passiveis de editar os dados obtidos a partir do outro instrumento, obrigar-nos-ia a abrir mão de diferenças potencialmente relevantes. Como apresentado no APENDICE C, apesar da correlação ser alta, há diferença significativa entre os horários de início do sono (diário) e início de repouso (actímetro), e entre a duração do sono (diário) e a duração do repouso (actímetro).

Os indivíduos portadores de diabetes foram separados em grupos, um com controle glicêmico adequado e outro com controle glicêmico inadequado, através de

\footnotetext{
${ }^{1}$ Informação fornecida por Clarissa Bueno, em São Paulo, em 2010.
} 
dois critérios. Um dos critérios da separação em grupos foi a média da glicemia (MG) durante os 10 dias de coleta; o outro foi o desvio padrão da média da glicemia desse período (DP), interpretado como variabilidade glicêmica (Monnier et al., 2008). Os indivíduos com média da glicemia menor que $154 \mathrm{mg} / \mathrm{dl}$ compuseram o grupo GB (média da glicemia baixa), já que $154 \mathrm{mg} / \mathrm{dl}$ corresponde a $\mathrm{HbA} 1 \mathrm{c}$ de $7 \%$ (Nathan et al., 2008), considerado o limite superior do alvo de hemoglobina glicada para adultos com diabetes, segundo a American Diabetes Association (2009), enquanto os que apresentaram média da glicemia acima de $154 \mathrm{mg} / \mathrm{dl}$, foram denominados GA (média da glicemia alta). Quando separados de acordo com a variabilidade glicêmica, indivíduos com DP menor que $74 \mathrm{mg} / \mathrm{dl}$ constituíram o grupo VB (variabilidade da glicemia baixa), em oposição aos com DP maior que $74 \mathrm{mg} / \mathrm{dl}$, referidos com VA (variabilidade da glicemia alta). Neste caso, a decisão por utilizar o DP de $74 \mathrm{mg} / \mathrm{dl}$ baseou-se apenas no fato de metade da população DM1 estudada apresentar DP menor que $74 \mathrm{mg} / \mathrm{dl}$. Em algumas ocasiões dividimos ainda os indivíduos em três grupos, ficando no $1^{\circ}$ grupo os indivíduos com MG ou DP menor que o valor do $1^{\circ}$ quartil $(<138,3 \mathrm{mg} / \mathrm{dl}$ para $M G$ ou $<59,8 \mathrm{mg} / \mathrm{dl}$ para $\mathrm{DP})$, no $3^{\circ}$ grupo os indivíduos com valor de MG ou DP maior que do 3 q quartil do grupo (>189,6 mg/dl para MG, ou >82,4 mg/dl para DP), e no grupo 2 os valores intermediários. 


\section{RESULTADOS}

$\mathrm{Na}$ tabela abaixo (Tabela 1) aparecem características dos indivíduos de ambos os grupos, controle e DM1, que participaram do estudo.

Tabela 1 - Características dos voluntários do estudo.

\begin{tabular}{l|l|l}
\hline Característica (média) & \multicolumn{1}{l}{ Grupo controle } & \multicolumn{1}{l}{ Grupo DM1 } \\
\hline Idade (anos) & 28,8 (entre 23 e 38) & 26,3 (entre 20 e 38) \\
\hline Gênero & $5 \mathrm{~F}, 4 \mathrm{M}$ & $10 \mathrm{~F}, 8 \mathrm{M}$ \\
\hline $\mathrm{IMC}\left(\mathrm{kg} / \mathrm{m}^{2}\right.$ ) & $23,0($ entre 18,3 e 26,2) & 23 (entre 18,4 e 29,7) \\
\hline Tempo de diabetes (anos) & --- & 12,9 (entre 1 e 30) \\
\hline Glicemia (mg/dl) & 86,3 (entre 73 e 96)* & 166,5 (entre 116 e 241)** \\
\hline
\end{tabular}

* glicemia de jejum dosada em laboratório através de método enzimático colorimétrico.

** média das glicemias dosadas pelos indivíduos do grupo DM1 durante os 10 dias de coleta.

Na tabela 2 estão apresentadas as correlações entre os principais parâmetros indicadores de controle glicêmico e que foram usados para dividir os grupos e fazer as análises no presente estudo. As correlações significativas observadas são entre a média da glicemia e: a variabilidade glicêmica, a HbA1c pré-coleta, a HbA1c póscoleta, e a frequência de hipoglicemias. Além dessas, chamam também a atenção as correlações entre a variabilidade glicêmica e: a HbA1c pré-coleta, a HbA1c póscoleta, e a frequência de hiperglicemias. A média de testes realizados diariamente não se mostrou correlacionada nem com a variabilidade glicêmica $(r=-0,3584$; $p=0,1441)$, nem com a média da glicemia $(r=-0,3350 ; p=0,1742)$. Por outro lado, mostrou-se correlacionada à HbA1c pós-coleta (Tabela 2 ).

Tabela 2 - Correlação entre parâmetros indicadores de controle glicêmico.

\begin{tabular}{|c|c|c|c|c|}
\hline Correlações & HbA1c pré-coleta & HbA1c pós-coleta & $\begin{array}{l}\text { Média da } \\
\text { Glicemia }\end{array}$ & $\begin{array}{c}\text { Desvio Padrão da } \\
\text { Média }\end{array}$ \\
\hline HbA1c pós-coleta & $\begin{array}{c}r=0,8895 \\
p=0,0000008\end{array}$ & - & & \\
\hline $\begin{array}{l}\text { Média da } \\
\text { Glicemia }\end{array}$ & $\begin{array}{l}r=0,6736 \\
p=0,0022\end{array}$ & $\begin{array}{l}r=0,7537 \\
p=0,0003\end{array}$ & - & \\
\hline $\begin{array}{c}\text { Desvio Padrão da } \\
\text { Média }\end{array}$ & $\begin{array}{l}r=0,5068 \\
p=0,0318\end{array}$ & $\begin{array}{l}r=0,6228 \\
p=0,0058\end{array}$ & $\begin{array}{l}r=0,7311 \\
p=0,0006\end{array}$ & - \\
\hline $\begin{array}{c}\text { Média diária de } \\
\text { testes }\end{array}$ & $\begin{array}{l}r=-0,5903 \\
p=0,0099\end{array}$ & $\begin{array}{l}r=-0,5403 \\
p=0,0206\end{array}$ & ns & ns \\
\hline $\begin{array}{l}\text { Frequência de } \\
\text { Hipoglicemias }\end{array}$ & ns & ns & $\begin{array}{l}r=-0,6037 \\
p=0,0080\end{array}$ & ns \\
\hline $\begin{array}{l}\text { Frequência de } \\
\text { Hiperglicemias }\end{array}$ & $\begin{array}{l}r=0,6894 \\
p=0,0015\end{array}$ & $\begin{array}{l}r=0,7886 \\
p=0,0001\end{array}$ & $\begin{array}{l}r=0,9796 \\
p=0,0000\end{array}$ & $\begin{array}{l}r=0,7487 \\
p=0,0004\end{array}$ \\
\hline
\end{tabular}




\subsection{Melatonina}

Apesar de se observar uma tendência a níveis mais baixos de 6sulfatoximelatonina no grupo DM1, em comparação com o grupo controle, esta diferença não é significativa (Figura 1).

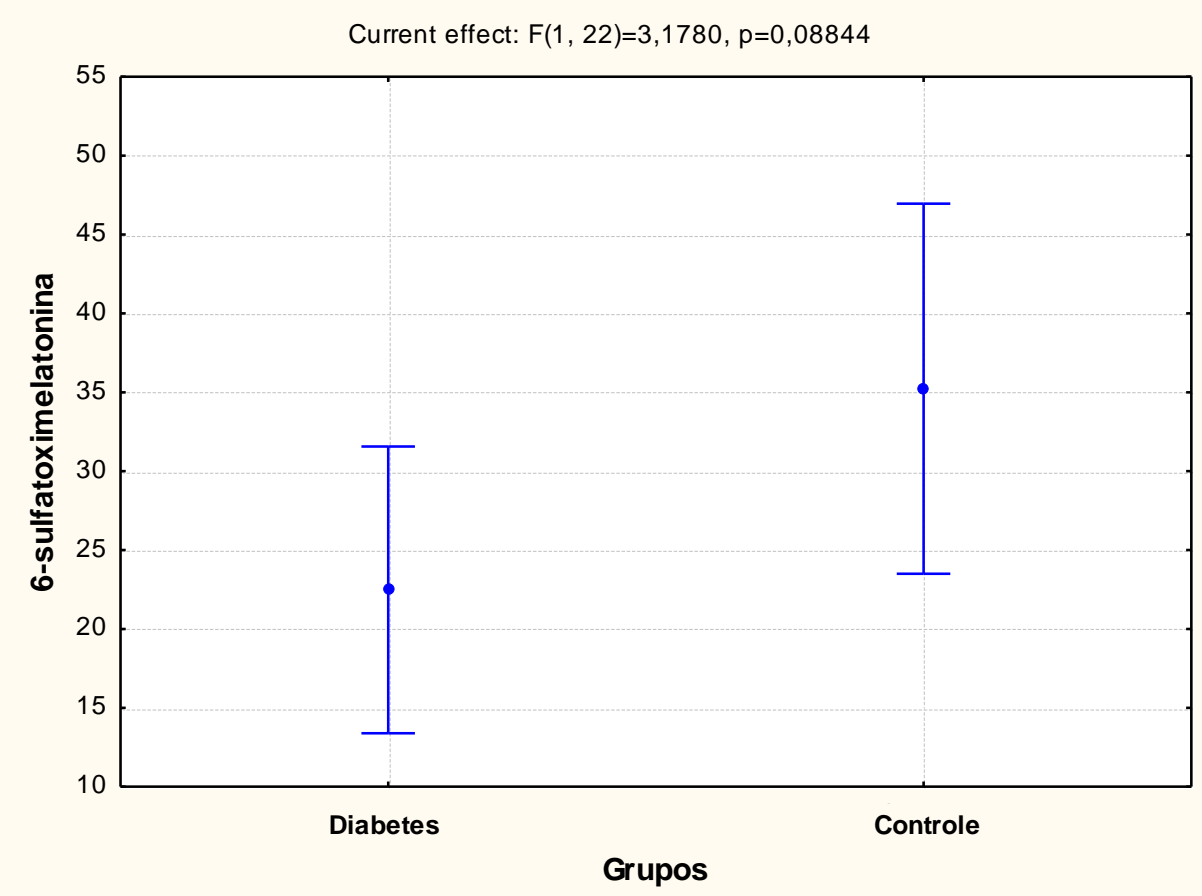

Figura 1 - Média dos níveis de 6-sulfatoximelatonina nos grupos DM1 e controle.

Ao se dividir o grupo DM1 em dois de acordo com a variabilidade glicêmica (desvio padrão da média de glicemia, DP), e se comparar ambos os grupos com o grupo controle, verifica-se não haver diferença estatística (Figura 2). 


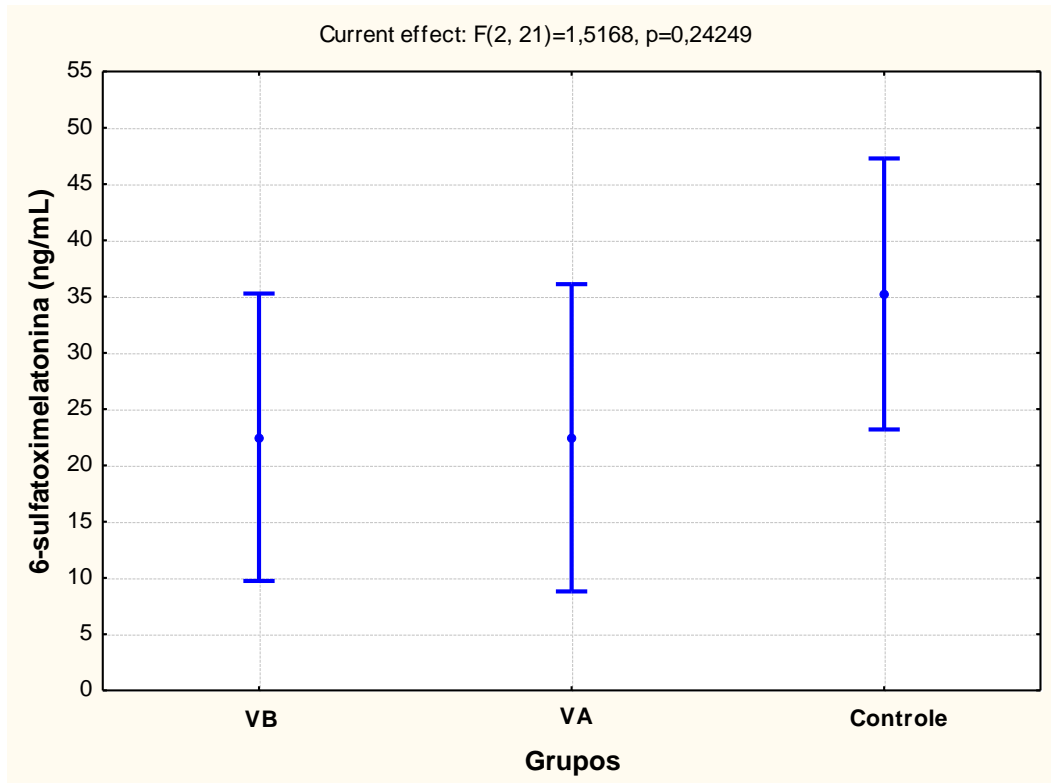

Figura 2 - Comparação da média de 6-sulfatoximelatonina entre os grupos VB, VA e controle.

Ao dividir os grupos de acordo com a média da glicemia, observa-se que apesar de não significativa, há uma aparente tendência a valores mais baixos de 6sulfatoximelatonina no grupo de média glicêmica mais elevada em comparação aos demais (Figura 3). Comparando então os níveis de 6-sulfatoximelatonina apenas do grupo de glicemia alta $(G A)$ com os níveis de 6-sulfatoximelatonina do grupo controle, observa-se diferença significativa (Figura 4).

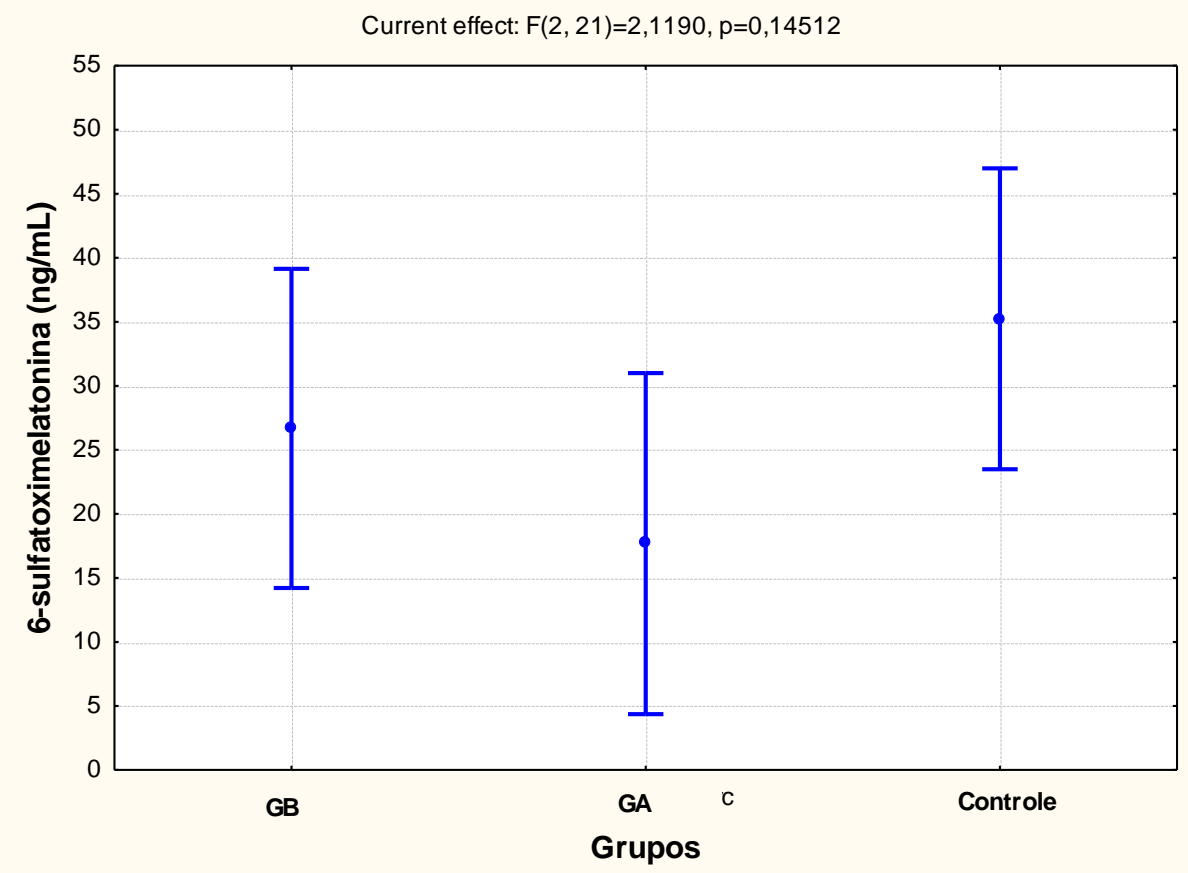

Figura 3 - Comparação da média de 6-sulfatoximelatonina entre os grupos GB, GA e controle. 


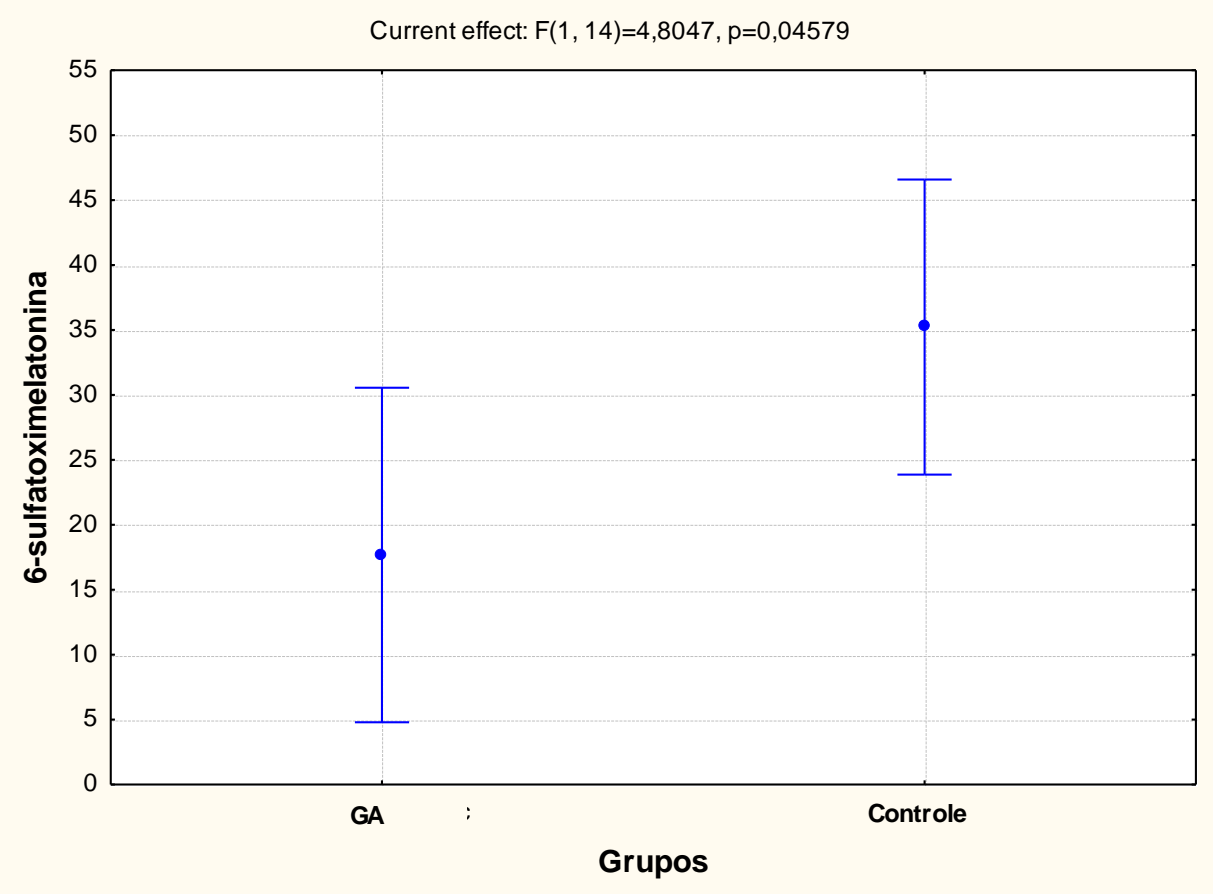

Figura 4 - Comparação da média de 6-sulfatoximelatonina entre os grupos GA e controle.

Verificou-se não haver correlação dos níveis de 6-sulfatoximelatonina com a variabilidade glicêmica $(r=-0,1003 ; p=0,7220)$, mas sim uma tendência de correlação negativa entre a 6-sulfatoximelatonina dosada e a média da glicemia $(r=-0,4600$; $p=0,0845$ ) (Figura 5).

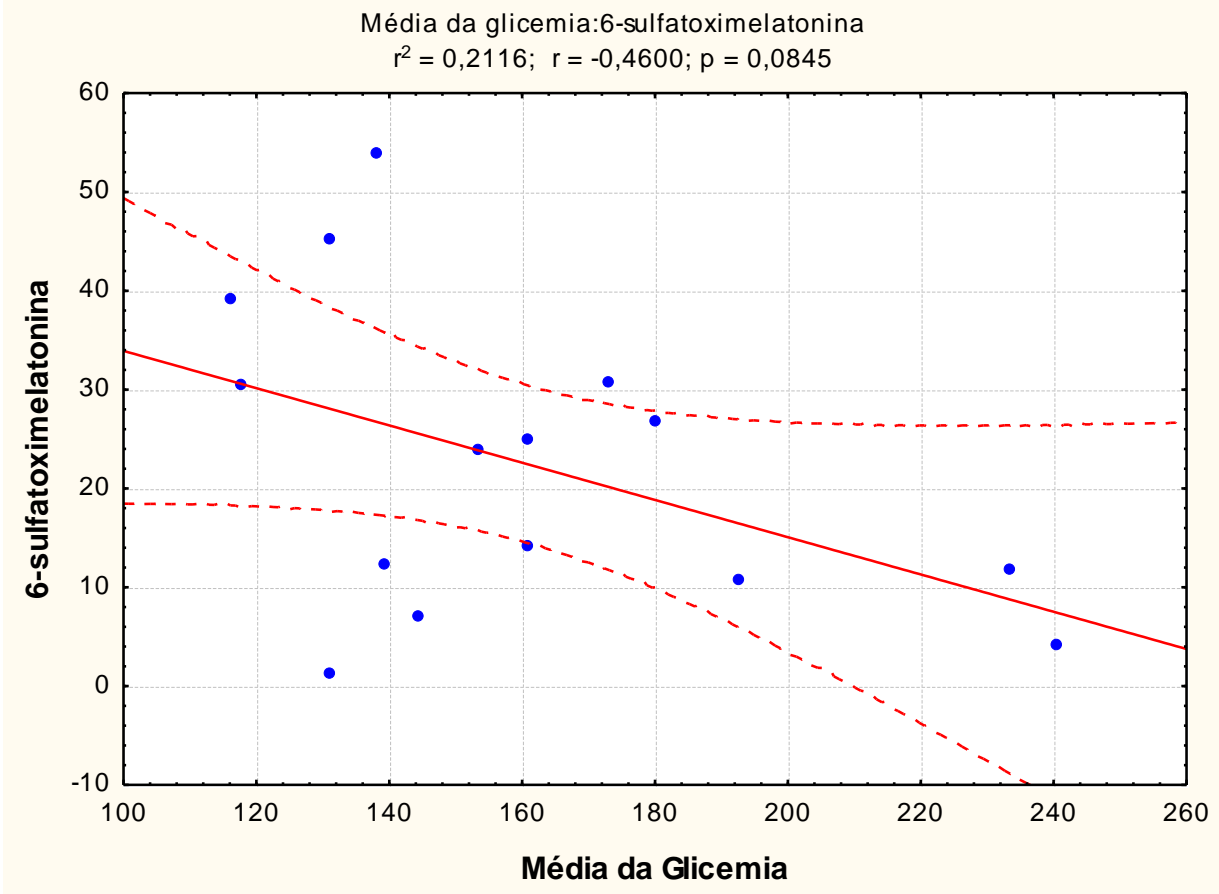

Figura 5 - Tendência à correlação negativa entre os níveis de 6-sulfatoximelatonina e a média da glicemia. 
Observou-se ainda correlação positiva e significativa entre a porcentagem de hipoglicemias (glicemias abaixo de $70 \mathrm{mg} / \mathrm{dl}$ ) durante a fase de coleta de dados, e o nível de 6-sulfatoximelatonina (Figura 6). 0 mesmo não acontece em relação à porcentagem de hiperglicemias (consideradas glicemias acima de $200 \mathrm{mg} / \mathrm{dl}$ ), $p=0,1133$.

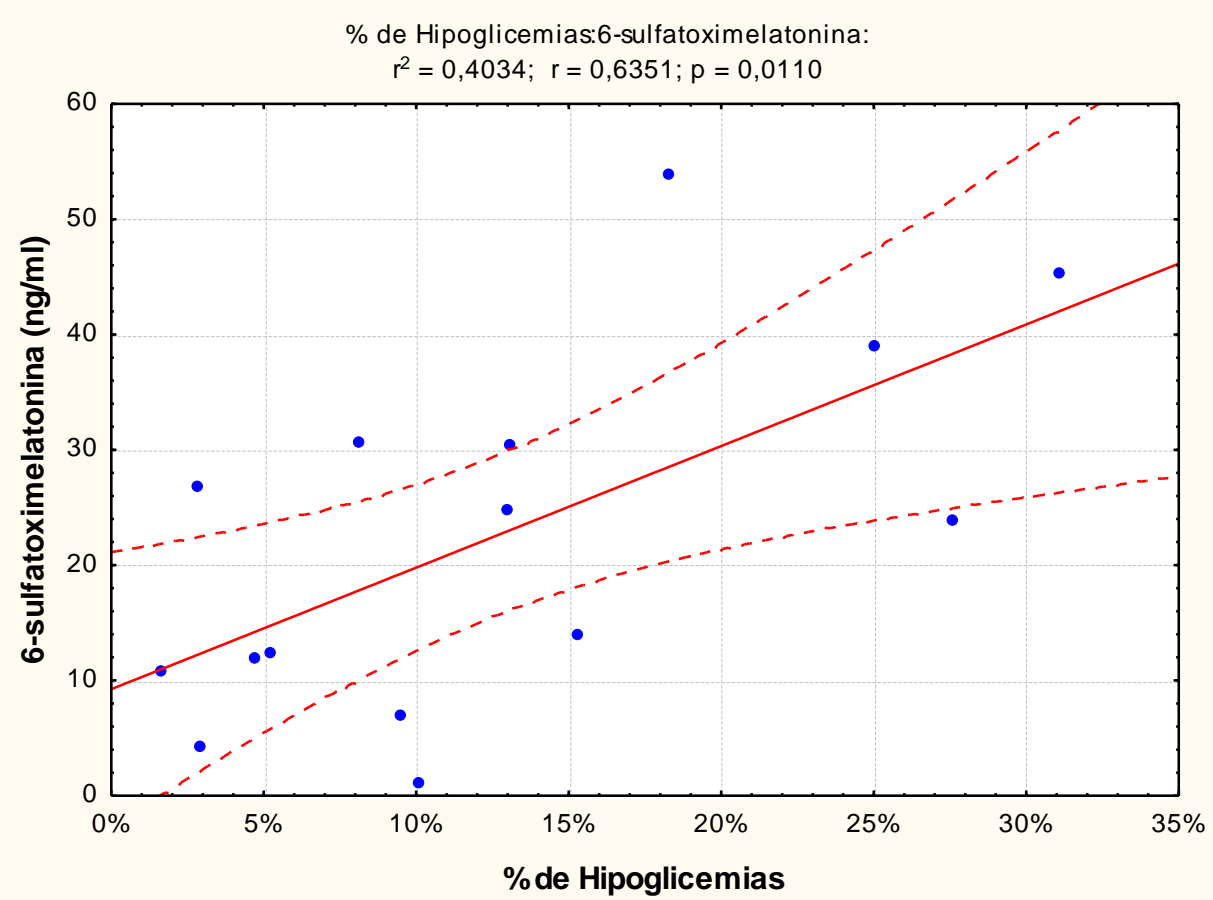

Figura 6 - Correlação entre frequência de hipoglicemias e níveis de 6-sulfatoximelatonina.

\subsection{Sono}

Abaixo foram analisados os dados obtidos a partir dos laudos da polissonografia realizada durante 1 noite, no Laboratório do Sono do InCor, em 15 indivíduos do grupo DM1 e 8 do grupo controle.

Nenhum indivíduo apresentou distúrbio do sono, e nenhum dos principais parâmetros avaliados, incluindo latência para o sono e para o sono paradoxal, eficiência do sono, e os índices de: apnéia-hipopnéia, apnea central, microdespertares (arousal), e despertares totais apresentaram diferença entre os grupos controle e DM1. Por outro lado, o número de despertares e de microdespertares por hora se correlacionaram positivamente à hemoglobina glicada pós-coleta de dados (Figuras 7 e 8 , respectivamente). Diferente do número de microdespertares por hora, o número de despertares completos por hora se 
correlacionou positivamente também à média da glicemia $(r=0,5684 ; p=0,0271)$, e se mostrou significativamente diferente entre os três grupos divididos de acordo com os quartis da variabilidade glicêmica, tendo o $3^{\circ}$ grupo um número muito mais elevado de despertares por hora de sono que os demais (Figura 9).

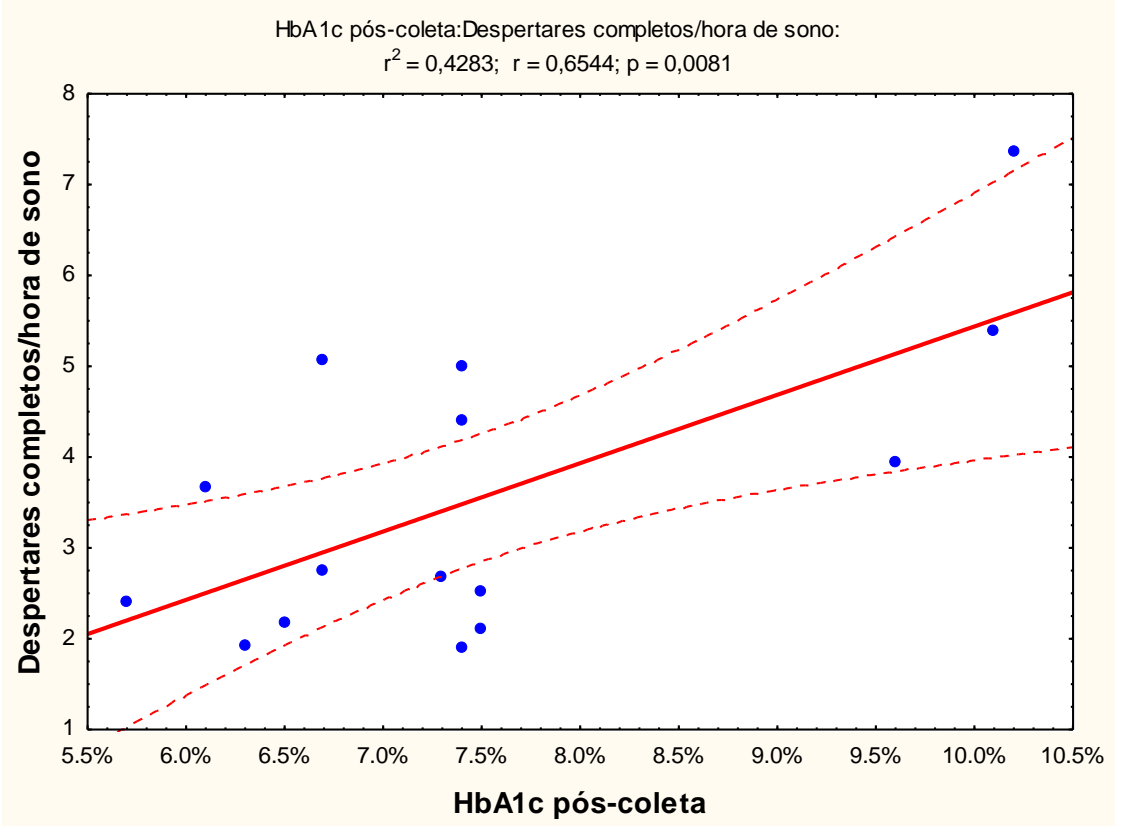

Figura 7 - Correlação entre o número de despertares completos por hora e a HbA1c.

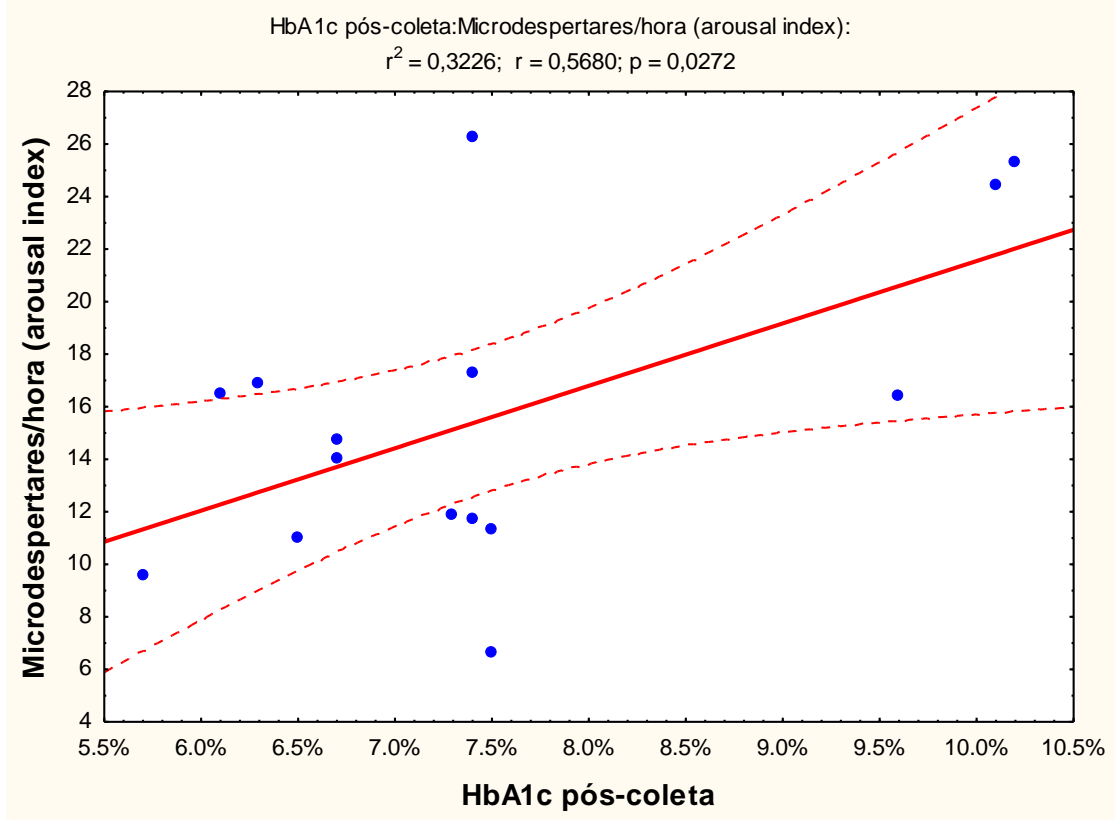

Figura 8 - Correlação entre o número de microdespertares por hora e a HbA1c 


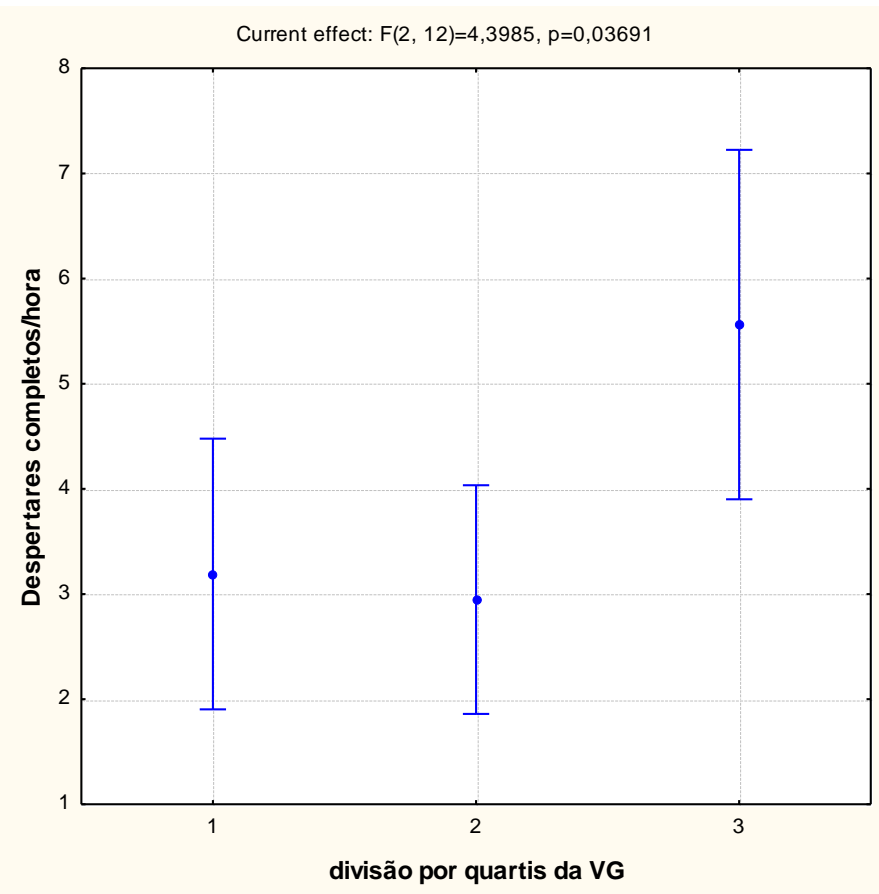

Figura 9 - Despertares completos por hora nos três grupos de quartis da variabilidade glicêmica.

Outra correlação significativa foi observada do índice de apnéia-hipopnéia (AHI) com a média da glicemia, assim como com a variabilidade glicêmica (Figuras 10 e 11). Ao se dividir os valores da média da glicemia em mediana e quartis, observa-se que os valores abaixo de primeiro quartil $(<138,3 \mathrm{mg} / \mathrm{dl})$, apresentam AHI significativamente mais elevado que os demais (Figura 12).

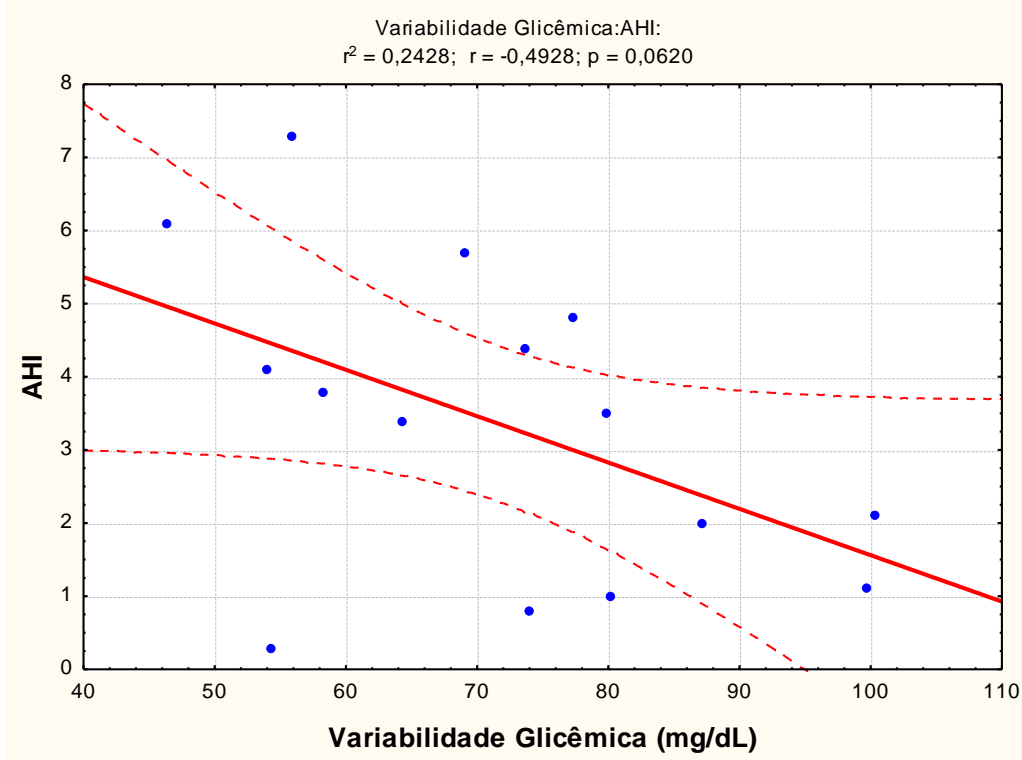

Figura 10 - Correlação entre o índice de apnéia-hipopnéia e a variabilidade glicêmica. 


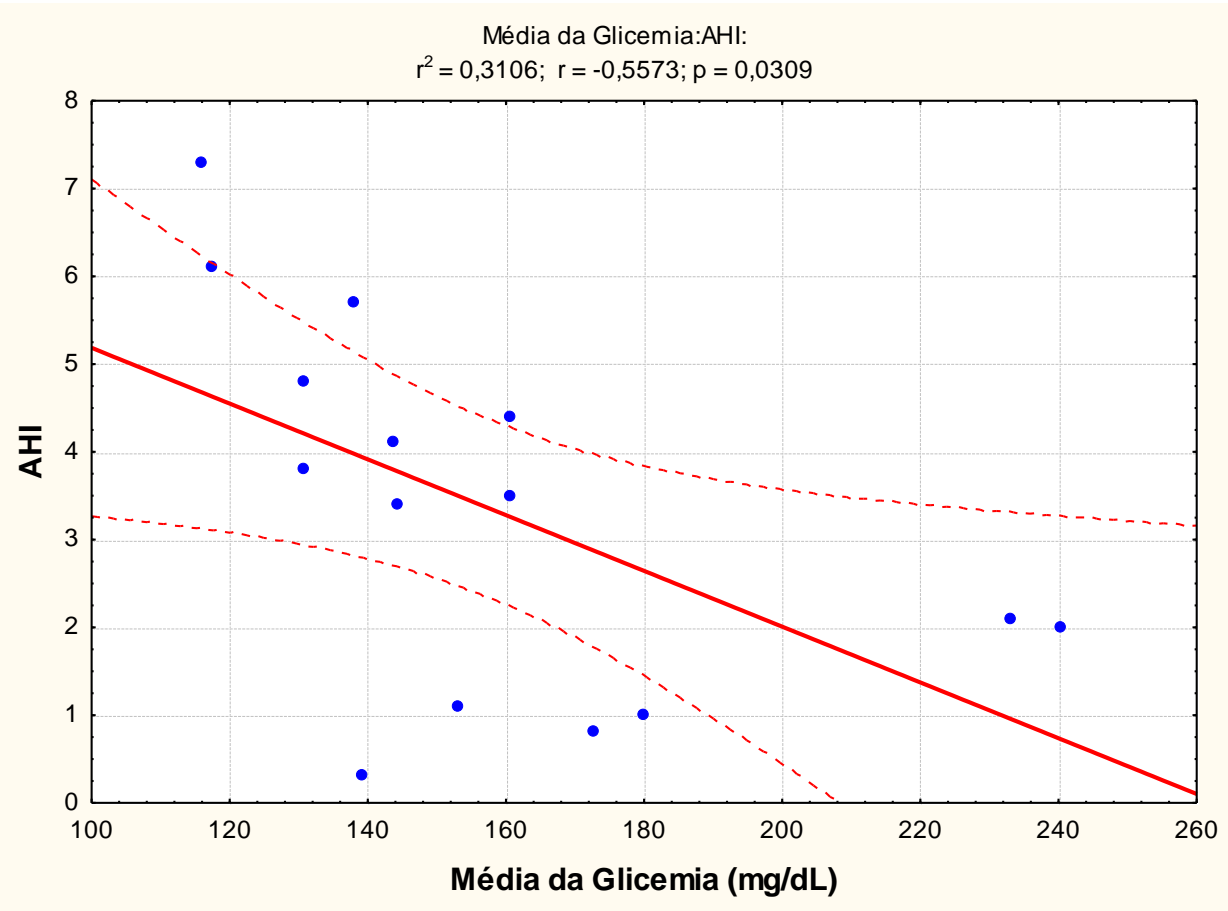

Figura 11 - Correlação entre o índice de apnéia-hipopnéia e a média da glicemia.

Current effect: $F(2,12)=8,0393, p=0,00609$

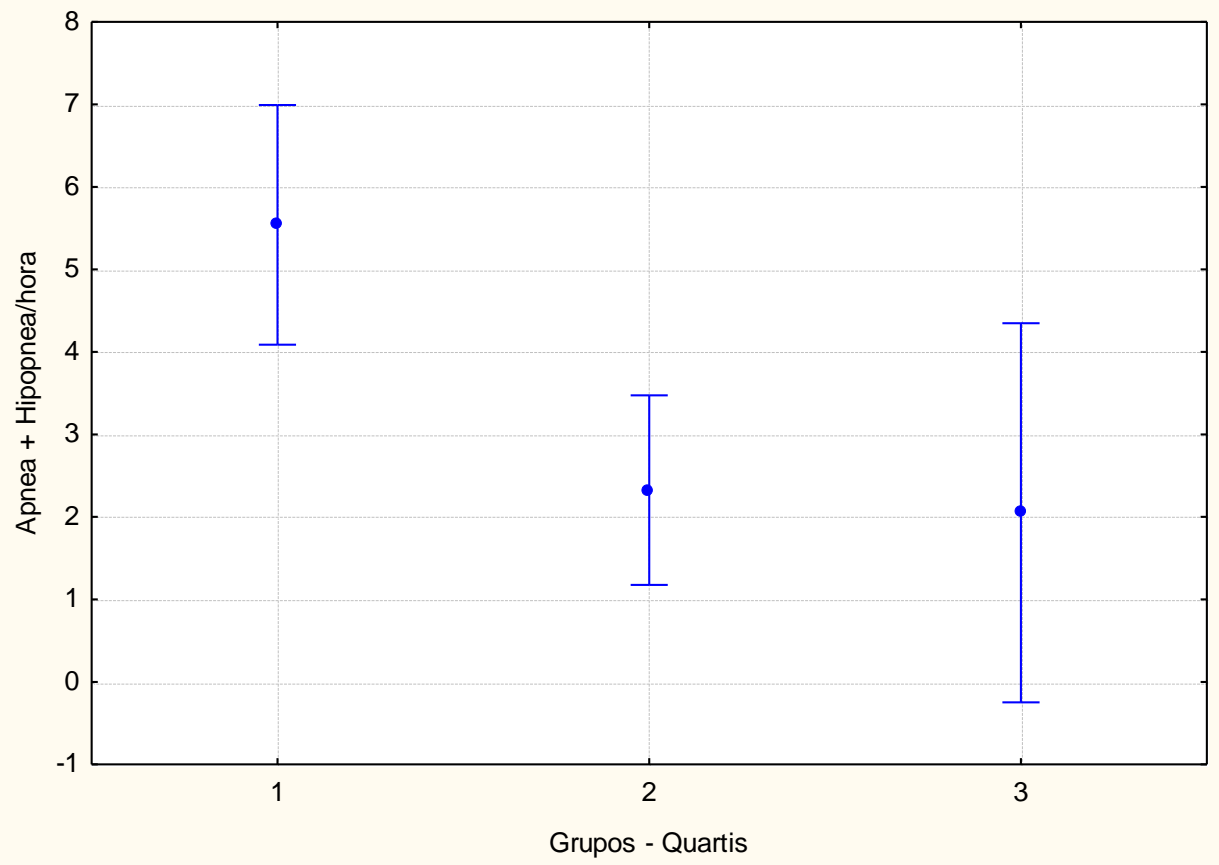

Figura 12 - Valores médios do índice de apnéia-hipopnéia nos três grupos de quartis da média da glicemia.

A glicose intersticial de 11 voluntários DM1 foi monitorada continuamente durante a noite com o sensor do equipamento CGMS. Destes voluntários, 6 tiveram a média da glicose abaixo de $160 \mathrm{mg} / \mathrm{dl}$ e 5 acima desse valor. Apenas 1 voluntário apresentou valores de glicose abaixo de $60 \mathrm{mg} / \mathrm{dl}$. Este indivíduo permaneceu com a 
glicose abaixo de $70 \mathrm{mg} / \mathrm{dl}$ por mais de três horas, das quais, mais de 2 horas abaixo de $40 \mathrm{mg} / \mathrm{dl}$. O hipnograma da maioria dos voluntários não chama a atenção, porém, deste indivíduo, a glicose baixa durante um longo tempo, chama a atenção a não ocorrência de despertares e a longa duração de sono paradoxal durante a hipoglicemia (Figura 13).

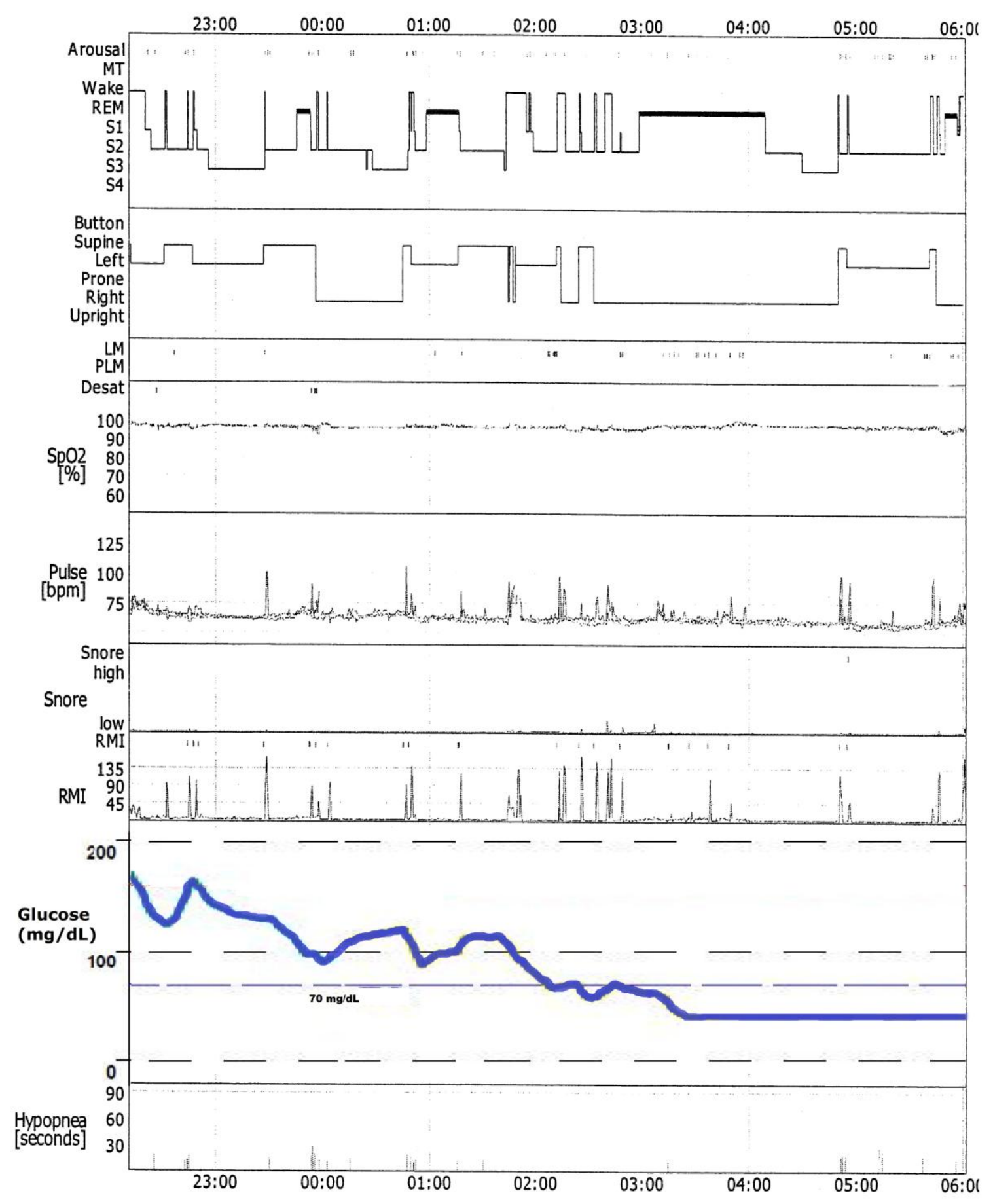

Figura 13 - Hipnograma e glicose de um voluntário do grupo DM1. 
Nem a média, nem a variabilidade da glicose, registrada pelo equipamento CGMS acoplado ao sensor introduzido no subcutâneo dos voluntários DM1, durante a polissonografia, correlacionaram-se com os principais parâmetros avaliados no exame de polissonografia. A única exceção foi a tendência a correlação positiva entre a variabilidade da glicose dessa noite com o número de despertares completos por hora (Figura 14).

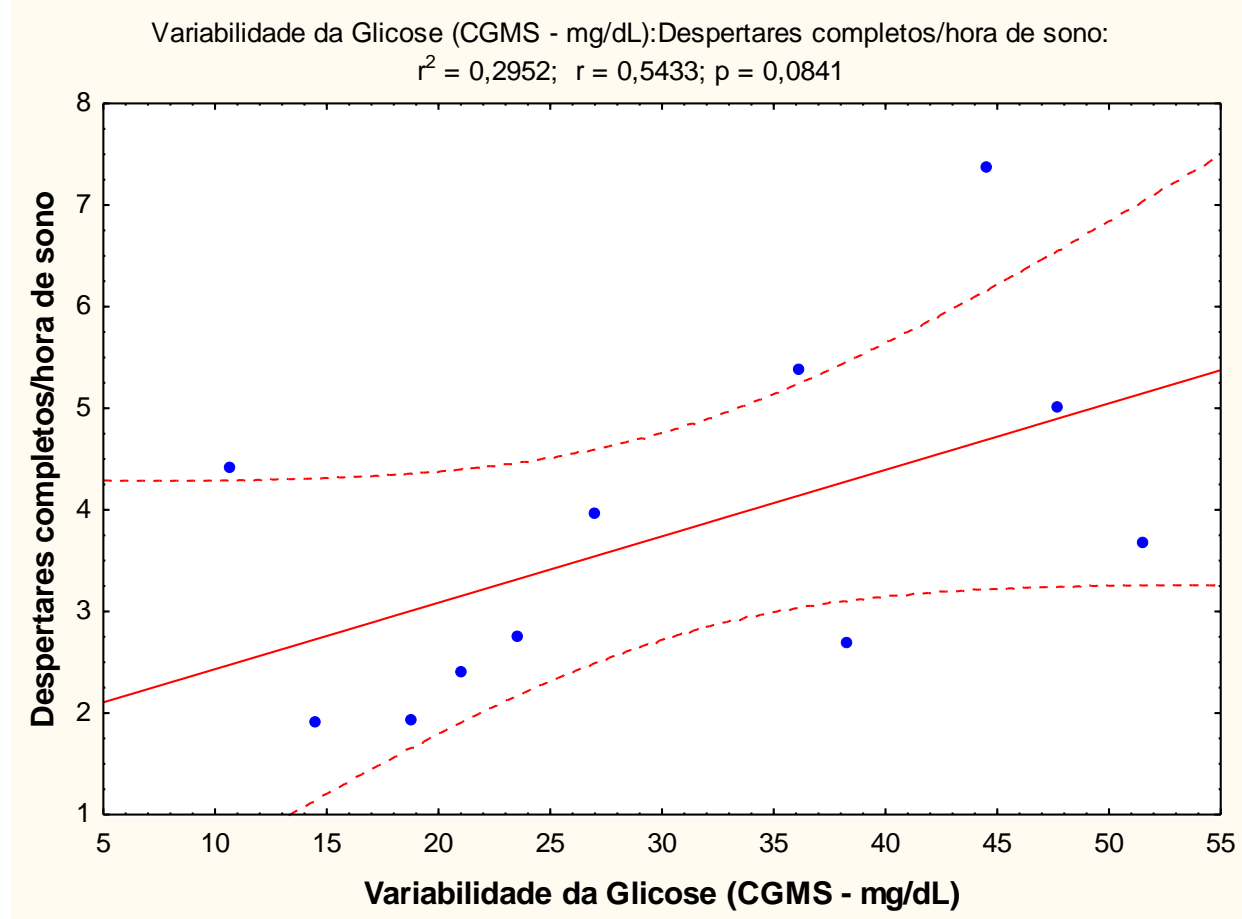

Figura 14 - Correlação entre a variabilidade da glicose (CGMS) e o número de despertares completos por hora de sono.

\subsection{Ciclo vigília/sono}

Os resultados abaixo são resultado da análise dos diários de sono preenchidos durante 10 dias por todos os voluntários.

A média da qualidade do sono mostrou-se negativamente correlacionada à média da sonolência diurna, incluindo-se aí todos os indivíduos dos grupos DM1 e controle (Figura 15). Já a média da duração total de sono por dia apresentou correlação positiva com a média da sonolência diurna (Figura 16). A pontuação da escala de sonolência de Epworth se mostrou positivamente correlacionada à média de tempo diário de cochilo (Figura 17). O número de despertares não espontâneos, 
ou melhor, número de vezes em que o indivíduo foi despertado por alguém ou pelo despertador, mostrou-se correlacionado negativamente à média da duração do sono noturno (Figura 18). Nota-se ainda que a sonolência diurna não é explicada por despertares não espontâneos, e vice versa $\left(r^{2}=0,0322 ; r=0,1794 ; p=0,3706\right)$.

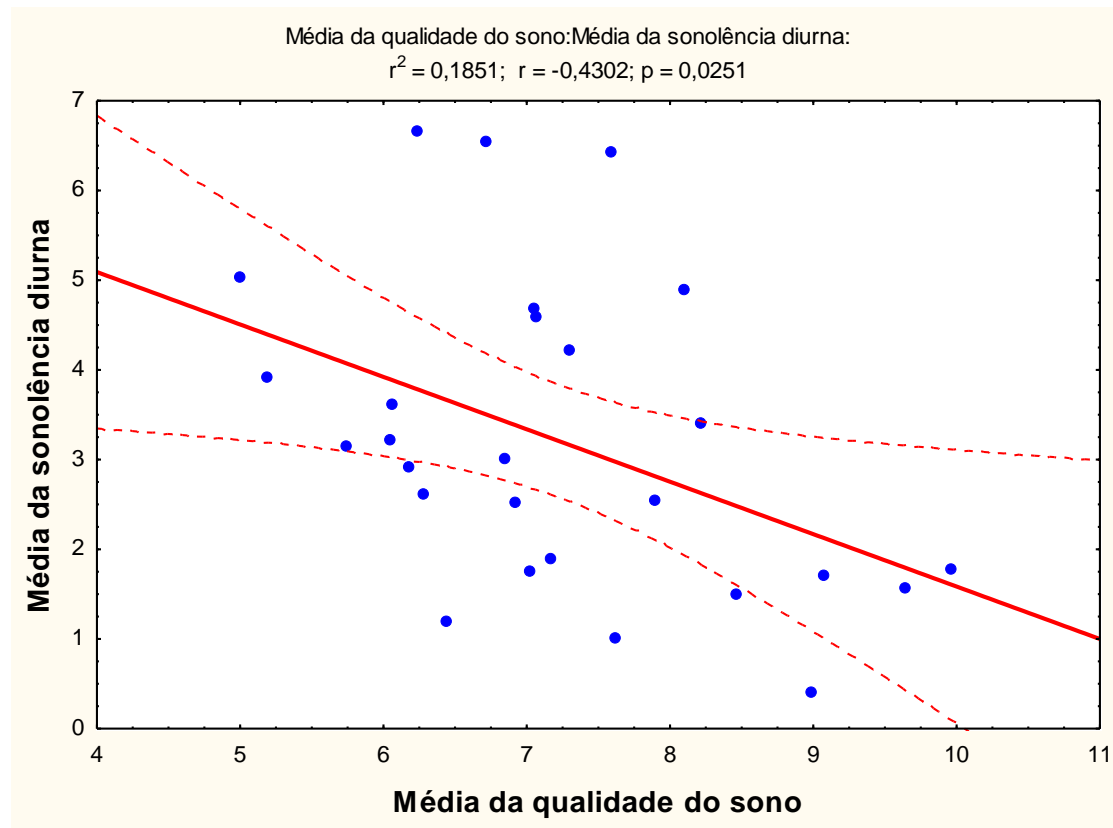

Figura 15 - Correlação entre a média da qualidade do sono noturno e a média da sonolência diurna.

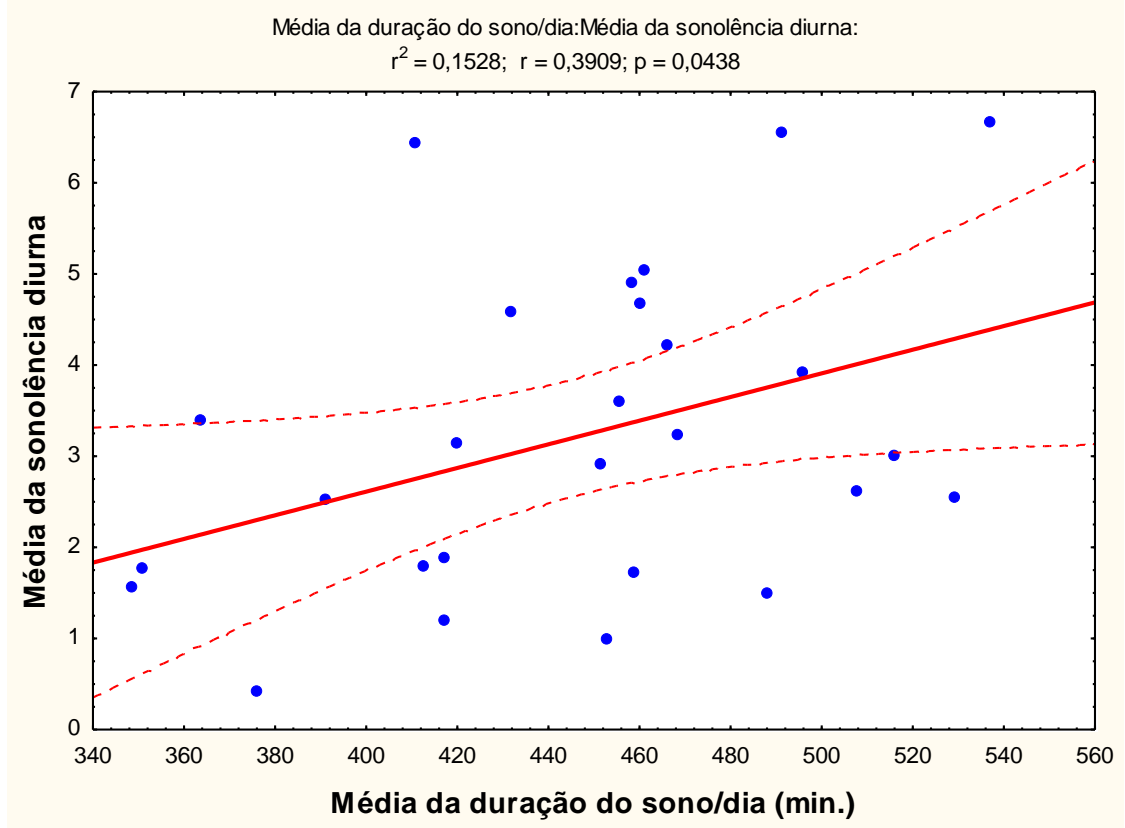

Figura 16 - Correlação entre a média da sonolência diurna e a duração do sono por dia (sono noturno + cochilos). 


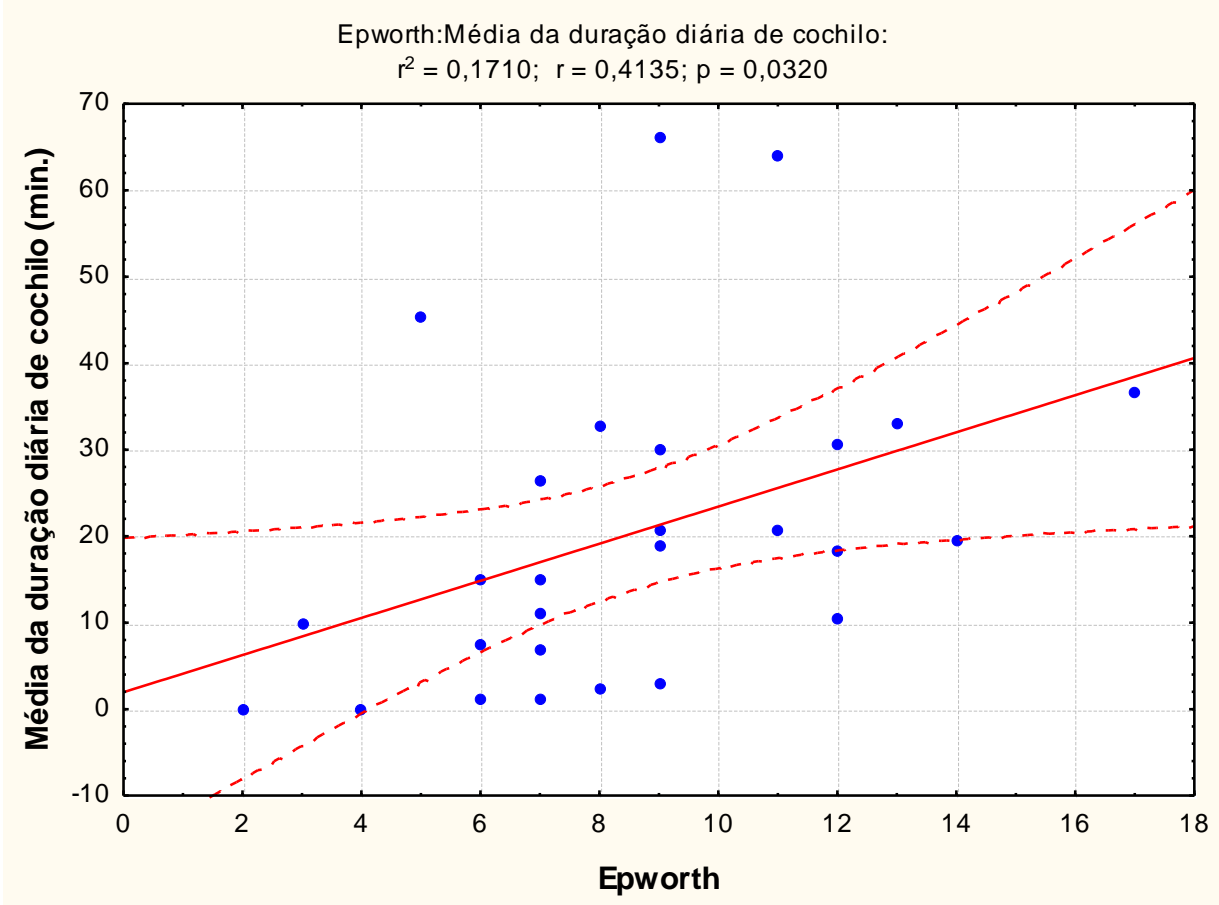

Figura 17 - Correlação entre pontuação na escala de sonolência de Epworth e a média da duração diária de cochilos.

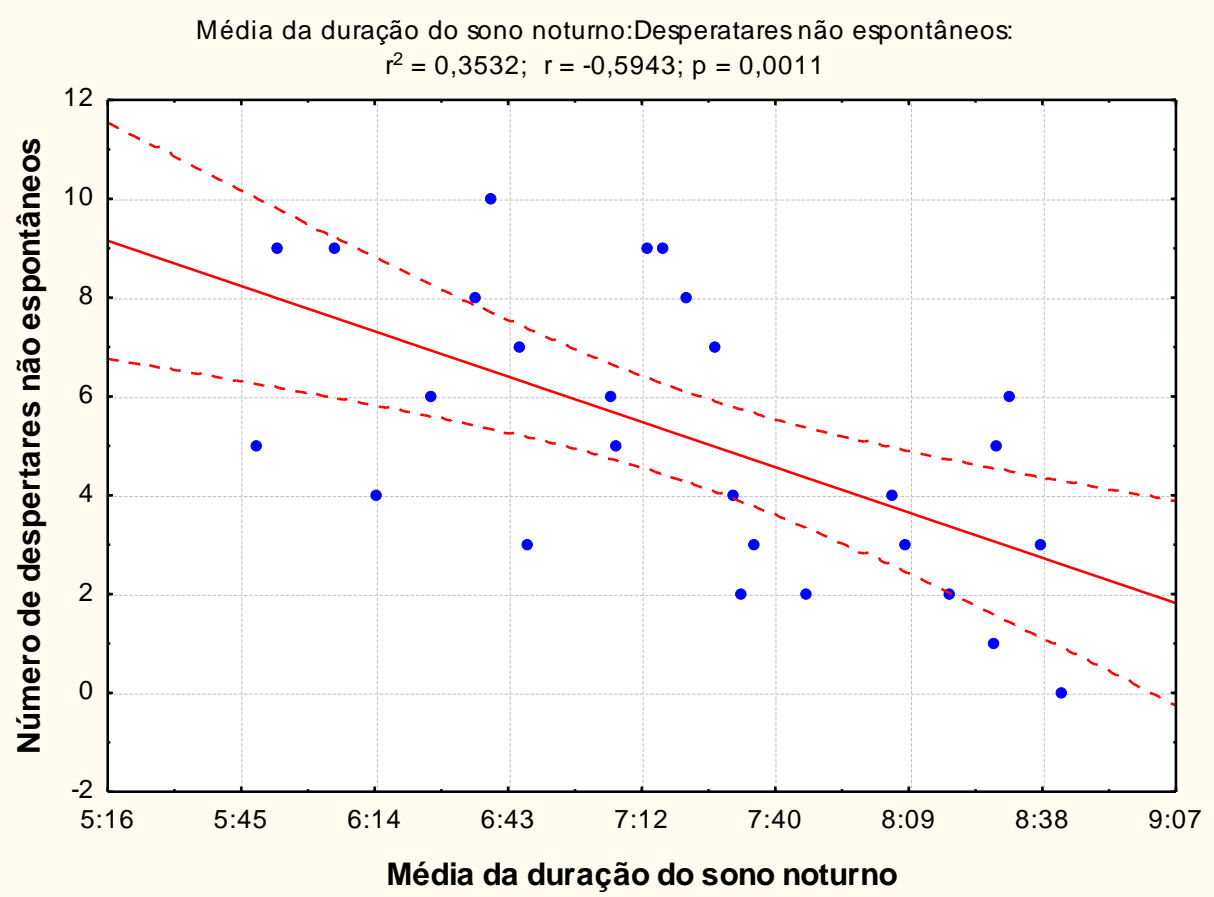

Figura 18 - Correlação entre a média da duração do sono noturno e o número de despertares não espontâneos. 
O gráfico abaixo (Figura 19) foi construído retirando-se da análise os dados dos dois voluntários do grupo DM1 e de um voluntário do grupo controle com média de latência do sono acima de 30 minutos. No mesmo, evidencia-se a correlação negativa entre latência do sono e pontuação no questionário de sonolência de Epworth. Caso a análise tivesse sido feita incluindo-se todos os voluntários, o valor de $p$ seria 0,1849 .

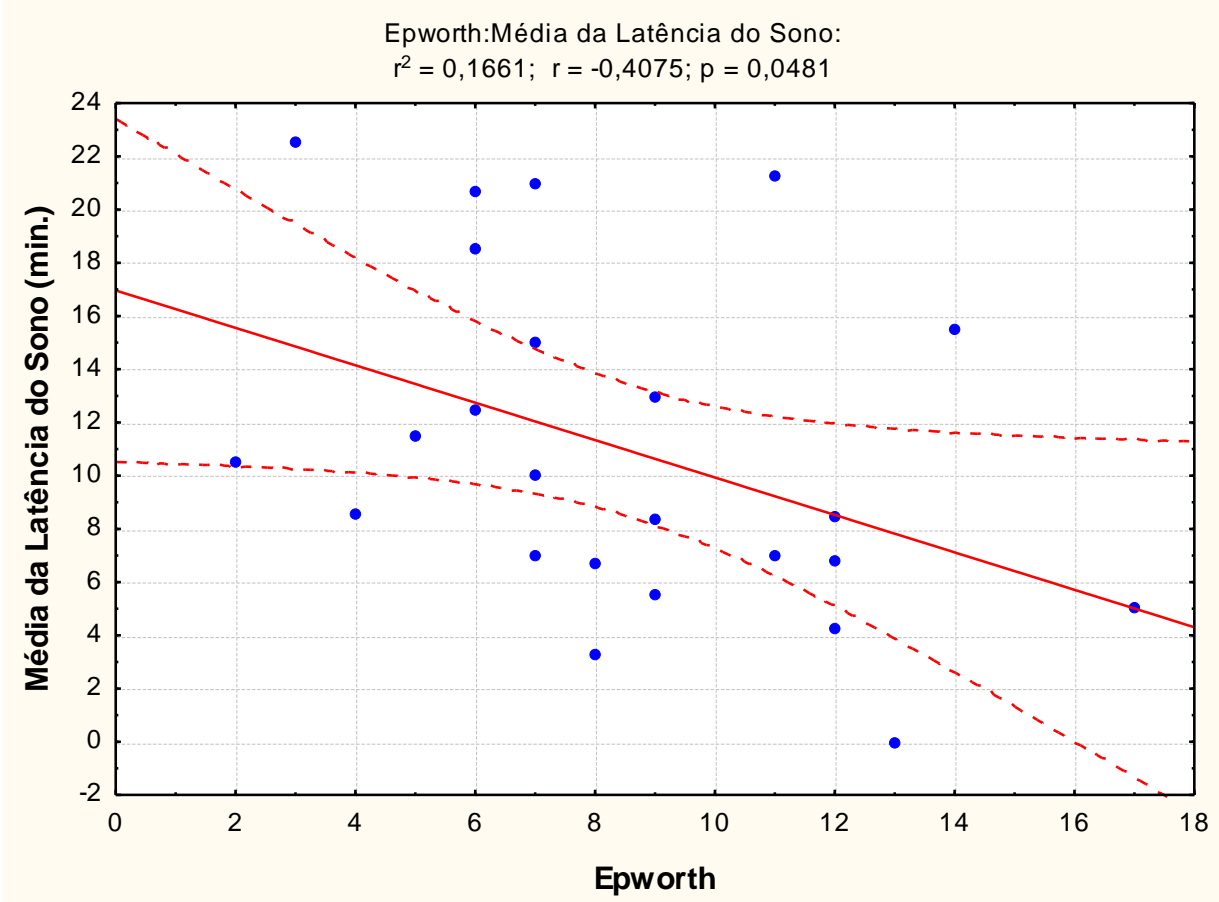

Figura 19 - Correlação entre a pontuação na escala de sonolência de Epworth e a média da latência do sono, excluindo a análise 3 voluntários com latência do sono acima de 30 minutos.

Quanto à média da qualidade do sono, não se observou diferença significativa entre os grupos $\mathrm{GB}$ e $\mathrm{GA}(p=0,42045)$, apesar da média da qualidade do sono do

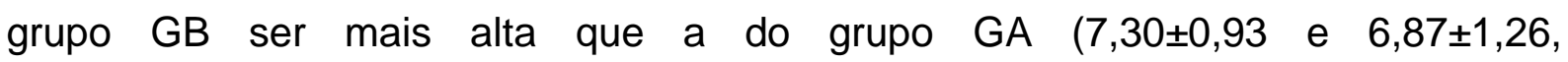
respectivamente). Ao se dividir o grupo em quartis, de acordo com a média da glicemia, visualmente se nota uma tendência em o grupo do $1^{\circ}$ quartil apresentar média da qualidade do sono mais alta que os outros dois grupos (Figura 20) Também não há diferença entre os grupos DM1 e controle $(p=0,43034)$. Apesar de a média da qualidade do sono não se correlacionar à média da glicemia, quando incluídos todos os indivíduos do grupo DM1 ( $r=-0,1950 ; p=0,4381)$, ao se separar os grupos de acordo com a média da glicemia, observa-se que a média da qualidade do sono dos indivíduos do grupo GB (média da glicemia menor que $154 \mathrm{mg} / \mathrm{dl}$ ) está 
fortemente correlacionada à média da glicemia no período (Figura 21), diferente do que ocorre no grupo GA $(r=0,1752 ; p=0,6520)$.

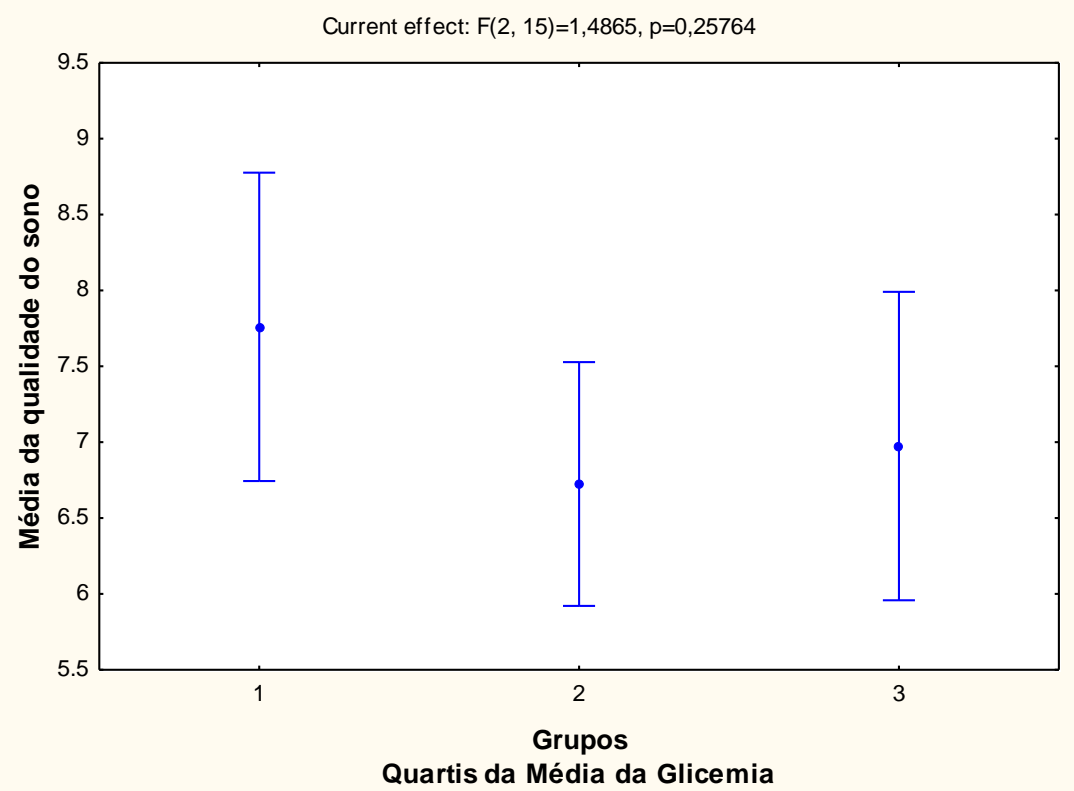

Figura 20 - Valores médios da qualidade do sono nos indivíduos DM1 divididos em 3 grupos de acordo com os quartis da média da glicemia.

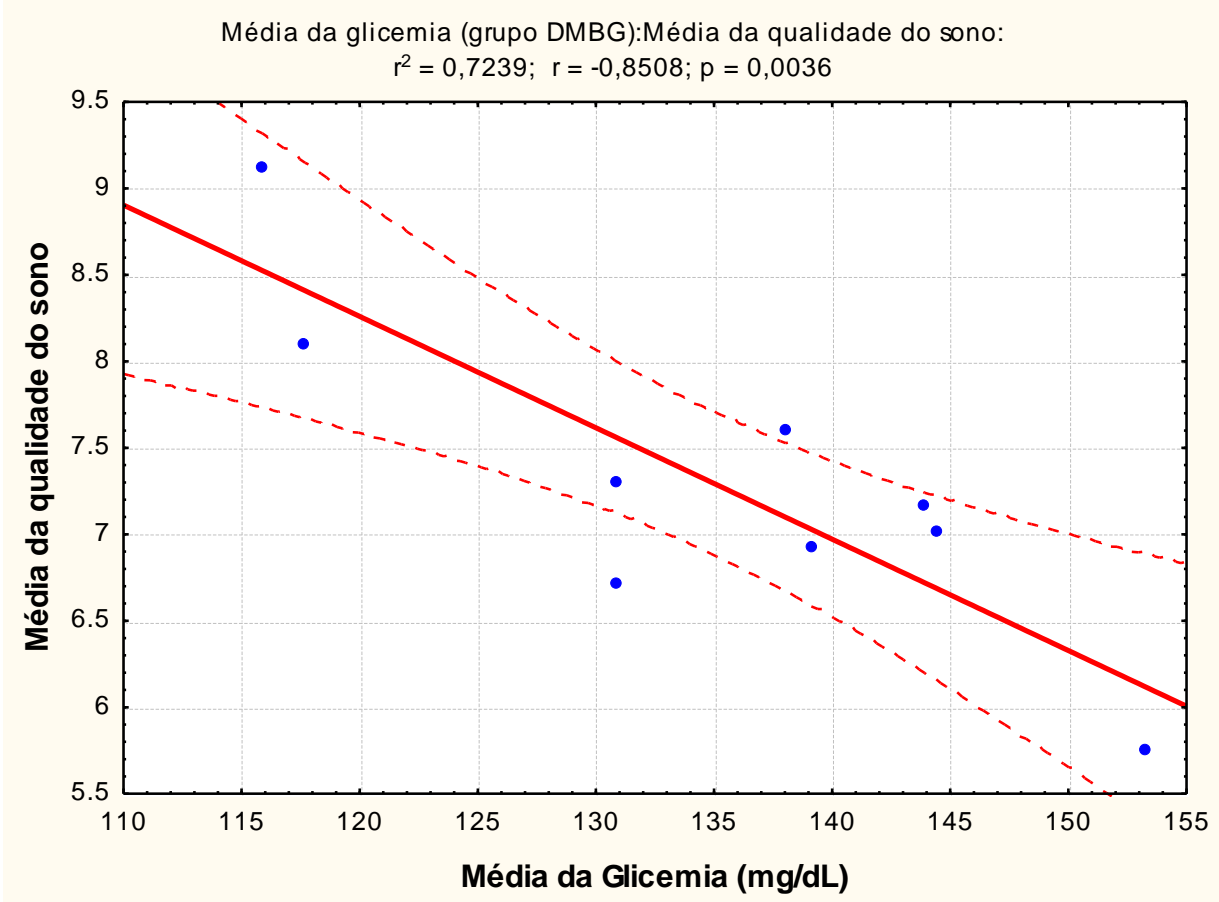

Figura 21 - Correlação entre a média da glicemia e a média da qualidade do sono em voluntários do grupo GB. 
Ao se dividir os indivíduos do grupo DM1 de acordo com a variabilidade glicêmica, não se observou diferença quanto à qualidade do sono $(p=0,82460)$. Também não houve correlação significativa entre essas variáveis (média da qualidade do sono e variabilidade glicêmica) $(r=-0,2093 ; p=0,4046)$. Analisando-se os grupos VB e VA em separado, apesar do grupo com baixa variabilidade glicêmica ter apresentado uma tendência negativa de correlação com a média da qualidade do sono $(r=-0,6568$, Figura 22$)$, nenhum deles se mostrou significativamente correlacionado ( $p=0,0546$ e $p=0,9813$, respectivamente).

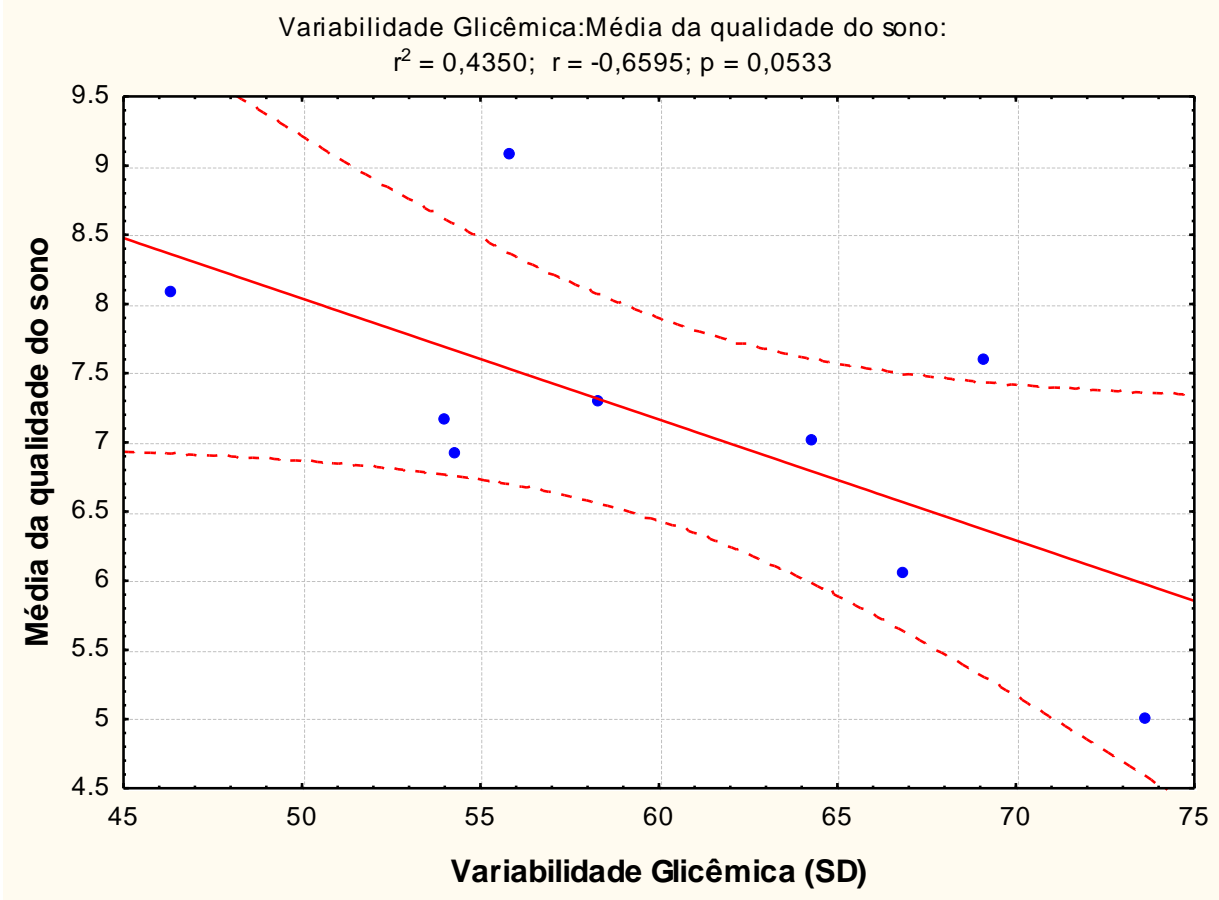

Figura 22 - Correlação entre a variabilidade glicêmica e a média da qualidade do sono no grupo VB.

A correlação entre a média da duração do sono noturno e a média da glicemia não foi significativa $(r=0,3043 ; p=0,2196)$. Ao se dividir o grupo $D M 1$ nos grupos $G B$ e GA, nota-se que apesar do grupo com média da glicemia mais elevada apresentar maior média da duração do sono noturno, essa diferença não foi significativa $(p=0,20806)$. A variabilidade glicêmica também não se mostrou correlacionada à média da duração do sono noturno ( $p=0,6710)$, e não houve diferença da duração do sono noturno entre os dois grupos, VB e VA, $(p=0,99192)$. Ao se comparar a média da duração do sono noturno entre o grupo DM1 e o grupo controle, verifica-se não haver diferença $(p=0,31462)$. 
Como se vê na figura 23, os voluntários da pesquisa (incluindo DM1 e controles) dormiam mais tempo durante o final de semana que durante a semana. Consideraram-se para a média da duração do sono noturno de fim de semana as noites entre sexta e sábado e entre sábado e domingo. A duração de sono entre as noites de terça a quarta-feira, de quarta a quinta-feira, e de quinta a sexta-feira foram consideradas para se calcular a média da duração de sono durante a semana. Comparando a média da duração do sono, tanto durante a semana quanto durante os fins de semana, não houve diferença entre os grupos controle e DM1 ( $p=0,10977$; $p=0,82802$, respectivamente).

Foram considerados privados de sono durante a semana os indivíduos que apresentaram média de duração do sono maior durante o fim de semana, em comparação à média da duração do sono durante a semana. A porcentagem de indivíduos de ambos os grupos, DM1 e controle, que se mostraram privados de sono durante a semana foi exatamente a mesma, 78\%. Contudo, apesar da maioria dos indivíduos de ambos os grupos estar aparentemente privada de sono durante a semana, e de não haver diferença estatística da duração do sono entre os indivíduos privados do grupo controle e do grupo DM1, nem durante a semana, nem nos finais de semana (média da duração do sono durante a semana dos indivíduos privados: 6h59min00s, controle; 6h21min54s, DM1, $p=0,19915$; média da duração do sono durante os finais de semana dos indivíduos privados: 7 h 56 min 17 s, controle, 8 h $23 \min 27 \mathrm{~s}$, DM1, $p=0,23349)$, os indivíduos do grupo DM1 privados de sono revelaram-se significativamente mais privados (Figura 24), ou melhor, com a diferença entre a duração do sono durante os finais de semana, em relação à duração do sono durante a semana, maior que do grupo controle $(2 \mathrm{~h} 01 \mathrm{~min} 33 \mathrm{~s} \pm$ $1 \mathrm{~h} 07 \min 19 \mathrm{~s}$ e $57 \mathrm{~min} 17 \mathrm{~s} \pm 36 \mathrm{~min} 24 \mathrm{~s}$, respectivamente). Apenas como exemplo, nos gráficos, figura 25 e figura 26, estão plotados a duração do sono de um voluntário do grupo controle e de um voluntário do grupo DM1, respectivamente. 


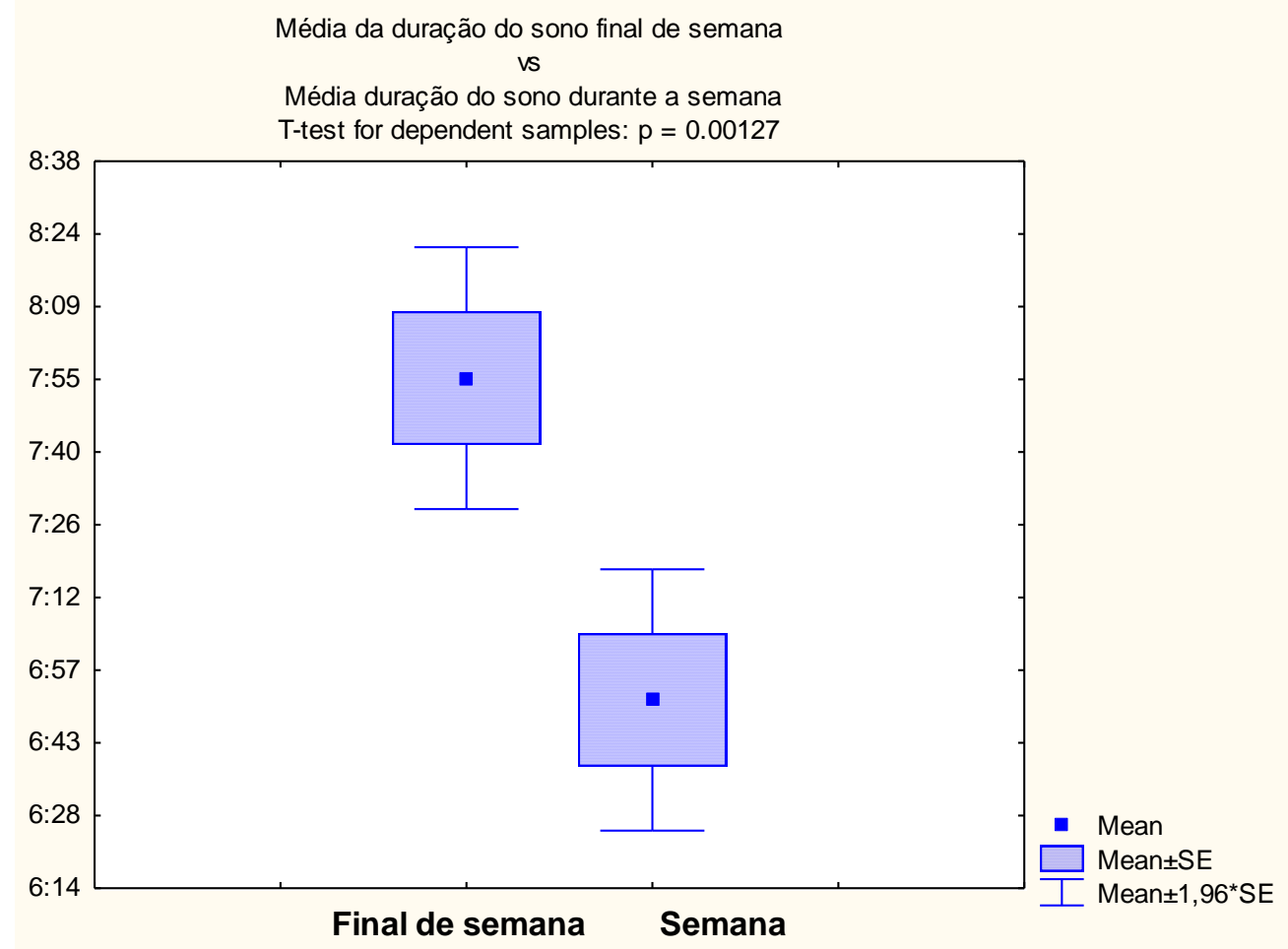

Figura 23 - Média da duração de sono durante a semana e nos finais de semana.

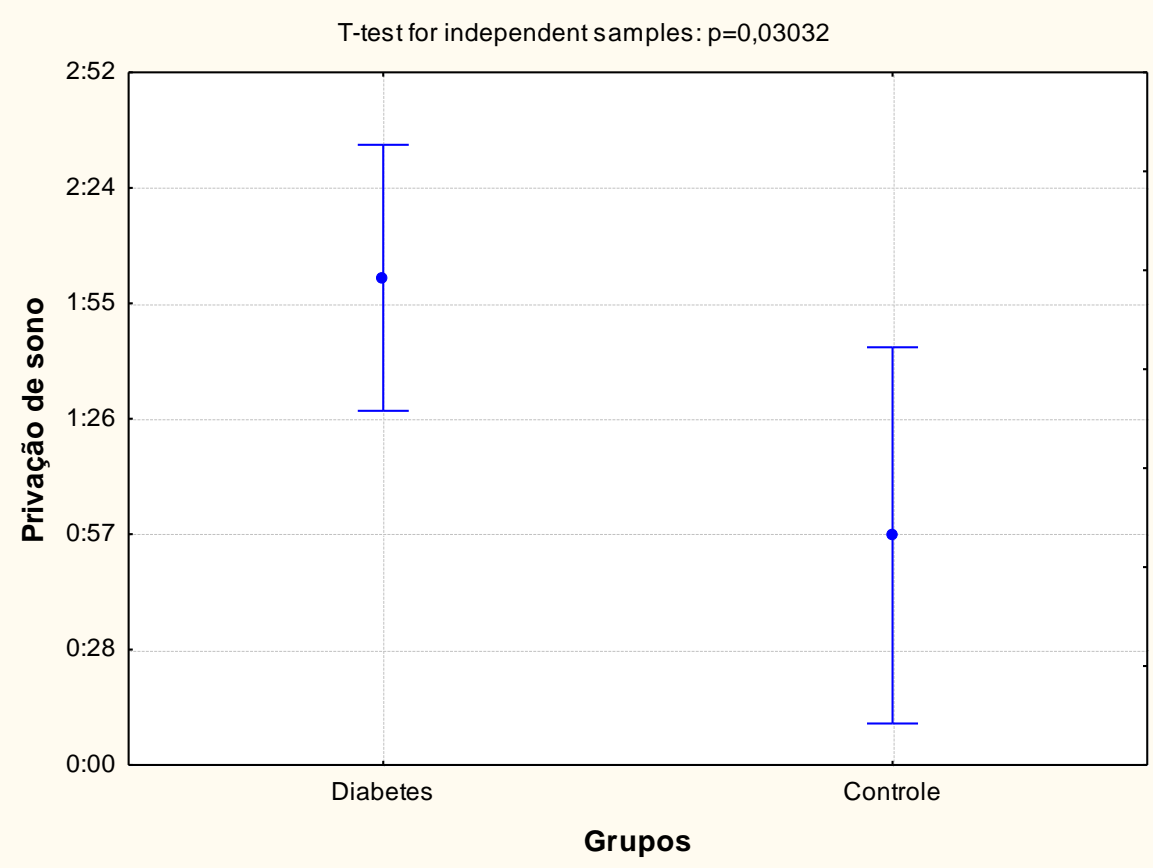

Figura 24 - Média da privação de sono (diferença entre a média de sono durante a semana e média da duração de sono durante os fins de semana) nos indivíduos que se mostraram privados dos grupos DM1 e controle. 


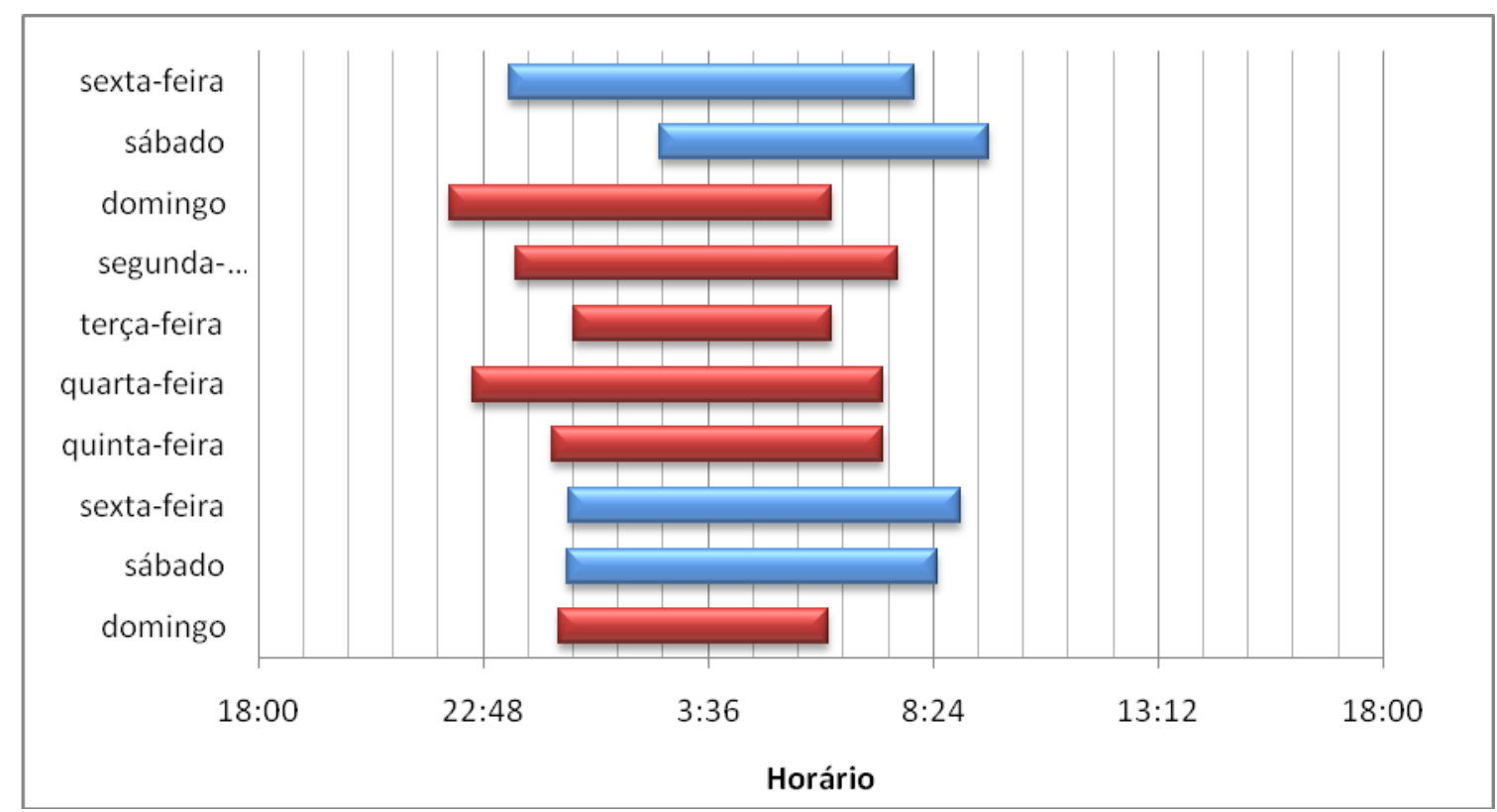

Figura 25 - Sono de um indivíduo do grupo controle.

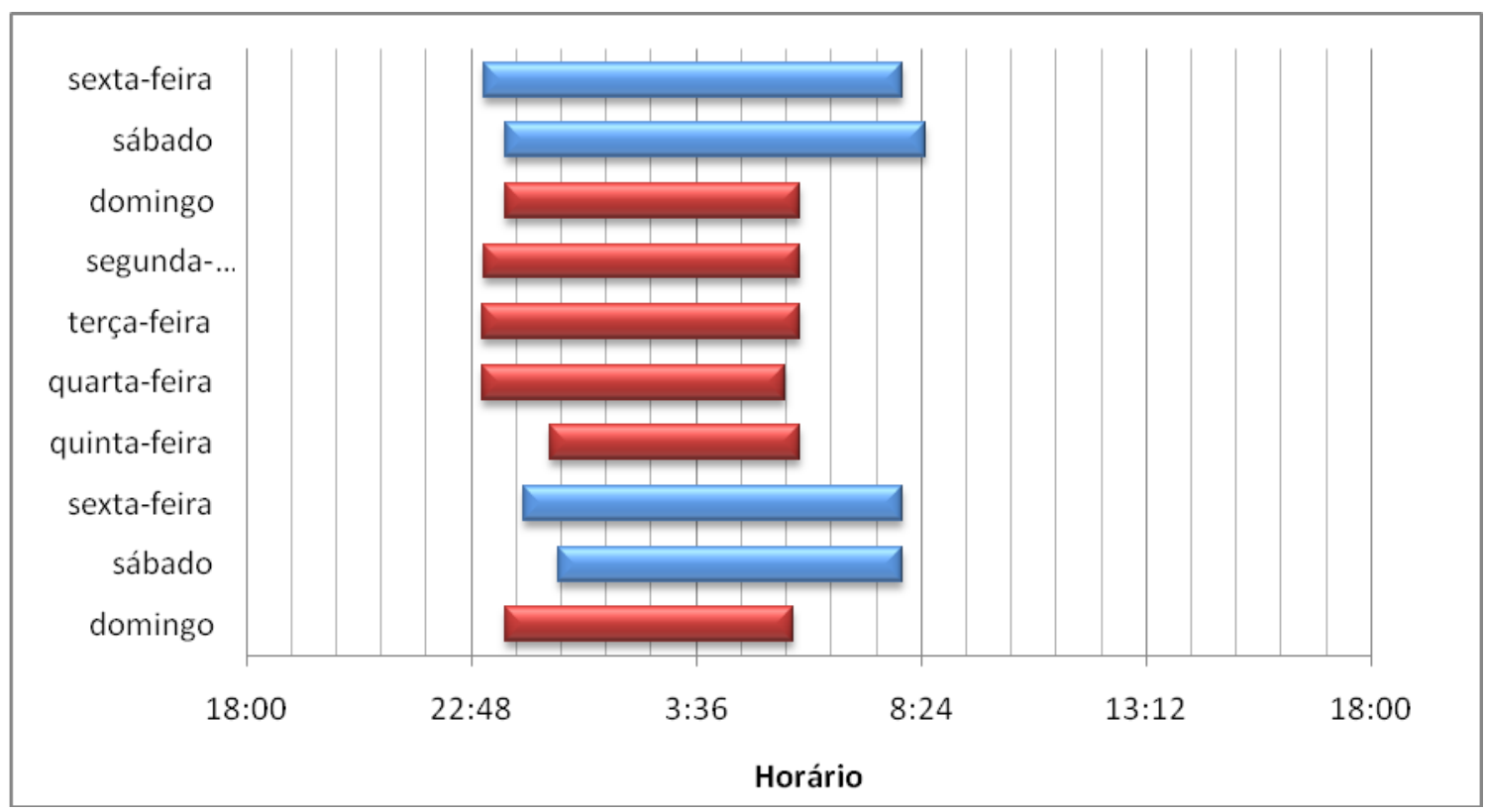

Figura 26 - Sono de um indivíduo do grupo DM1.

Não houve diferença significativa entre a média da latência de sono do grupo controle e a média da latência de sono do grupo DM1 ( $p=0,5037$, Mann-Whitney U Test). Por outro lado, a média da latência de sono se mostrou positivamente correlacionada à variabilidade glicêmica $\left(r^{2}=0,4258 ; r=0,6525 ; p=0,0033\right.$; Figura 27). Em relação à correlação entre a média da latência de sono e a média da glicemia, 
só foi evidenciada correlação positiva, significativa, quando excluídos da amostra os dois valores de média de latência de sono superiores a 30 minutos (incluindo valores de todos os indivíduos: $r^{2}=0,0784, r=0,2800, p=0,2604$; excluindo-se os dois valores mencionados: $r^{2}=0,3628, r=0,6024, p=0,0135$; Figura 28). Observou-se, ainda, que a diferença entre os grupos GB e GA só foi significativa ao se excluir os mesmos dois valores (incluindo valores de todos os indivíduos: Mann-Whitney $U$ Test: $p=0,0851$; excluindo-se os dois valores: Mann-Whitney U Test: $p=0,0357$; Figura 29).

Os dois valores excluídos são exatamente do último voluntário do grupo GB, portanto o valor da média de glicemia mais elevada desse grupo, e do primeiro voluntário do grupo GA, portanto, da mesma forma, o valor da média de glicemia mais baixa deste grupo. Interessante observar, ainda, que o voluntário com a média da latência do sono superior a 30 minutos do grupo GB apresenta HbA1c pós-coleta mais baixa que apenas um dos voluntários do grupo GA (HbA1c de 10\%, em comparação a $12 \%$ do voluntário com HbA1c mais elevada). Ao se dividir os indivíduos de acordo com a variabilidade glicêmica, observa-se diferença significativa entre a média da latência de sono do grupo VB e do grupo VA $(p=0,0243$; Figura 30).

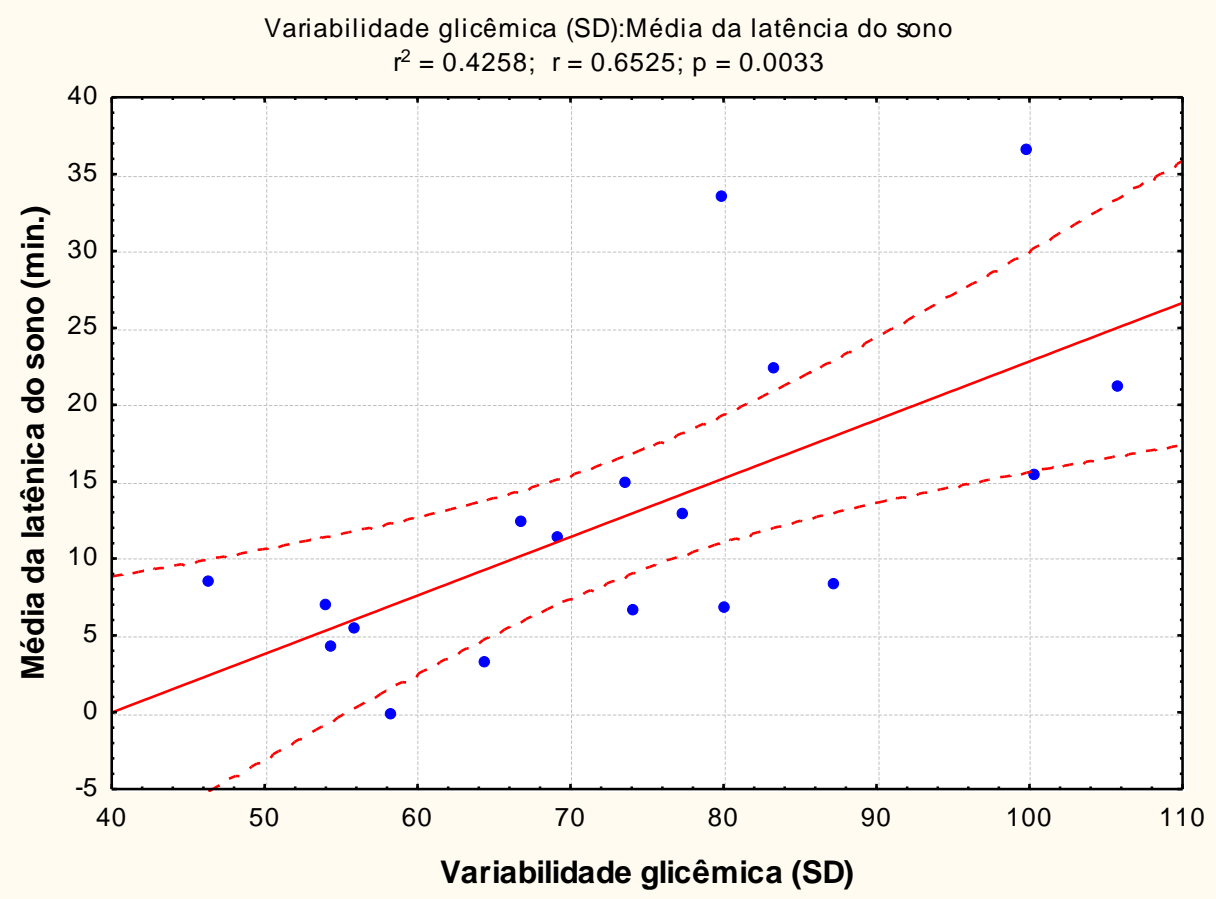

Figura 27 - Correlação entre variabilidade glicêmica e media da latência do sono. 


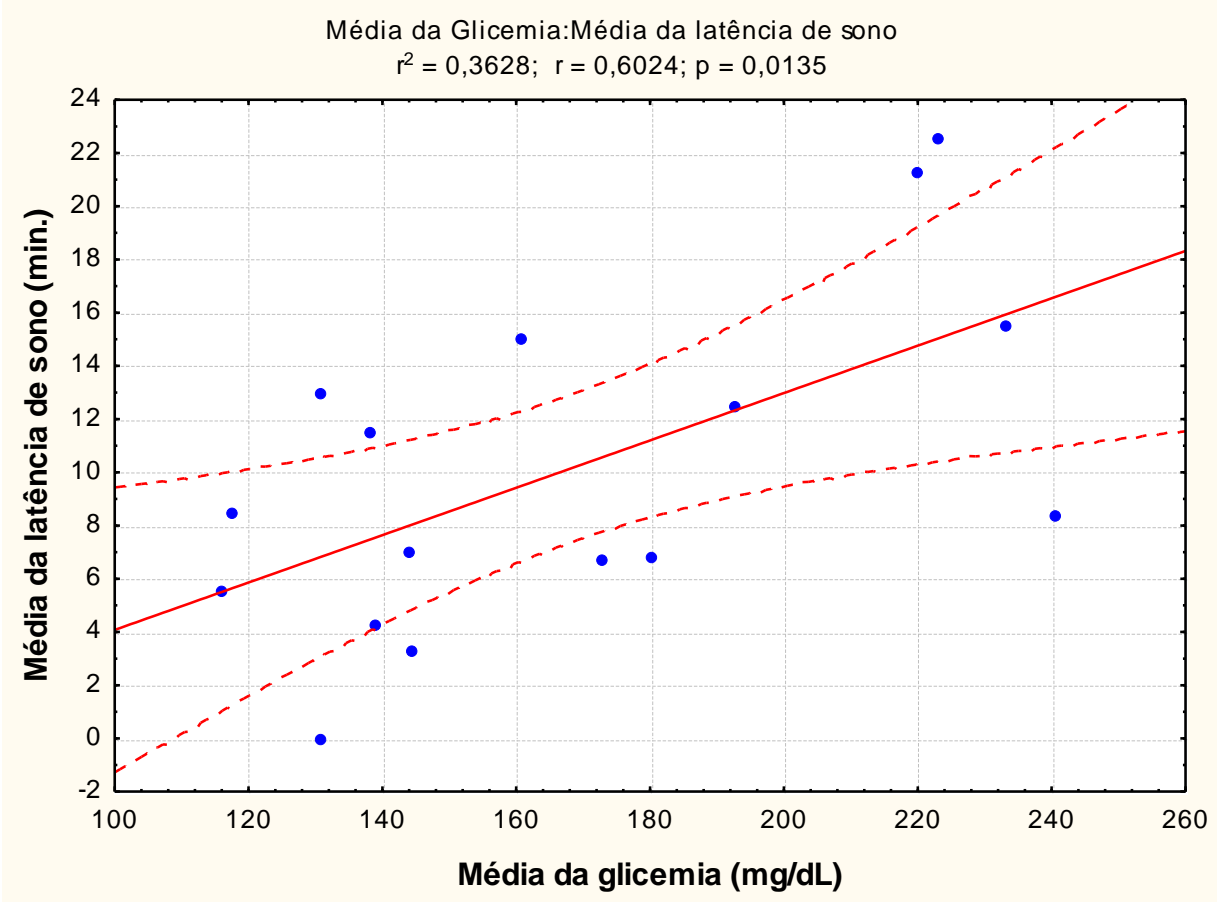

Figura 28 - Correlação entre a média da glicemia e a média da latência do sono, excluindo-se da análise dados de dois indivíduos com média da latência do sono maior que 30 minutos.

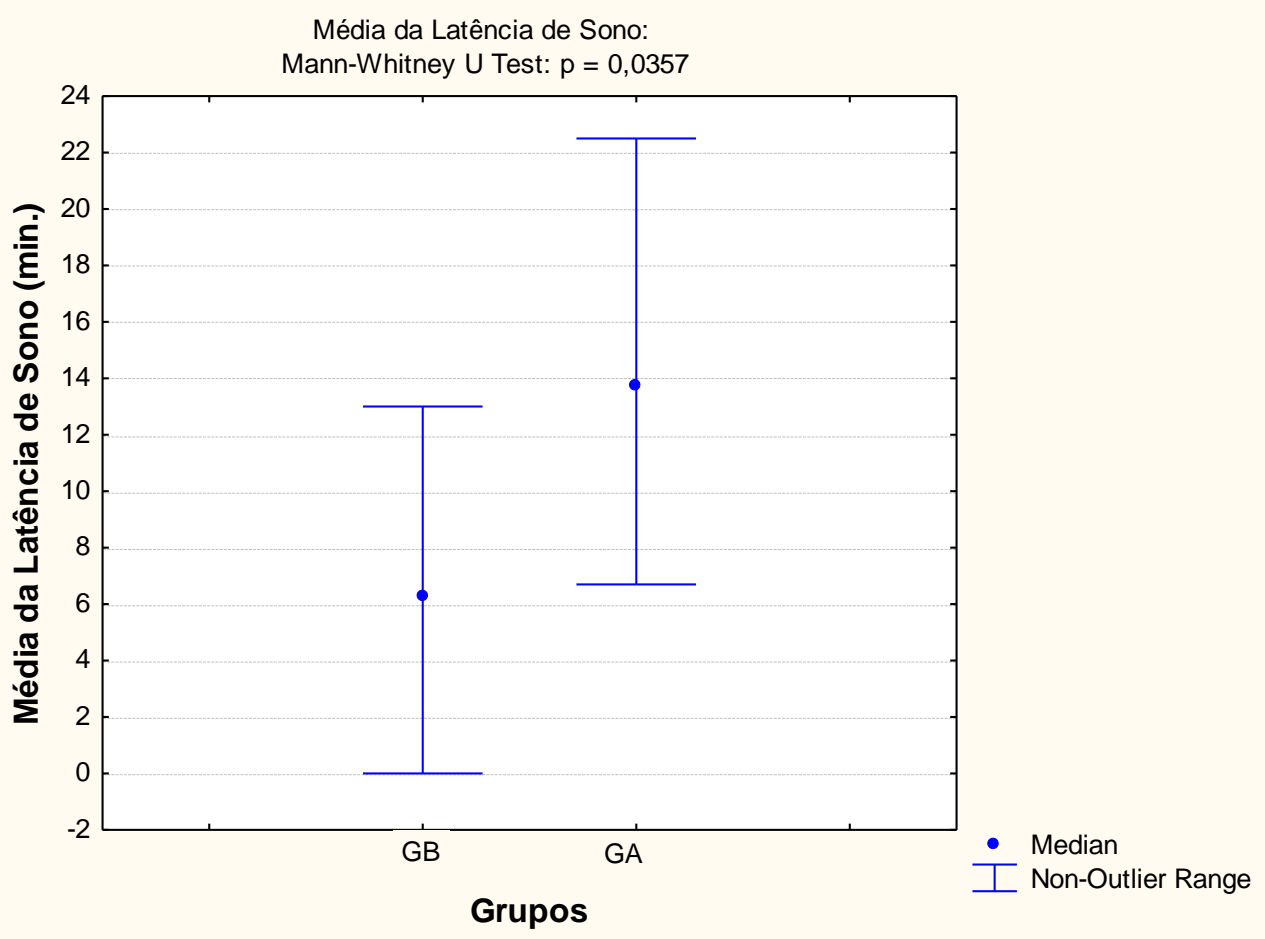

Figura 29 - Média da latência do sono dos grupos GB e GA. 


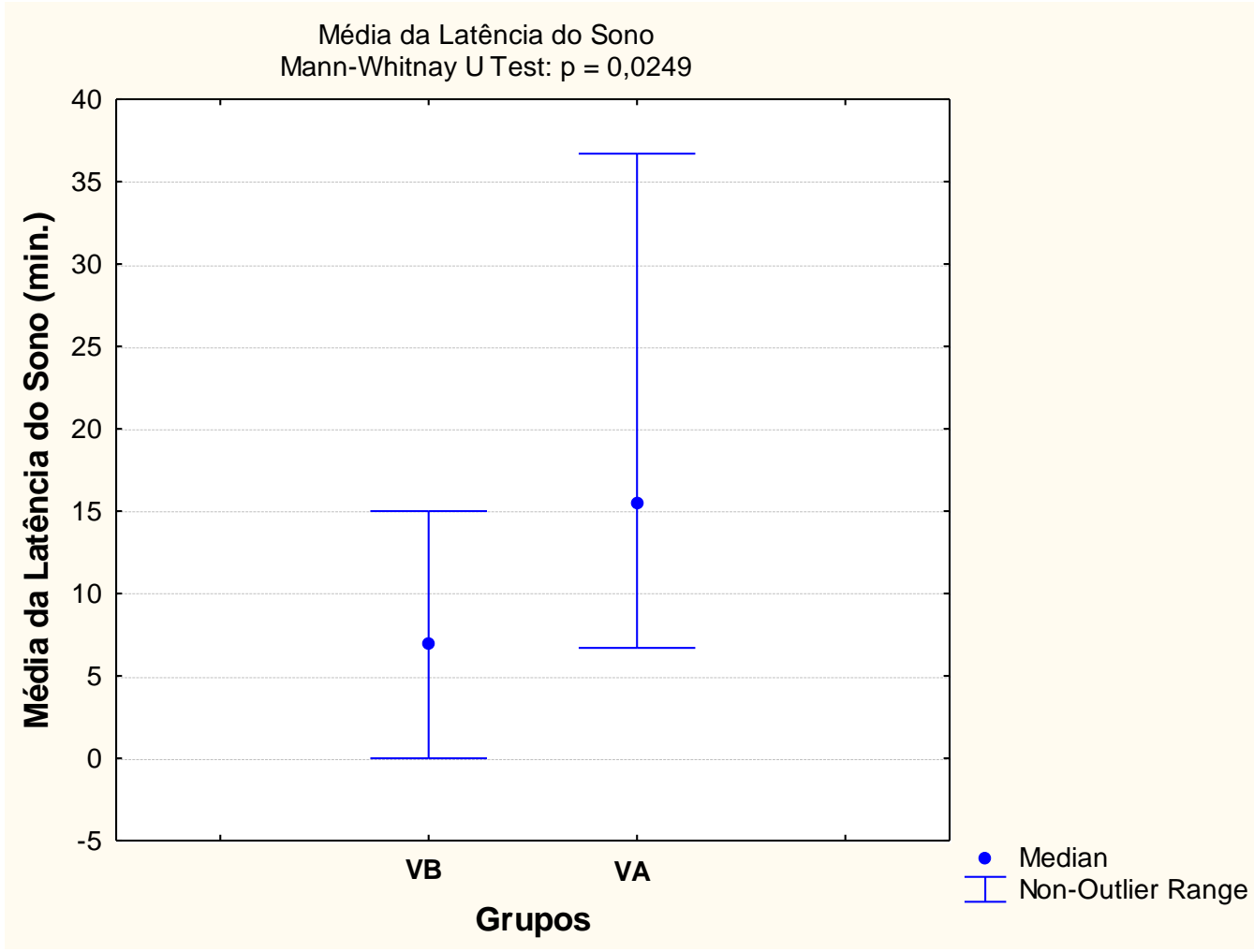

Figura 30 - Média da latência do sono dos grupos VB e VA.

Apesar de a média de pontos obtidos na escala de sonolência de Epworth ter sido maior no grupo DM1 do que no grupo controle, não houve diferença significativa $(p=0,10653)$. Por outro lado, se optássemos por fazer essa comparação utilizando um teste não paramétrico, como o teste Mann-Whitney $\mathrm{U}$, o que foi inicialmente descartado devido ao fato da distribuição dos pontos da escala de sonolência ter apresentado distribuição normal (Shapiro-Wilk $W=0,97582, p=0,75833$ ), observar-seia diferença significativa entre os grupos DM1 e controle (Figura 31). 


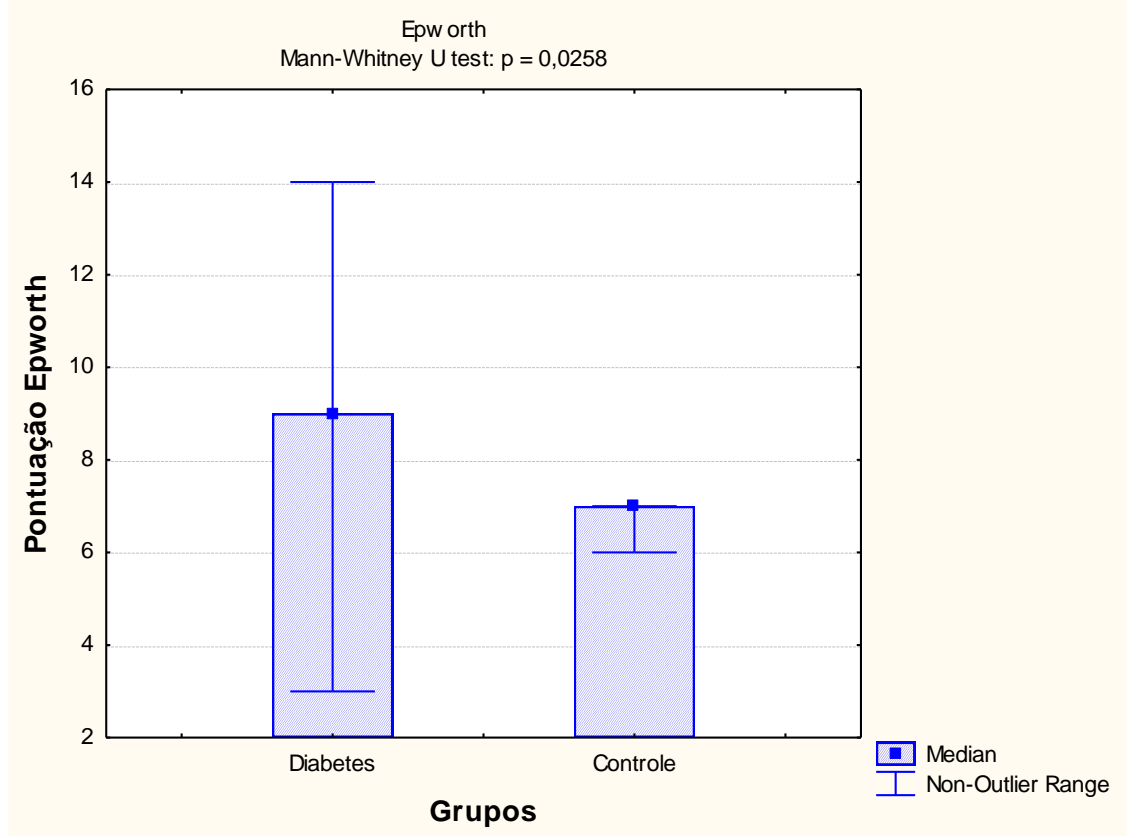

Figura 31 - Pontuação na escala de sonolência de Epworth nos grupos DM1 e controle.

Ao se comparar os três grupos (grupo controle e dois grupos DM1), não importando se divididos de acordo com a média da glicemia ou a variabilidade glicêmica, assim como ao se comparar entre os subgrupos do DM1, não é observada diferença significativa para a pontuação da escala de sonolência ( $p>0,05)$. Destaca-se, porém, que enquanto apenas 1 voluntário $(11 \%)$ do grupo controle obteve pontuação na escala de sonolência acima de 10 , sete voluntários do grupo DM1 (39\%) obtiveram tal pontuação (Figura 32).

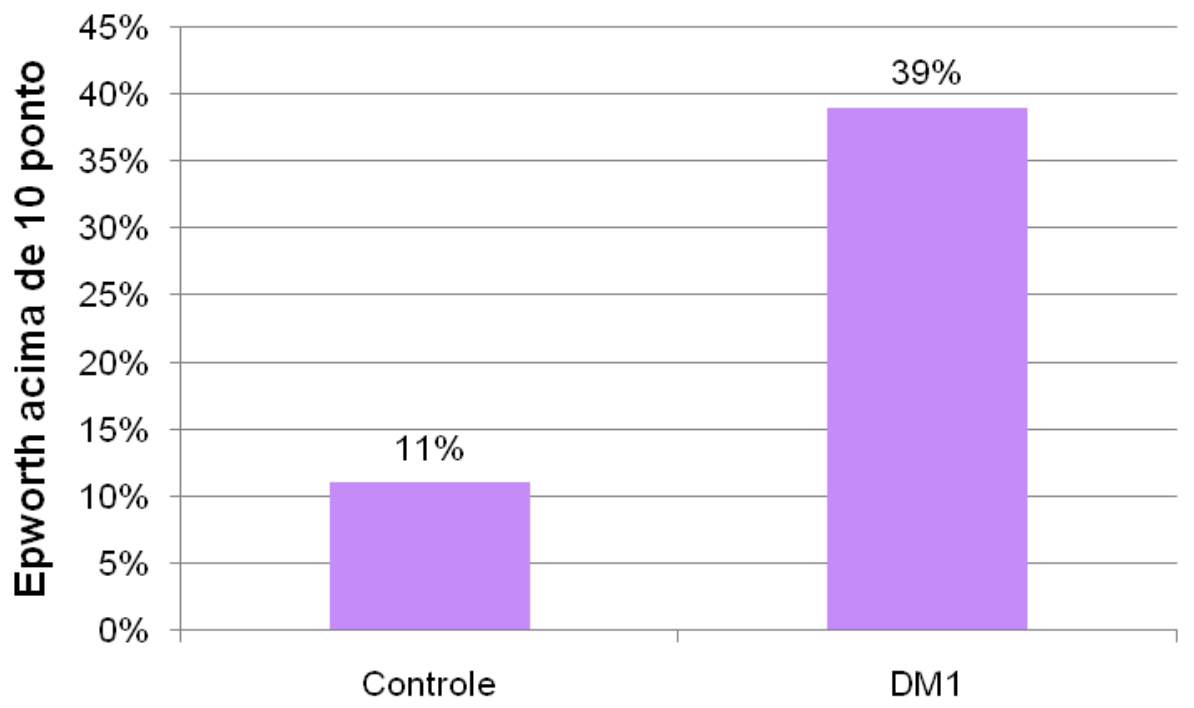

Figura 32 - Pontuação na escala de sonolência de Epworth nos grupos controle e DM1. 


\subsection{Ritmo de atividade/repouso}

Os resultados abaixo são baseados na análise dos dados de actimetria. É importante ressaltar que os dados do Tempatilumi de actimetria foram obtidos de 12 indivíduos do grupo DM1, e 7 indivíduos do grupo controle.

A média da sonolência diurna se mostrou fortemente correlacionada à média da duração total de repouso por dia (Figura 33). Nos indivíduos do grupo DM1 a correlação entre sonolência diurna e a média da duração do repouso noturno também se mostraram correlacionadas (Figura 34). Porém, ao se incluir o grupo controle, portanto grupo DM1 e grupo controle juntos, essa correlação deixa de ser significativa $(p=0,1414)$.

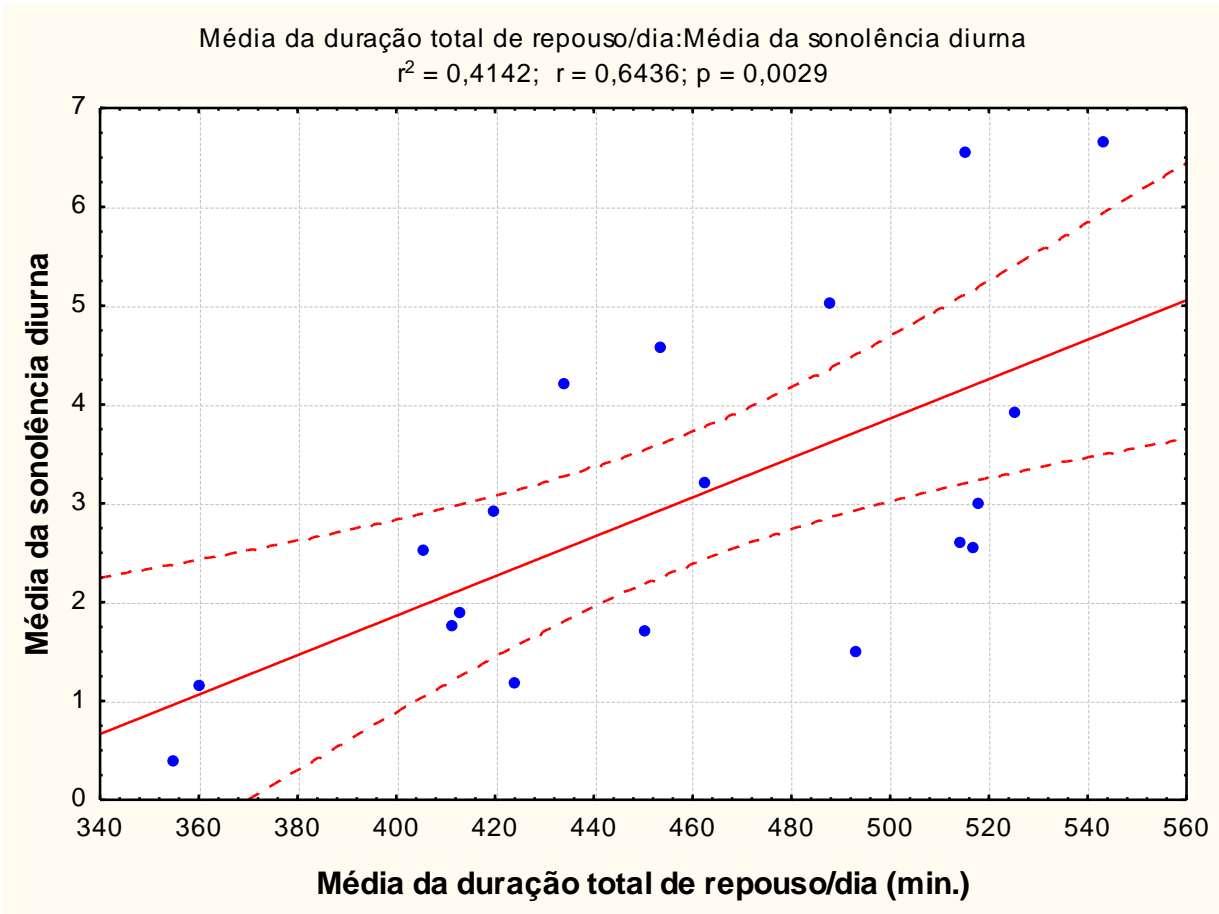

Figura 33 - Correlação entre a média da duração total de repouso por dia e a média da sonolência diurna. 


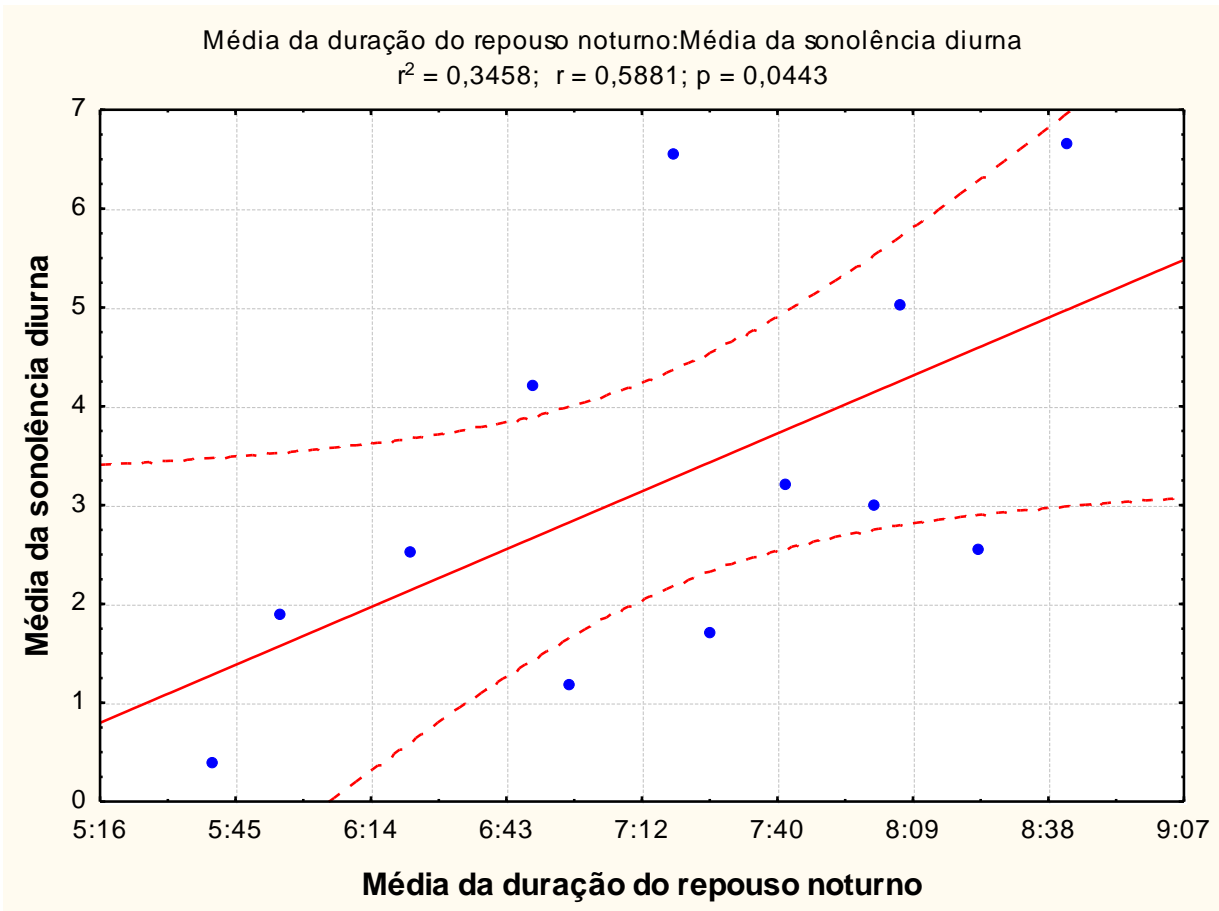

Figura 34 - Correlação entre a média da duração do repouso noturno dos indivíduos do grupo DM1 e a média da sonolência diurna.

$\mathrm{Na}$ figura 35 se observa que o número de despertares não espontâneos apresentou correlação negativa significativa com a média da duração do repouso noturno. Apesar da correlação significativa entre as variáveis média da sonolência e despertares não espontâneos com a média da duração do repouso noturno, essas duas variáveis não apresentam correlação significativa entre si $(p=0,3706$, incluindo todos os indivíduos; $p=0,2376$, apenas grupo DM1). 


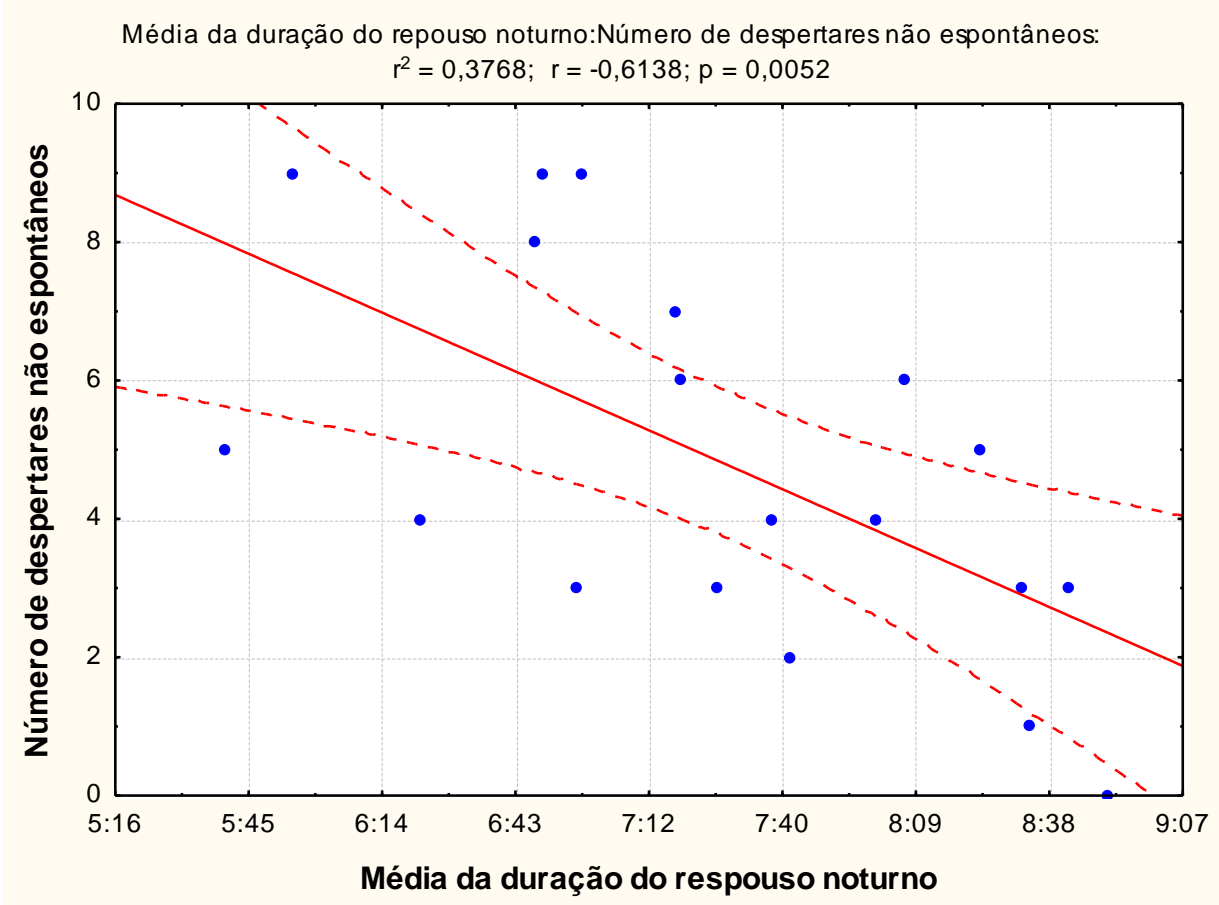

Figura 35 - Correlação entre a média da duração do repouso noturno e o número de despertares espontâneos.

Como se observa abaixo, a média da duração do repouso noturno apresenta uma tendência à correlação positiva com a média da glicemia (Figura 36). Semelhante tendência também se apresenta em relação à variabilidade glicêmica (DP) (Figura 37). Excluindo-se os dados de um indivíduo do grupo DM1, que, diferente da tendência do grupo, apresentava alta variabilidade glicêmica, acima de $74 \mathrm{mg} / \mathrm{dl}$, mesmo tendo a menor duração do sono, observou-se correlação positiva da variabilidade glicêmica (DP) tanto com a média da duração do repouso noturno (incluindo os dados de todos os indivíduos: $r=0,5706 ; p=0,0527$; excluindo os dados do indivíduo mencionado: $r=0,7745 ; p=0,0051)$, quanto com a média da duração total do repouso por dia (todos: $r=0,5481 ; p=0,0650$; excluindo 1: $r=0,7971$, $p=0,0033$ ) (Figuras 38 e 39). 


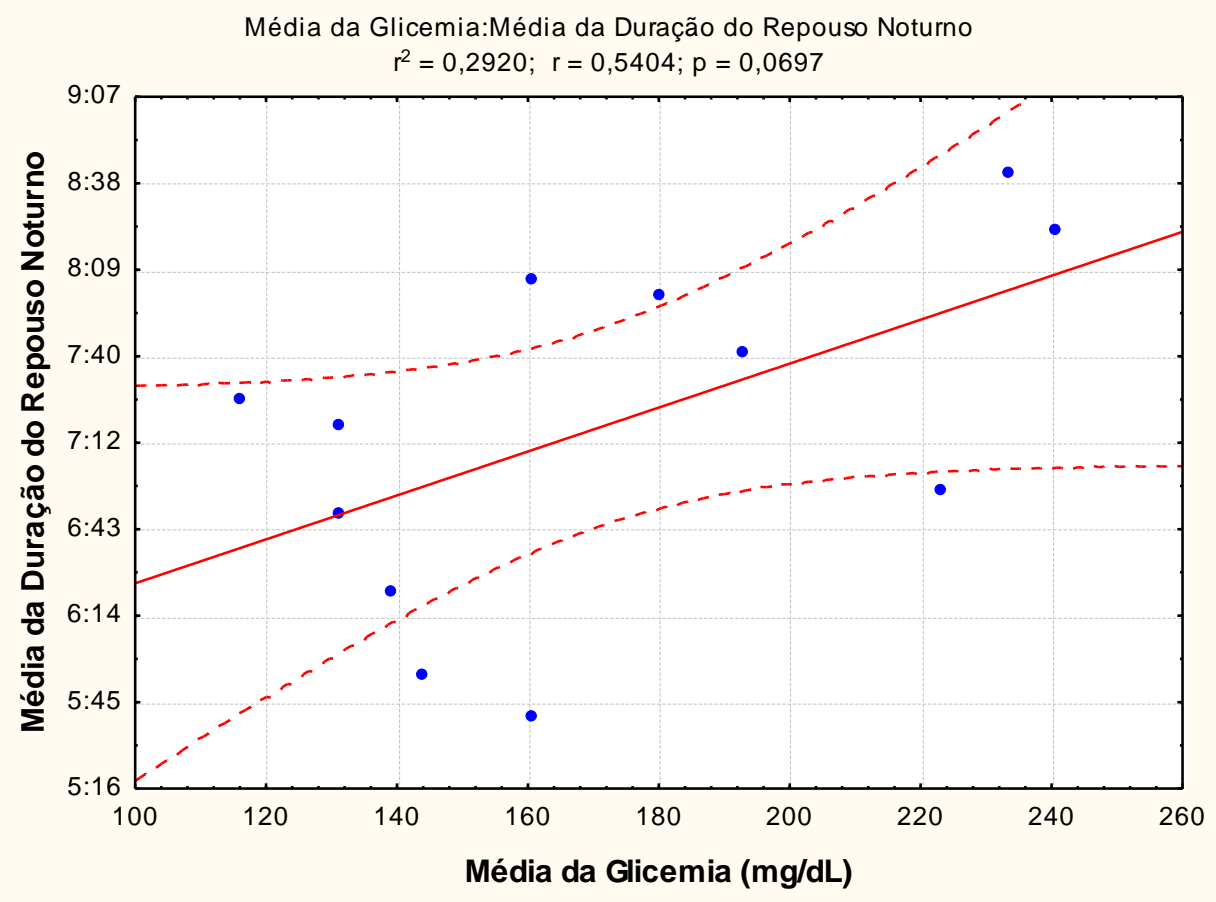

Figura 36 - Correlação entre a média da glicemia e a média da duração do repouso noturno.

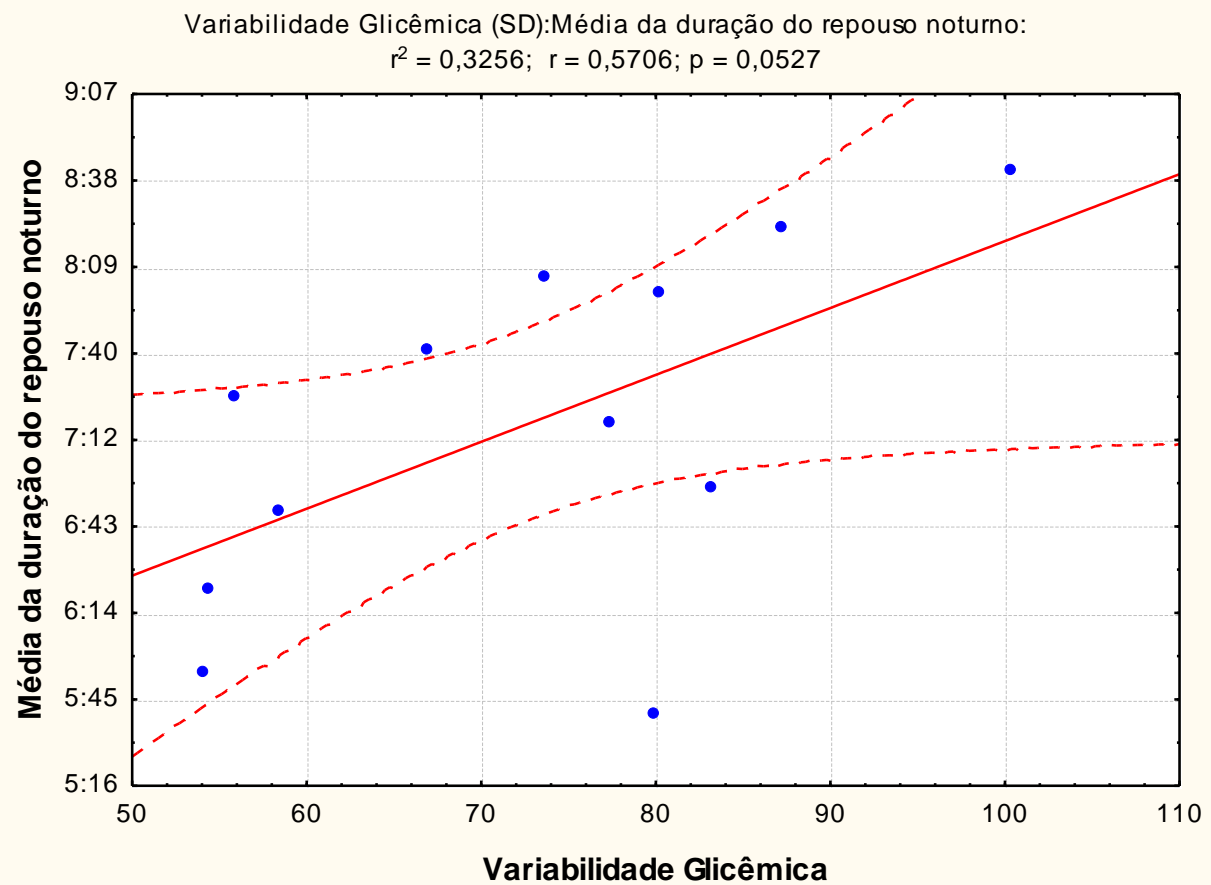

Figura 37- Tendência de correlação entre a variabilidade glicêmica e a média da duração do repouso noturno. 


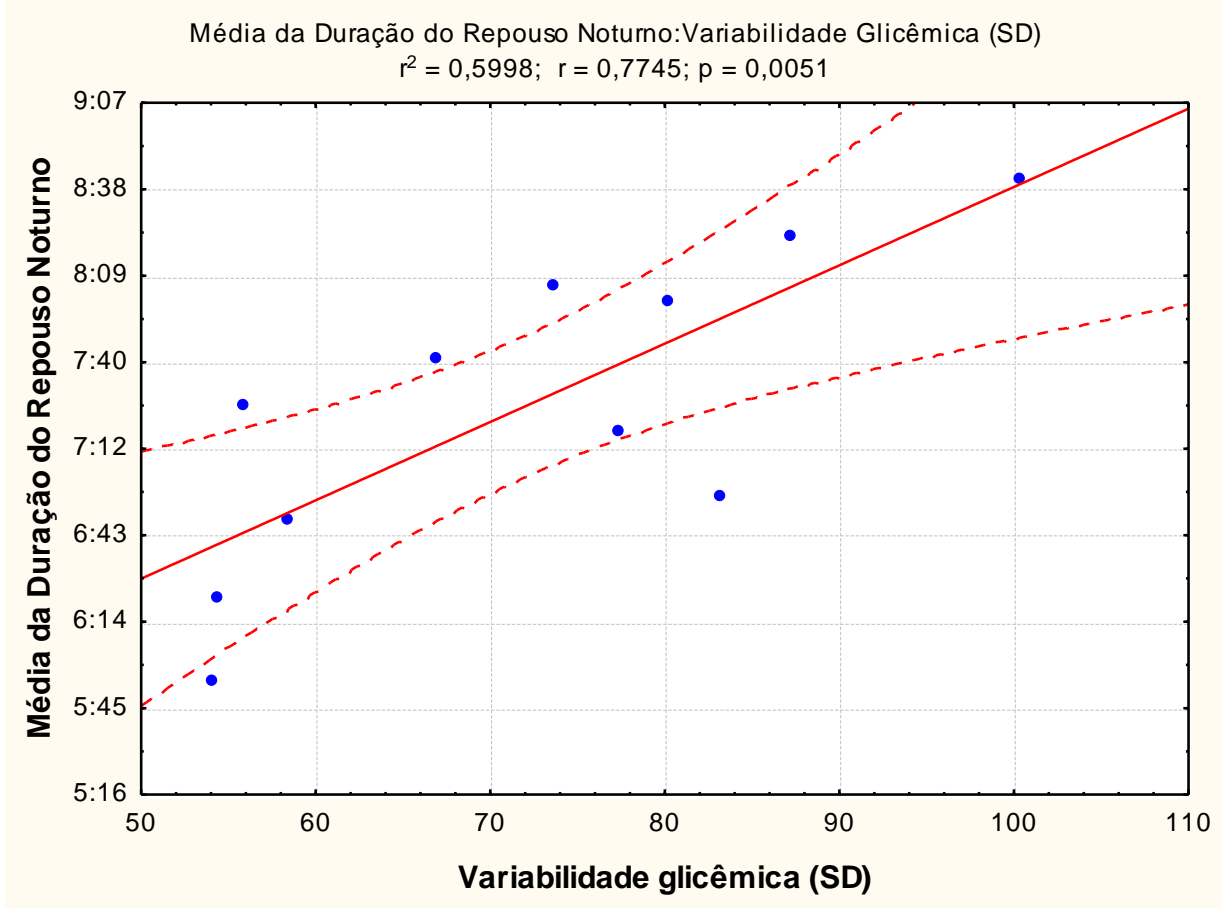

Figura 38 - Correlação entre a média da duração do repouso noturno e a variabilidade glicêmica, ao se excluir os dados de um indivíduo da amostra.

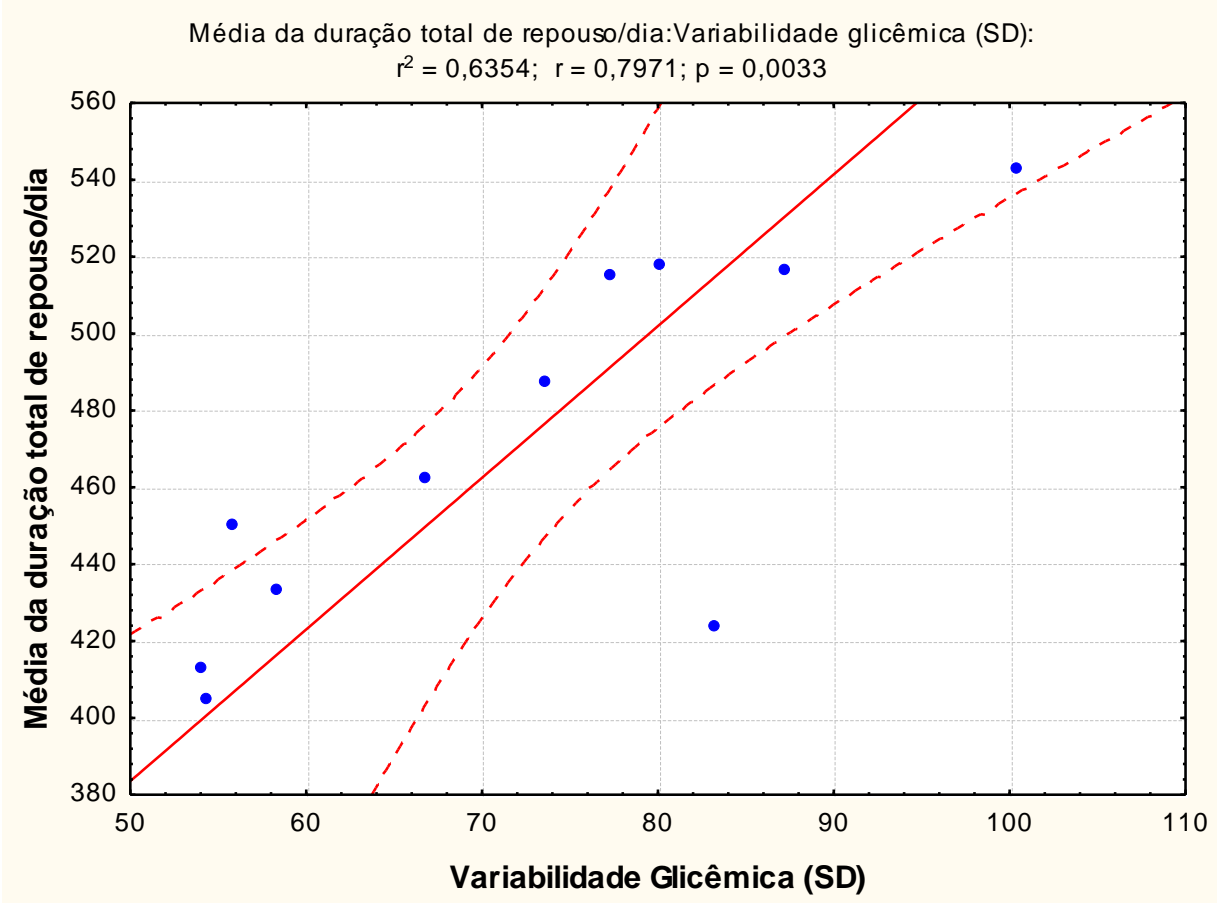

Figura 39 - Correlação entre a média da duração total de repouso por dia (repouso noturno e diurno) com a variabilidade glicêmica, ao se excluir os dados de um indivíduo da amostra.

Ao se dividir os indivíduos do grupo DM1 nos subgrupos GB, GA, VB e VA, observa-se apenas no grupo GB a média da duração do repouso noturno 
correlacionada à média da glicemia. Diferente do que se viu ao incluir todos os indivíduos, neste caso a correlação observada foi negativa (Figura 40).

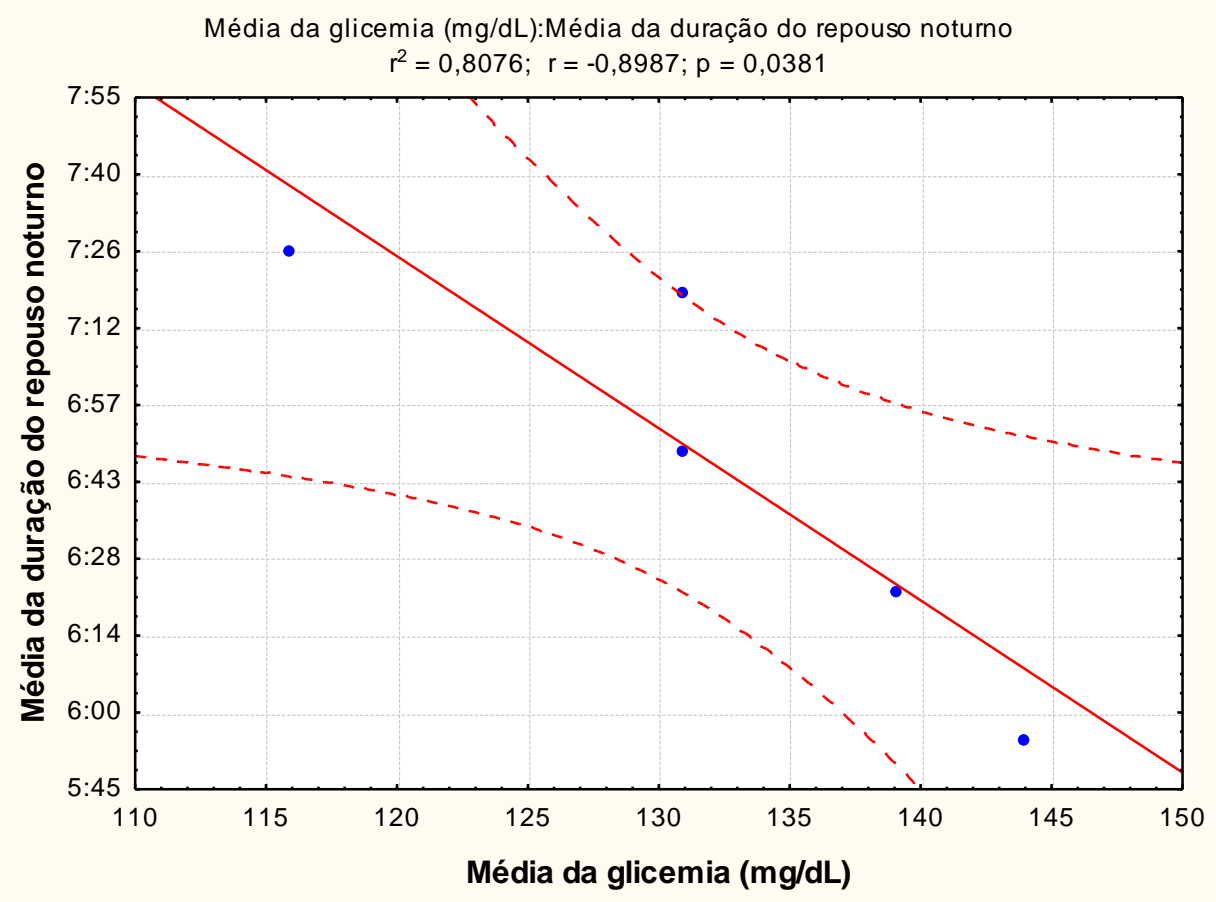

Figura 40 - Correlação entre a média da glicemia e a média da duração do repouso noturno no grupo GB.

Quanto à comparação entre variáveis do ritmo de atividade/repouso, incluindo amplitude, potência do ritmo, porcentagem de variância total e diferença entre o período observado e $24 \mathrm{~h}$, não se observou nenhuma diferença entre o grupo controle e o grupo DM1. Na figura 41 estão o actograma, o Cosinor e o periodograma de um indivíduo do grupo controle (do lado esquerdo), e os mesmos elementos do ritmo de atividade/repouso de um indivíduo do grupo DM1 (do lado direito). No actograma nota-se padrão muito semelhante de atividade (blocos pretos) e repouso (área brancas) em ambos indivíduos, dia após dia (Figura 41a e 41d). $\mathrm{Na}$ representação gráfica do Cosinor nota-se que em ambos os casos os dados do ritmo de atividade/repouso se ajustaram à curva cosseno, já que o vetor toca a margem do círculo, e em ambos os casos a acrofase foi próxima às 16 horas (Figura 41b e 41e). Nos periodogramas nota-se que o ritmo em questão é diário, com período muito próximo a 24 horas, ou 1440 minutos, e que em ambos os indivíduos a potência desse ritmo é bastante semelhante (Figura 41c e 41f). 

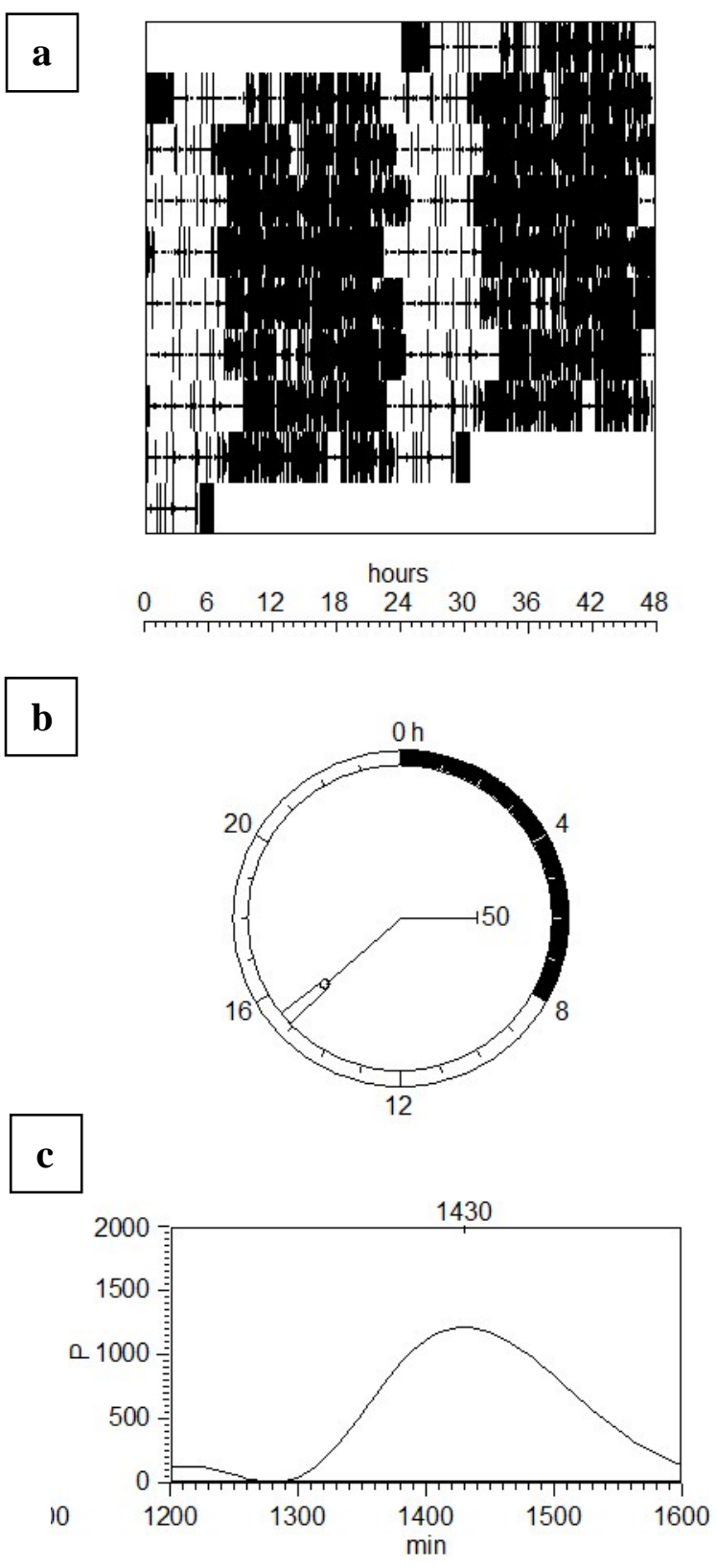
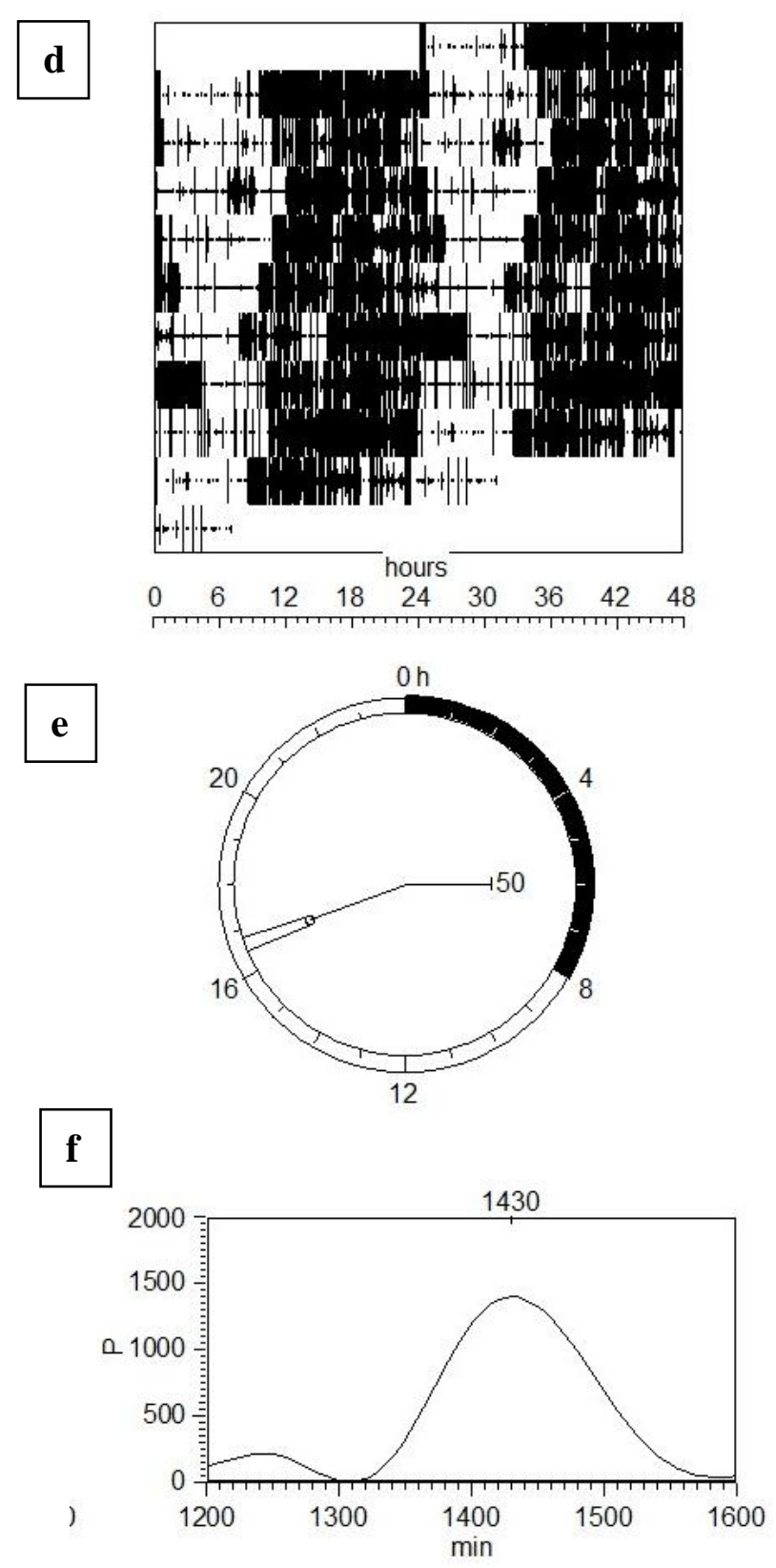

Figura 41 - Ritmo de atividade/repouso. 38a - Exemplo de actograma controle; 38b - Cosinor dos dados do mesmo indivíduo; 38c - Periodograma idem. 38d - Exemplo de actograma grupo DM1; 38e - Cosinor dos dados do mesmo indivíduo; 38f - Periodograma idem.

Abaixo se observa o teste de Rayleigh para as acrofases do ritmo circadiano de atividade/repouso do grupo controle (Figura 42a, $r=0.978972$ ) e do grupo DM1 (Figura 42b, $r=0,97299$ ). Em ambos os casos as acrofases se agrupam de forma significativa, já que o vetor ultrapassa o circulo interno, e não há diferença estatística entre as acrofases nos dois grupos $(p=0,32829)$. 

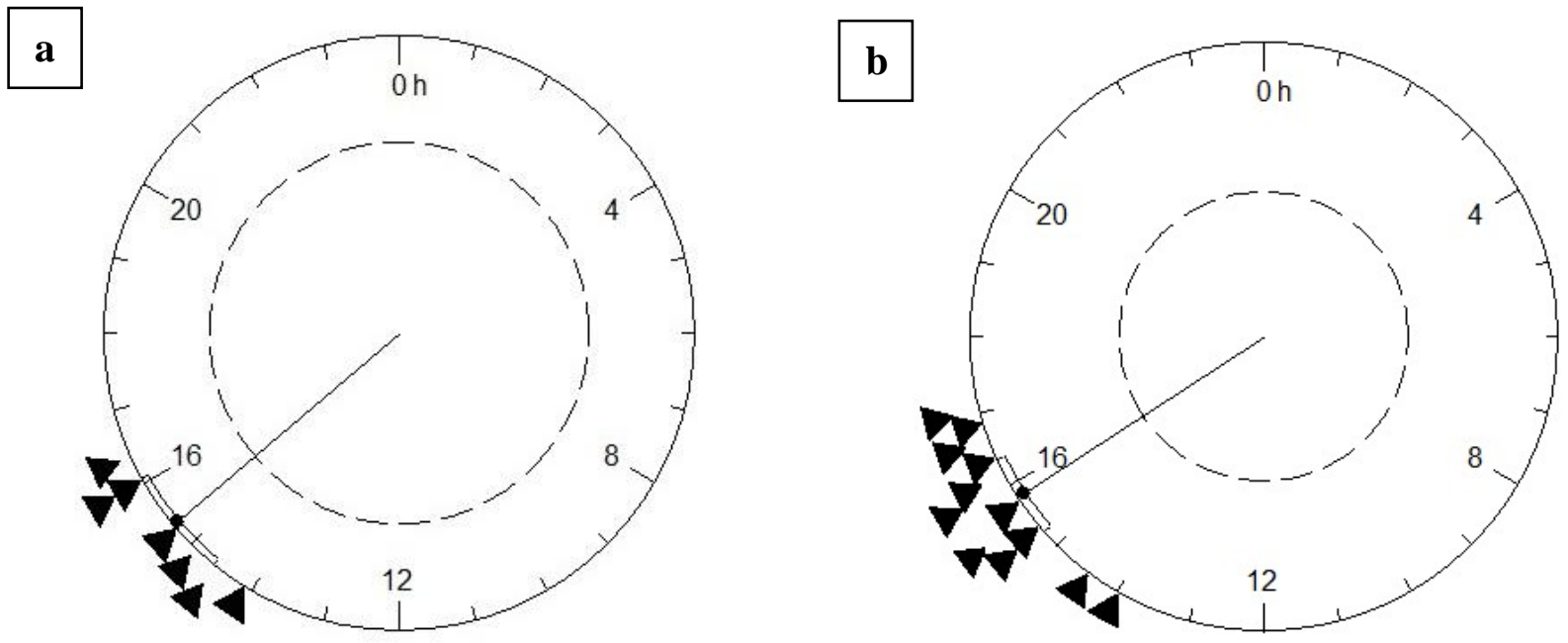

Figura 42 - Teste de Rayleigh para as acrofases do ritmo circadiano de atividade/repouso do grupo controle (a) e do grupo DM1 (b). 


\section{DISCUSSÃO}

As correlações positivas e significativas encontradas entre $\mathrm{HbA} 1 \mathrm{c}$, em especial a HbA1c pós-coleta, e a média da glicemia durante o período de coleta eram esperadas (Nathan et al., 2008). Essa confirmação da correlação levou-nos a considerar a média da glicemia, no lugar da $\mathrm{HbA1c}$, como parâmetro para separar os grupos. O principal motivo para isso é entender que a média da glicemia refletia a fase de coleta, enquanto mesmo a HbA1c pós-coleta refletia o controle metabólico de um intervalo maior. Dessa forma, utilizando, na maior partes das vezes, parâmetros que refletem o controle metabólico apenas durante a fase de coleta, acreditamos estar dividindo os grupos de forma mais precisa, a fim de podermos correlacionar o controle glicêmico aos dados dos ritmos CVS e atividade/repouso. Além da média da glicemia, a variabilidade glicêmica (desvio padrão da média da glicemia) também apresentou correlação positiva e significativa com a HbA1c e com a média da glicemia, e também foi usada para dividir o grupo DM1 em subgrupos. A HbA1c, substituída no caso pela média da glicemia e variabilidade glicêmica, é considerada exame padrão ouro para acompanhamento do controle glicêmico, e como preditora do desenvolvimento de complicações crônicas do diabetes mellitus (Dailey, 2007).

Entendemos que ainda há dúvidas quanto ao uso da variabilidade glicêmica como parâmetro para avaliar o controle glicêmico e predizer o desenvolvimento de complicações, e que a melhor forma de se calcular a variabilidade glicêmica ainda é controversa (Siegelaar et al., 2010). Contudo, os resultados obtidos por Pillar et al. (2003), indicam que variações bruscas de glicemia em DM1 podem interferir no sono, causando despertares, mais que valores absolutos altos ou baixos de glicemia. Entendemos que apesar de limitado, pelo fato de não revelar a taxa de variação, o cálculo da variabilidade glicêmica em DM1, através do desvio padrão, pode ser um indicador de variação útil para os nossos objetivos. Acreditamos que indivíduos com maior variabilidade glicêmica podem apresentar maior tendência a problemas do sono, como apontam alguns dos nossos resultados, discutidos adiante. 
Quanto ao número diário de testes de glicemia capilar, estudos anteriores já apontaram para a correlação negativa entre a HbA1c e a média diária de testes, como observamos em relação à HbA1c pós-coleta (Schütt et al., 2006). Portanto, quanto maior o número de testes de glicemia que o indivíduo realiza diariamente, menor o valor da hemoglobina glicada do mesmo. Isso se deve, provavelmente, ao fato de que indivíduos que entendem a necessidade de monitorar mais intensivamente a glicemia, também fazem maior número de correções da glicemia, e mantém, assim, a glicemia próxima aos valores normais na maior parte do tempo. Por outro lado, é interessante observar que não houve correlação entre a média do número diário de testes de glicemia capilar com a média da glicemia, nem com a variabilidade glicêmica. Talvez isso aponte para um efeito positivo do maior número diário de testes de glicemia capilar que só possa ser evidenciado mais em longo prazo.

\subsection{Melatonina}

Nosso interesse em dosar melatonina, no caso 6-sulfatoximelatonina, metabólito este que se correlaciona fortemente ao total de melatonina secretada (Bojkowskl et al., 1987), deu-se especialmente pelo fato de já ter se verificado atenuação dos níveis de melatonina em portadores de DM2 (Radziuk e Pye, 2006). Além disso, diferenças na secreção de melatonina entre os grupos nos ajudariam a explicar outros achados, já que a melatonina está sabidamente envolvida na regulação do ciclo vigília/sono, do início do sono e do metabolismo (Seabra e Cipolla-Neto, 2008; Peschke, 2008; Markut et al., 2003).

Como apresentado na introdução, há divergências sobre a ação da insulina na produção de melatonina. Enquanto alguns autores afirmam que a insulina pode inibir a secreção de melatonina, outros dizem que não há interação, ou mesmo que a insulina estimularia a produção de melatonina (Peschke, 2008). Poderíamos então fazer duas especulações sobre motivos da aparente redução da melatonina plasmática observada em DM2 (Radziuk e Pye, 2006), e em DM1 com média da glicemia mais elevada, como observamos. Uma possibilidade seria a ação direta da 
insulina inibindo a produção da melatonina. O estado hiperinsulinêmico típico de indivíduos com DM2 no início da doença, assim como de DM1 em uso de insulina exógena, explicaria a redução dos níveis de melatonina nesse caso. Alternativamente podemos pensar não em ações diretas da insulina, mas sim da glicemia sobre a produção de melatonina. Assim, indivíduos com a média da glicemia mais elevada, ou com picos de glicemia que ultrapassam com frequência a faixa de normoglicemia, fenômenos comuns em DM1 e DM2, teriam a produção da melatonina inibida.

No caso do presente estudo, apesar de a diferença não ser significativa, observamos que a média do nível de 6-sulfatoximelatonina dosada em indivíduos do grupo controle foi mais elevada que no grupo DM1. Porém, diferente do que esperávamos, não houve diferença entre os grupos com melhor e com pior controle glicêmico (entre GB e GA e entre VB e VA). Por outro lado, a excreção significativamente menor de 6-SMT em indivíduos com média da glicemia alta, em comparação com indivíduos do grupo controle foi importante para evidenciar algo que já esperávamos encontrar (não haver diferença significativa entre indivíduos do grupo controle com os DM1 de controle glicêmico adequado, mas sim com os indivíduos DM1 de pior controle glicêmico).

Adicionalmente, encontrar correlação positiva e significativa entre 6-SMT e a porcentagem de hipoglicemias nos deu mais uma pista de nossa hipótese ser coerente. Entendemos que a frequência de hipoglicemias revela indiretamente a associação entre melhor controle glicêmico e maior produção de melatonina, já que sabemos que um melhor controle glicêmico em DM1 pode implicar em maior número de hipoglicemias (The Diabetes Control and Complications Trial Research Group, 1993). Essa hipótese foi reforçada pelo fato de, como apresentado nos resultados, a média da glicemia ter se correlacionado negativamente com porcentagem de hipoglicemias $(r=-0,6037 ; p=0,0080)$. Dessa forma entendemos que a maior ocorrência de hipoglicemias talvez não esteja estimulando diretamente a maior secreção de melatonina, mas apenas refletindo um melhor controle metabólico em DM1, levando assim à uma secreção de melatonina mais próxima à secretada por indivíduos sem a disfunção.

Com isso, especulamos que, talvez, em uma amostra maior os níveis de melatonina em portadores de diabetes com pior controle glicêmico se mostrariam 
significativamente mais baixos do que os níveis em indivíduos DM1 com melhor controle glicêmico. As complicações crônicas do diabetes, bastante comuns e diretamente correlacionadas ao controle glicêmico podem, em parte, estar associadas a essa redução na secreção de melatonina dos indivíduos com pior controle glicêmico. Isso devido à poderosa ação antioxidante desse hormônio. Pensando nisso, alguns autores já têm inclusive demonstrado que a melatonina pode ter efeito protetor sobre tecidos tipicamente afetados pela glicemia elevada em portadores de diabetes (Paskaloglu et al., 2004; Winiarska et al., 2005; Kadhim et al., 2006).

\subsection{Sono}

Chamaram-nos muito a atenção os resultados de polissonografia devido ao fato de estudos anteriores revelarem alterações de sono em crianças e adultos com DM1 (Villa et al., 2000; Jauch-Chara et al., 2008). Enquanto Villa et al. (2000) encontraram maior índice de apnéia central e de apnéia-hipopnéia em crianças com DM1, mostrando que ambos os índices se correlacionavam positivamente ao controle glicêmico $(\mathrm{HbA} 1 \mathrm{c})$, e à duração do diagnóstico; em nosso estudo não observamos tais correlações. Observamos, na verdade, uma correlação inversa entre o índice de apnéia-hipopnéia $(\mathrm{AHI})$ e o controle glicêmico. Porém, mesmo esse achado deve ser visto com cautela, já que nenhum desses indivíduos apresentou $\mathrm{AHI}$ que caracterizasse distúrbio respiratório do sono (acima de 5 episódios com sintoma, ou acima de 15 episódios, segundo a American Academy of Sleep Medicine (2005), e não houve diferença entre o grupo DM1 e o grupo controle em relação ao $\mathrm{AHI}(p=0,63433)$. Dessa forma, entendemos que em adultos as conclusões do grupo italiano não se aplicam, e que a especulação sobre a maior ocorrência de apnéia central em crianças com DM1 ser um sinal precoce de disfunção autonômica, mesmo sem sinais clínico de neuropatia, necessita ser melhor investigada.

A razão para não termos encontrado distúrbios respiratórios do sono, entre outros distúrbios, diferente de outros autores, talvez tenha sido resultado da nossa 
criteriosa seleção de voluntários sem complicações crônicas. Mondini e Guilleminault (1985) mostraram, por exemplo, que $41,7 \%$ dos DM1 não obesos que participaram de seu estudo apresentaram distúrbio respiratório do sono, e que os distúrbios respiratórios estavam claramente relacionados à presença de neuropatia.

Uma menor porcentagem de sono de ondas lentas, estágio 3, poderia ter caracterizado o sono dos indivíduos com pior controle glicêmico, já que a redução desse estágio do sono, que está relacionada à resistência à insulina, já foi demonstrada em DM2 (Pallayova et al., 2010; Tasali et al., 2008). Porém, no presente estudo, diferente do que mostrou Jauch-Chara et al. (2008), nenhuma diferença entre os estágios do sono dos indivíduos do grupos controle e DM1, nem entre os grupos divididos de acordo com o controle glicêmico, foi observada (controle vs DM1 - \% sono paradoxal: $21,5 \% \pm 5,3 \%$ vs 19,9\% $\pm 7,7 \%, p=0,62158 ; \%$ estágio $3,21,7 \% \pm 8,4 \%$ vs $20,6 \% \pm 8,3 \%$ : $p=0,76682$ ).

Outros distúrbios, como síndrome de pernas inquietas, ou mesmo diferenças significativas em relação à duração, eficiência e latência do sono em DM1 (neste momento estamos nos referindo à latência na noite do exame de polissonografia), descritos por outros grupos (Pillar et al., 2003; Happe et al., 2005), não foram observados por nós.

Os parâmetros que nos chamaram mais a atenção na análise dos grupos, foram os índices de despertares e microdespertares, que se correlacionaram positivamente à HbA1c pós-coleta. Esses resultados revelam uma associação importante entre a estabilidade, ou fragmentação, do sono e o controle glicêmico. Além disso, viu-se que o índice de despertares completos se correlacionou à média da glicemia, e que os indivíduos do $3^{\circ}$ quartil da variabilidade glicêmica apresentaram quase o dobro de despertares completos que os demais. Portanto, os indivíduos com pior controle glicêmico apresentam sono mais fragmentado, com mais despertares e microdespertares. Ao mesmo tempo, como sabemos, a fragmentação do sono aumenta a resistência à insulina e a atividade adrenocortical e do sistema nervoso simpático, o que, por sua vez, pode dificultar a manutenção de um bom controle glicêmico (Stamatakis e Punjabi, 2010; Barone e Menna-Barreto, 2011).

É conhecido o fato de a resposta neuro-hormonal, assim como os sintomas clássicos da hipoglicemia, serem comprometidos em indivíduos com diabetes tipo 1, 
em especial nos que fazem um controle glicêmico mais estrito (Kinsley e Simonson, 1996; Gabriely e Shamoon, 2007). O comprometimento da resposta hormonal contraregulatória, incluindo em especial os hormônios glucagon, adrenalina e cortisol, foi demonstrado em diversos experimentos. Hoje se entende que, em parte, ele é resultado do comprometimento da resposta autonômica simpatoadrenal, agravada quando o indivíduo é previamente exposto a hipoglicemias (Gabriely e Shamoon, 2007). No presente projeto apenas 1 indivíduo apresentou hipoglicemia enquanto dormia e, como reportam estudos anteriores, o indivíduo não despertou (Schultes et al., 2007; Banarer e Cryer, 2003; Pillar et al., 2003).

A ausência de despertar em indivíduos com diabetes durante hipoglicemia parece estar relacionada não só ao fato de as respostas neuro-hormonais e sintomas de hipoglicemia estarem reduzidos nesses indivíduos, mas também a um fator inibidor exercido pelo próprio sono, ou pelo fato de a hipoglicemia inibir o despertar, ou aprofundar o sono, como sugerem Pillar et al. (2003). Banarer e Cryer (2003), assim como Schultes et al. (2007), induziram hipoglicemia em indivíduos DM1 e controles durante o sono. Schultes et al. (2007) observaram que apenas 1 de 16 indivíduos DM1 despertou, enquanto 10 dos 16 controles despertaram durante a hipoglicemia. Banarer e Cryer (2003) mostraram que os níveis de adrenalina, noraadrenalia, polipeptídeo pancreático e cortisol estavam reduzidos nos indivíduos DM1 em resposta à hipoglicemia, e ainda mais reduzidos durante o sono. Pillar et al. (2003) evidenciou ainda a ausência de resposta simpato-adrenérgica em crianças DM1 durante o sono, através da ausência de vasoconstrição periférica, medida por tonometria arterial periférica, de taquicardia e de microdespertares ("arousal response").

Diferente do que foi observado por Pillar et al. (2003) em crianças com DM1, o voluntário que teve hipoglicemia não apresentou maior tempo de sono em estágio 3. Da mesma forma, enquanto Pillar et al. (2003) e Banarer e Cryer (2003) descrevem que os indivíduos que tiveram hipoglicemia apresentaram maior eficiência do sono, a eficiência do sono deste voluntário foi praticamente idêntica à mediana do grupo DM1 ( $92,3 \%$ vs $92,2 \%$, respectivamente). Por outro lado, nota-se que durante a hipoglicemia o indivíduo teve grande porcentagem de sono paradoxal e que seu sono aparentemente ficou mais estável, com menos eventos de hipopnéia e de despertares completos (a hipoglicemia perfez $42,4 \%$ do tempo total de sono do 
voluntário, quando aconteceram 33,3\% do total de hipopnéias e 31,6\% do total de despertares completos).

Apesar de ter sido apenas um caso no presente estudo, por se tratar de um fenômeno potencialmente grave, o acompanhamento para que se evite a ocorrência de hipoglicemia durante o sono é de grande importância. Alternativas para minimizar sua ocorrência, como insulinização mais adequada e personalizada e monitorização mais freqüente da glicemia, têm sido propostas. Clínicos e pesquisadores alertam que o não despertar durante hipoglicemias em indivíduos com DM1 pode levar à síndrome da morte súbita no leito, resultado de arritmia provocada pela hipoglicemia severa durante o sono (Schultes et al., 2007; Gill et al., 2009; Pires, 2010).

\subsection{Ciclo vigília/sono}

Alguns dos resultados obtidos a partir da análise dos dados dos diários de sono refletem associações esperadas entre os parâmetros avaliados. Evidenciase, por exemplo, que a maior média de sonolência durante o dia está associada à maior duração do sono (Figura 16). Da mesma forma, os indivíduos que tiveram maior pontuação na escala de sonolência de Epworth mostraram indícios de compensação, apresentando maior média da duração diária de cochilos; e aqueles com maior média na duração do sono noturno, despertaram mais vezes espontaneamente. Como apresentado nos resultados, a latência do sono, ao se excluir os dados dos indivíduos com latência maior que 30 minutos, mostrou-se negativamente correlacionada à pontuação da escala de sonolência de Epworth. Johns (1991) já havia observado essa associação entre a escala e a latência do sono, que evidência simplesmente a tendência a pegar no sono em menos tempo nos indivíduos com mais sonolência.

Interessante notar ainda a correlação negativa entre a qualidade do sono e a sonolência diurna, indicando, possivelmente, que quanto maior a qualidade do sono noturno dos nossos voluntários, menor a sonolência diurna dos mesmos. Porém, é importante notar, como indica o coeficiente de determinação, que a contribuição relativa tanto da média da duração total do sono, quanto da média da qualidade do 
sono, sobre a sonolência diurna não chega a 16\% e 19\%, respectivamente. Contribuição mais importante, e esperada, pode ser atribuída à média da duração do sono noturno sobre o número de despertares não espontâneos, que ultrapassa 35\%.

A qualidade do sono é um parâmetro que muito nos interessa, já que em DM2 já foi demonstrada correlação negativa entre a qualidade do sono e a HbA1c (Knutson et al., 2006). Portanto, seja a qualidade do sono um fator que afeta o controle glicêmico, ou seja a glicemia um modulador da qualidade do sono, o fato é que um parece afetar o outro. Acreditamos que haja realmente um circulo vicioso, em que essas duas variáveis se retroalimentam e se agravam (Barone e MennaBarreto, 2011). Apesar de não ter aparecido correlação significativa entre média da qualidade do sono e média da glicemia no grupo DM1 como um todo, é interessante notar que no grupo de indivíduos com a média da glicemia mais baixa (GB) essa correlação negativa aparece de forma bastante importante, com coeficiente de determinação de mais de $72 \%$. Ao se dividir o grupo DM1 de acordo com a variabilidade glicêmica observa-se tendência à correlação negativa apenas no grupo com variabilidade glicêmica mais baixa.

É importante ter em mente que a qualidade do sono é um parâmetro subjetivo e, por isso, delicado para se comparar entre diferentes indivíduos. Acreditamos que a percepção da qualidade do sono deva estar influenciada pela experiência recente de sono do indivíduo, algo parecido a uma adaptação a um determinado nível de qualidade do sono. Devido a esse fato, e levando em conta que a média da glicemia parece ter uma influência tão importante sobre a média da qualidade do sono no grupo GB, especulamos que os indivíduos com a média da glicemia e variabilidade glicêmica mais elevadas, pelo fato de terem a qualidade do sono de certa forma permanentemente comprometida, apresentariam mais dificuldade em perceber variações. Por isso, ao incluir os dados desses indivíduos na análise, ou ao analisar somente os dados dos mesmos, não é evidenciada nenhuma correlação. Por outro lado, poderíamos imaginar simplesmente que a partir de uma determinada média glicêmica o impacto sobre a qualidade do sono se estabiliza.

Nossos resultados podem ainda ter relação com os instrumentos utilizados. No presente estudo avaliamos qualidade do sono através de escala analógica visual (Aitken, 1969), preenchida pelos indivíduos no diário de sono, ao despertarem. Jauch-Chara et al. (2008) utilizaram um questionário para avaliar humor e fadiga dos 
indivíduos, e Knutson et al. (2006) utilizaram o índice de qualidade do sono de Pittsburgh. Enquanto não encontramos diferença entre o grupo controle e o grupo DM1, Jauch-Chara et al. (2008) concluíram, através da análise dos questionários aplicados, que o sono dos indivíduos do grupo DM1 foi menos restaurador que dos indivíduos do grupo controle; e Knutson et al. (2006) encontraram evidências de que a qualidade do sono é um preditor da $\mathrm{HbA} 1 \mathrm{c}$ em DM2.

Assim como Yeshayahu e Mahmud (2010), também não encontramos correlação entre o controle glicêmico e a média da duração do sono noturno. Não houve ainda correlação entre o controle e a média da duração do sono durante os dias da semana, nem entre o controle e a média da duração do sono durante os dias dos finais de semana. Por outro lado, Yeshayahu e Mahmud (2010) encontraram diferença entre a duração do sono dos adolescentes DM1 e seus controles $(8,4 \mathrm{~h}$ vs 8,0h, respectivamente, $p=0,01)$, enquanto nós não encontramos diferença significativa. Talvez em adolescentes essa diferença tenha aparecido por se tratar de um grupo etário com menos demandas sociais moduladoras dos horários e da duração do sono. No nosso grupo DM1 notamos que apenas $28 \%$ dormem, em média, mais de 8 horas por noite, enquanto 44\% dormem, em média, 7 ou menos horas por noite.

Como apontam nossos resultados, a duração do sono dos voluntários (DM1 e controle juntos) nos finais de semana foi significativamente maior que nos dias de semana; indicando que nossos voluntários estavam privados de sono durante a semana. Em relação a isso, dois outros pontos nos chamaram muito a atenção. $O$ primeiro é o fato de a mesma porcentagem de indivíduos de ambos os grupos $78 \%$ estar privada de sono. O segundo é que, apesar dessa coincidência de porcentagem e de não haver diferença estatística da média da duração do sono durante a semana nem durante os finais de semana entre os indivíduos privados do grupo DM1 e grupo controle $(p=0,19915$, semana e $p=0,23349$, finais de semana), há sim diferença significativa na diferença entre a média da duração do sono nos finais de semana e durante a semana entre os grupos $(p=0,03032)$. Entendemos isso como uma evidência de maior privação e maior compensação nos finais de semana entre aqueles $78 \%$ do grupo DM1, em relação aos $78 \%$ do grupo controle. Isso nos leva a indagar se os indivíduos DM1 teriam necessidade de maior duração do sono, o que 
iria ao encontro dos achados de Yeshayahu e Mahmud (2010) e, por isso, estariam no fim de semana compensando de forma mais expressiva essa privação.

De qualquer forma, para os $78 \%$ dos voluntários que estão privados de sono durante a semana, e especialmente para os do grupo DM1 que estão ainda mais privados, isso pode ter consequências importantes tanto em termos gerais de qualidade de vida quanto em relação ao controle glicêmico. Além da privação do sono potencialmente levar à deterioração do aprendizado, da memória, dificuldade de atenção, comprometimento da resposta imunológica, da função cardiovascular, e da regulação neuro-hormonal (Walker, 2008; Van Cauter et al., 2008), nossa preocupação maior está ligada ao metabolismo de carboidratos. Sabe-se que a privação de sono leva a consequências importantes sobre o metabolismo, podendo favorecer o desenvolvimento de DM2, ou exacerbar a resistência à insulina e reduzir a tolerância à glicose (Spiegel et al., 1999, Spiegel et al., 2005; Schmid et al., 2011). Apesar de esses achados terem muitas vezes sido atribuídos ao possível aumento do tônus simpatovagal, estimulação do eixo hipotálamo-hipófise-adrenal e aumento na produção de cortisol (Leproult et al., 1997; Barone e Menna-Barreto, 2011), Schmid et al. (2011) não observaram alterações nos níveis de ACTH e cortisol após duas noites de privação parcial de sono em indivíduos saudáveis. Ao mesmo tempo, entendemos que um pior controle glicêmico possa ter impacto sobre o sono, seja estando relacionado a um maior número de despertares completos, como vimos nos nossos resultados, seja na associação entre a latência do sono e o controle glicêmico, como será discutido adiante (Barone e Menna-Barreto, 2011).

Mais recentemente, como apresentado na introdução, foi publicado um trabalho sobre portadores de DM1 confirmando que apenas uma noite de privação parcial de sono pode produzir resistência periférica à insulina, levando à redução de 14-21\% da sensibilidade a esse hormônio (Donga et al., 2010). Os autores desse estudo, levando em consideração seus resultados e o que já foi observado tanto em indivíduos saudáveis, quanto em DM2, concluem que a privação crônica do sono, comum em nossa sociedade, também pode favorecer a resistência à insulina em DM1, o que aumenta os riscos para o desenvolvimento de complicações microvasculares e macrovasculares nesses indivíduos (Donga et al., 2010; Chillarón et al., 2009; Barone e Menna-Barreto, 2011), provavelmente por tornar o controle glicêmico mais difícil. Por isso, o achado de que a maioria de nossos voluntários 
está privada de sono durante a semana, em especial os do grupo DM1, merece especial atenção.

A latência do sono, apesar de ser um parâmetro subjetivo, foi o que melhor retratou o que esperávamos encontrar, diferença significativa entre os grupos DM1, com menor média da latência de sono nos indivíduos com menor variabilidade glicêmica ou menor média da glicemia. Portanto, concluímos que a média da glicemia e, especialmente, a variabilidade da mesma, são fatores determinantes no tempo em que o indivíduo leva para pegar no sono. Esse resultado pode estar relacionado à tendência de correlação negativa entre 0 nível de 6sulfatoximelatonina e a média da glicemia, já que se sabe que a melatonina é capaz de diminuir a latência para o início do sono (Gilbert et al., 1999). Assim, acreditamos que indivíduos com a média da glicemia mais elevada tendem a secretar menos melatonina, o que contribuiria para uma maior latência de sono.

Diferentemente dos nossos resultados, Pillar et al. (2003) encontraram, em estudo incluindo 15 crianças DM1 e 15 crianças controle, tendência a maior latência e menor duração do sono nas crianças com DM1.Assim como no nosso caso, esse estudo tem a limitação de contar com um pequeno número de participantes. De qualquer forma, é interessante notar que no estudo de Pillar et al. (2003) as 5 crianças do grupo DM1 que apresentaram hipoglicemia noturna influenciaram a média da duração do sono para valores superiores. Além disso, a média da latência do sono dessas mesmas 5 crianças foi menor que a média da latência do sono das outras 10 do grupo DM1 (36 minutos e 49 minutos, respectivamente). Se por um lado esses resultados se distanciam dos nossos, ao entender a hipoglicemia noturna dessas crianças como um parâmetro para avaliar o controle glicêmico ${ }^{2}$, não nos espanta o fato dessas crianças terem apresentado maior duração do sono que as demais com DM1, resultado este semelhante ao que discutiremos adiante sobre a correlação entre duração do repouso noturno e controle glicêmico.

Em relação à pontuação no questionário de sonolência de Epworth, evidencia-se o número mais de 3 vezes maior de voluntários do grupo DM1 com pontuação acima de 10 (39\%), em comparação com o número de indivíduos do grupo controle (11\%). Apesar da diferença na pontuação da escala entre os grupos

\footnotetext{
${ }^{2}$ Nota-se que nesse estudo, apesar de a diferença não ser estatisticamente significativa, o grupo DM1 com hipoglicemia durante o sono apresentou média da $\mathrm{HbA1c}$ mais elevada que o grupo DM1 sem hipoglicemia noturna $(9,0 \pm 1,2$ vs $8,2 \pm 0,9 \mathrm{mg} / \mathrm{dl}, p=0,22)$.
} 
se tratar apenas de uma tendência, consideramos tal achado relevante, já que a escala é amplamente utilizada para identificar indivíduos com grandes chances de apresentar algum tipo de distúrbio do sono quando a pontuação obtida é superior a 10 (Johns, 1991). Portanto, entendemos que, na nossa amostra, mais indivíduos portadores DM1 têm potencial para desenvolver distúrbios do sono, que indivíduos do grupo controle. Dizemos potencial já que, de acordo com o exame de polissonografia, nenhum dos voluntários possui distúrbio no momento.

\subsection{Ritmo de atividade/repouso}

A sonolência diurna se mostrou correlacionada à média da duração do repouso em $24 \mathrm{~h}$ (incluindo repouso noturno e diurno). Já a média da duração do repouso noturno se mostrou correlacionada à sonolência diurna apenas no grupo DM1. Apesar de esperado, é interessante notar que o número de despertares espontâneos tenha sido maior nos indivíduos que tiveram maior média da duração do repouso noturno, já que esses também apresentaram maior média de sonolência diurna. Por esse motivo, esperávamos que, mesmo tendo mais tempo de repouso noturno, talvez não tivessem mais episódios de despertar espontâneo pela manhã. Contudo, ao analisarmos, encontramos que realmente apesar de ambos, despertares espontâneos e sonolência diurna, estarem correlacionados à média da duração do repouso, eles não afetam diretamente um ao outro.

O que talvez seja mais intrigante nos resultados das correlações entre média e variabilidade glicêmica, com a média da duração do repouso, foi verificar que a correlação, ou tendência à correlação, foi sempre positiva, a não ser ao se isolar apenas o grupo de média da glicemia mais baixa (GB). Entendemos que, apesar de surpreendente, isso possa sugerir que quanto pior o controle glicêmico, seja avaliado através da média da glicemia, seja através da variabilidade glicêmica, maior a necessidade de repouso, seguindo a mesma linha de pensamento de mecanismo de compensação discutida anteriormente.

Porém, ao se observar somente os indivíduos com média glicêmica abaixo de $154 \mathrm{mg} / \mathrm{dl}$ (grupo GB), esse padrão deixa de aparecer e um outro padrão, que pode 
ser resultado de demandas sociais individuais, ou um fenômeno específico para essa faixa de média da glicemia, passa a se evidenciar. Como vimos anteriormente, quando o grupo GB foi analisado em separado, a média da glicemia também se correlacionou negativamente, como esperávamos, com a qualidade do sono. Essas correlações que apareceram somente no grupo GB eram o que esperávamos observar em todo o grupo, devido aos fatores já discutidos anteriormente; duração do repouso encurtada, ou baixa qualidade do sono, levando a resistência à insulina, que dificultaria o controle glicêmico (Barone e Menna-Barreto, 2011). Interessante salientar que se levado em consideração apenas os dados do grupo GA, nenhum padrão é observado.

No teste de Rayleigh para as acrofases do ritmo circadiano de atividade/repouso se observa que em ambos os grupos, controle e DM1, as acrofases se agrupam de forma significativa (vetor ultrapassa o circulo interno) e há pouca diferença na alocação entre os grupos, estando ambos muito próximos às 16 horas (aproximadamente às $15 \mathrm{~h} 15 \mathrm{~min}$ para o grupo controle e 15h45min para o grupo DM1). O teste ANOVA de uma via também aponta para ausência de diferença entre os grupos. Além disso, o coeficiente de correlação linear para ambos os grupos é bastante próximo e se aproxima muito a 1 , indicando que o agrupamento ao redor de um valor é bastante consistente.

Portanto, apesar de nosso interesse, conforme apresentado na introdução, uma vez que há alteração na alocação da fase do ritmo de tolerância à glicose em portadores de DM1 (Van Cauter et al., 1997) e preocupações em relação à amplitude extrema da glicemia (Mejean et al., 1988), os parâmetros avaliados do ritmo de atividade/repouso dos indivíduos portadores de DM1 não diferem dos do grupo controle. Faz-se importante ressaltar que nosso grupo é específico em termos de faixa etária, IMC e especialmente por não contar com indivíduos portadores de complicações crônicas. 


\subsection{Limitações do presente estudo}

Entendemos que apesar dos resultados do presente estudo trazerem novas contribuições aos estudos da área, há limitações que devem ser consideradas. $A$ primeira delas é em relação ao número de voluntários. Com o objetivo de estudar diferentes parâmetros em um grupo com características restritas, tivemos que optar por trabalhar com um número pequeno de sujeitos, mesmo sabendo que isso nos imporia o questionamento de se poder estender os achados a outros indivíduos com o perfil estudado. Importante ainda mencionar que, devido ao fato de termos elaborado critérios de inclusão bastante rigorosos, tivemos muita dificuldade em encontrar voluntários suficientes para o estudo. Em meses de busca, provavelmente menos de $10 \%$ dos sujeitos indicados estavam realmente dentro dos critérios de inclusão e concordaram em participar do estudo. Muitos não sabiam que tinham complicações crônicas, ou tomavam algum medicamento que interferia sobre o sono, e outros não concordaram em continuar no estudo, principalmente porque seria um estudo com diferentes etapas e que demandaria grande dedicação dos voluntários.

Outras limitações também dizem respeito aos materiais usados ou ao número de coletas. O diário de sono, por exemplo, é um instrumento muito utilizado na cronobiologia e nos estudos do sono, porém, assim como a escala de sonolência de Epworth, tem caráter subjetivo. Em relação à 6-sulfatoximelatonina temos como limitações o fato de ter sido dosada apenas 1 vez em cada voluntário e, de certa forma, estarmos considerando que esse valor representa fielmente a secreção noturna de melatonina de cada um dos voluntários. Além disso, não tomamos o cuidado de ajustar o nível de 6-SMT à função renal dos voluntários, apesar de sabermos que nenhum apresenta disfunção renal. Da mesma forma, a polissonografia foi realizada uma única vez. Apesar de muitas vezes se sugerir que o voluntário durma uma noite no laboratório do sono, para se habituar, e apenas em uma segunda noite se faça o exame, muitos grupos já não seguem esse protocolo pelo motivo de ser dispendioso ocupar um leito do laboratório, por não se ter garantia de que os indivíduos se habituarão passando essa noite a mais no laboratório, e também por se correr o risco de perder o voluntário. 
E, finalmente, sobre o equipamento desenvolvido pelo grupo e utilizado para registrar a atividade dos indivíduos, o actímetro Tempatilumi, a limitação principal é não dispor nem de programa para análise dos dados coletados e nem validação, por se tratar de um equipamento novo.

Tivemos ainda a limitação de perder dados de alguns voluntários por falha em equipamentos, como no Tempatilumi, e no registro ou computador onde estavam armazenados os registros dos polissonógrafos. Da mesma forma, tivemos perda de algumas amostras de urina durante o processamento para a dosagem de 6-SMT. 


\section{CONCLUSÃO}

Entendemos que nossos achados vão ao encontro de nossas hipóteses e objetivos. Em relação ao ciclo vigília/sono, encontramos correlação negativa entre a média da glicemia dos indivíduos com a média da glicemia baixa ( $<154 \mathrm{mg} / \mathrm{dl})$ e a média da qualidade do sono, evidenciando que, entre os que têm melhor controle glicêmico, quanto melhor o controle, melhor a qualidade do sono. A média da latência do sono reforçou o impacto do controle glicêmico, já que os grupos com pior controle, tanto em termos de média da glicemia, quanto em variabilidade glicêmica, apresentaram maior média da latência do sono. Entendemos que uma das razões para isso possa ser a redução na secreção de melatonina nos indivíduos com maior média da glicemia, como se verificou tanto na forma de tendência a correlação negativa entre a média da glicemia e os níveis de 6-sulfatoximelatonina quanto em relação aos níveis significativamente mais baixos de 6-sulfatoximelatonina do grupo de média da glicemia alta, em relação ao grupo controle.

Sobre o sono, as diferenças entre o sono do grupo DM1 e do grupo controle que se destacaram foram: maior tempo de compensação do sono durante os finais de semana no grupo DM1 (maior privação de sono durante a semana), apesar de a mesma porcentagem de indivíduos de ambos os grupos estar privada de sono (78\%); e o número mais de 3 vezes maior de indivíduos do grupo DM1 com mais de 10 pontos na escala de sonolência de Epworth. Apesar de nenhum distúrbio ter sido detectado no exame de polissonografia, esse resultado na escala de sonolência de Epworth aponta para uma possível tendência a distúrbios do sono, especialmente entre os portadores de DM1.

Destacou-se ainda a correlação positiva entre o número de despertares completos e microdespertares e a $\mathrm{HbA} 1 \mathrm{c}$. Entendemos que esse resultado reforce a existência do ciclo vicioso que tem se apontado, no qual o descontrole da glicemia piora o sono e a piora do sono interfere negativamente sobre o controle da glicemia. A redução na secreção de melatonina nos indivíduos com pior controle glicêmico pode estar também contribuindo para esta maior fragmentação do sono dos indivíduos com pior controle glicêmico. 
Os estudos do ritmo de atividade/repouso, que está tão fortemente associado ao ciclo vigília/sono em seres humanos, nos trouxeram a evidência de que os indivíduos com pior controle glicêmico tendem a ter uma maior média de duração do repouso, enquanto, ao se analisar apenas os dados do grupo de média da glicemia baixa, nota-se que quanto mais baixa a glicemia, maior a média da duração do repouso. Lembrando que dividimos os grupos GB (média da glicemia baixa) e GA (média da glicemia alta) usando o valor $154 \mathrm{mg} / \mathrm{dl}$ (equivalente a 7\% da HbA1c) como linha de corte, as correlações negativas da média da glicemia do grupo GB tanto com a média da duração do repouso quanto com a média da qualidade do sono, chamaram-nos muito a atenção. Portanto, em indivíduos portadores de DM1 com controle glicêmico dentro do preconizado (MG <154 mg/dl, equivalente a HbA1c $7 \%$ ), quanto mais baixa a média glicêmica, maior a qualidade do sono e maior a duração do repouso. Assim, parece que esse valor tem realmente sua importância. Seria como um limite, a partir do qual diferenças na glicemia teriam menor ou diferente influência sobre os parâmetros do sono.

Concluímos que o ciclo vigília/sono de portadores de diabetes mellitus tipo 1 é influenciado pela glicemia, como prevíamos. O presente estudo permitiu-nos não só levantar evidências a esse respeito, como também suspeitar de alguns mecanismos responsáveis por esta associação entre controle glicêmico e ciclo vigília/sono. Verificamos, ainda, não haver evidências claras de diferenças do ciclo vigília/sono entre os grupos controle e DM1 com controle glicêmico adequado. Apesar de sabermos que outros trabalhos precisam ser realizados a fim de desvendar mais detalhes a respeito dos mecanismos de interação entre a glicemia e o sono ou o ciclo vigília/sono, entendemos que: a) suspeitas de distúrbios do sono devem ser investigadas e, caso confirmadas, tratadas; b) orientações em relação ao sono com duração adequada e qualidade podem contribuir para a melhora do controle glicêmico e qualidade de vida em portadores de diabetes mellitus; e c) um melhor controle glicêmico pode favorecer a qualidade do sono e melhorar a qualidade de vida desses indivíduos. 


\section{REFERÊNCIAS}

Acton KJ, Burrows NR, Moore K, Querec L, Geiss LS, Engelgau MM. Trends in Diabetes Prevalence Among American Indian and Alaska Native Children, Adolescents, and Young Adults. Am J Public Health. 2002;92(9):1485-90.

Aitken RCB. Measurement of feelings using visual analogue scales. Proc R Soc Med. 1969;62:989-93.

American Academy of Sleep Medicine. The AASM manual for the scoring of sleep and associated events: rules, terminology and technical specifications. Westchester, Illinois: American Academy of Sleep Medicine; 2007. 59 p.

American Academy of Sleep Medicine. The international classification of sleep disorders. 2nd ed. Westchester, Illinois: American Academy of Sleep Medicine; 2005. $298 \mathrm{p}$.

American Diabetes Association. Diagnosis and Classification of Diabetes Mellitus. Diabetes Care. 2011;34:S62-S69.

American Diabetes Association. Standards of Medical Care in Diabetes-2009. Diabetes Care. 2009;32:S13-S61.

Aronson D. Impaired modulation of circadian rhythms in patients with diabetes mellitus: a risk factor for cardiac thrombotic events? Chronobiology International. $2001 ; 18: 109-21$.

Banarer S, Cryer PE. Sleep-related hypoglycemia-associated autonomic failure in type 1 diabetes: reduced awakening from sleep during hypoglycemia. Diabetes. 2003;52(5):1195-203.

Barone MTU, Menna-Barreto L. Diabetes and sleep: A complex cause-and-effect relationship. Diabetes Res Clin Pract. 2011;91(2):129-37.

"De acordo com International Committee of Medical Journal Editors. Uniform requirements for manuscripts submitted to Biomedical Journal: sample references. Available from: http://icmje.org [2007 May 22.] 
Bass J, Takahashi JS Circadian Integration of Metabolism and Energetics. Science 2010;330:1349-54.

Boden G, Ruiz J, Urbain JL, Chen X. Evidence for a circadian rhythm of insulin secretion. Am J Physiol. 1996;271(2Pt1):E246-52.

Bojkowskl CJ, Arendt J, Shlh MC, Matlcey SP. Melatonin Secretion in Humans Assessed by Measuring Its Metabolite, 6-Sulfatoxymelatonin. Clin Chem. 1987;33(8):1343-48.

Cailotto C, La Fleur SE, Van Heijningen C, Wortel J, Kalsbeek A, Feenstra M, et al. The suprachiasmatic nucleus controls the daily variation of plasma glucose via the autonomic output to the liver: are the clock genes involved? European Journal of Neuroscience. 2005;22:2531-40.

Chillarón JJ, Goday A, Flores-Le-Roux JA, Benaiges D, Carrera MJ, Puig J, et al. Estimated glucose disposal rate in assessment of the metabolic syndrome and microvascular complications in patients with type 1 diabetes. J Clin Endocrinol Metab. 2009;94(9):3530-34.

Dailey G. Assessing glycemic control with self-monitoring of blood glucose and hemoglobin A(1c) measurements. Mayo Clin Proc. 2007;82(2):229-35.

Dinsmoor R. Sleep debt, a wake-up call. Diabetes Self-Management. 2001;19:67-71.

Donga E, Van Dijk M, Van Dijk JG, Biermasz NR, Lammers G-J, Van Kralingen K, et al. Partial sleep restriction decreases insulin sensitivity in type 1 diabetes. Diabetes Care. 2010;33:1573-77.

El-Osta A, Brasacchio D, Yao D, Pocai A, Jones PL, Roeder RG, et al. Transient high glucose causes persistent epigenetic changes and altered gene expression during subsequent normoglycemia. J Exp Med. 2008;205(10):2409-17.

Esquirol $\mathrm{Y}$, Bongard V, Mabile L, Jonnier B, Soulat JM, Perret B. Shift work and metabolic syndrome: respective impacts of job strain, physical activity, and dietary rhythms. Chronobiol Int. 2009;26(3):544-59.

Estrada CL, Danielson KK, Drum ML, Lipton RB. Insufficient sleep in young patients with diabetes and their families. Biol Res Nurs. 2011 Jan 28. In press. 
Gabriely I, Shamoon H. Awakening from sleep and hypoglycemia in type 1 diabetes mellitus. PLoS Med. 2007;4(2):e99.

Garcia RA, Afeche SC, Scialfa JH, do Amaral FG, dos Santos SH, Lima FB, et al. Insulin modulates norepinephrine-mediated melatonin synthesis in cultured rat pineal gland. Life Sci. 2008;82(1-2):108-14.

Gilbert SS, Van den Heuvel CJ, Dawson D. Daytime melatonin and temazepam in young adult humans: equivalent effects on sleep latency and body temperatures. J Physiol. 1999;514:905-14.

Gill GV, Woodward A, Casson IF, Weston PJ. Cardiac arrhythmia and nocturnal hypoglycaemia in type 1 diabetes--the 'dead in bed' syndrome revisited. Diabetologia. 2009;52(1):42-5.

Halberg F, Carandente F, Cornelissen G, Katinas GS. Glossary of chronobiology. Milano, Italia: Casa Editrice I1 Ponte; 1977. 189 p.

Happe S, Treptau N, Ziegler R, Harms E. Restless legs syndrome and sleep problems in children and adolescents with insulin-dependent diabetes mellitus type 1 . Neuropediatrics. 2005;36(2):98-103.

Hussain SA, Khadim HM, Khalaf $\mathrm{BH}$, Ismail $\mathrm{SH}$, Hussein $\mathrm{KI}$, Sahib AS. Effects of melatonin and zinc on glycemic control in type 2 diabetic patients poorly controlled with metformin. Saudi Med J. 2006;27(10):1483-88.

International Diabetes Federation (IDF). IDF Diabetes Atlas. Diabetes in the Young: a Global Perspective. [página na Internet] International Diabetes Federation. 2010. Available from: http://www.diabetesatlas.org/content/diabetes-young-globalperspective [2011 Jan 17].

Jauch-Chara K, Schmid SM, Hallschmid M, Born J, Schultes B. Altered neuroendocrine sleep architecture in patients with type 1 diabetes. Diabetes Care. 2008;31(6):1183-8.

Johns MW. A New method for measuring daytime sleepiness: the Epworth sleepiness scale. Sleep. 1991;14(6):540-45. 
Kadhim HM, Ismail SH, Hussein KI, Bakir IH, Sahib AS, Khalaf BH, et al. Effects of melatonin and zinc on lipid profile and renal function in type 2 diabetic patients poorly controlled with metformin. Journal of Pineal Research. 2006;41(2):189-93.

Kiess W, Böttner A, Raile K, Kapellen T, Müller G, Galler A, et al. Type 2 diabetes mellitus in children and adolescents: a review from a European perspective. Horm Res. 2003;59(SI):77-84.

Kinsley BT, Simonson DC. Evidence for a hypothalamic-pituitary versus adrenal cortical effect of glycemic control on counterregulatory hormone responses to hypoglycemia in insulin-dependent diabetes mellitus. J Clin Endocrinol Metab. 1996;81(2):684-91.

Knutson KL, Ryden AM, Mander BA, Van Cauter E. Role of sleep duration and quality in the risk and severity of type 2 diabetes mellitus. Arch Intern Med. 2006;166:1768-74.

Leproult R, Copinschi G, Buxton O, Van Cauter E. Sleep loss results in an elevation of cortisol levels the next evening. Sleep. 1997;20(10):865-70.

Lima FB, Machado UF, Bartol I, Seraphim PM, Sumida DH, Moraes SMF, et al. Pinealectomy causes glucose intolerance and decreases adipose cell responsiveness to insulin in rats. Am J Physiol Endocrinol Metab. 1998;275:E934E41.

Marcheva B, Ramsey KM, Buhr ED, Kobayashi Y, Su H, Ko CH, et al. Disruption of the clock components CLOCK and BMAL1 leads to hypoinsulinaemia and diabetes. Nature 2010;466(7306):627-31.

Markus RP, Afeche SC, Barbosa Jr EM, Lotufo CM da C, Ferreira ZS, Cipolla-Neto J. Glandula Pineal e Melatonina. In: Marques $\mathrm{N}$ e Menna-Barreto L, organizadores. Cronobiologia: Principios e Aplicacoes. São Paulo: Edusp e Editora Fiocruz; 2003. p. 191-222.

Mejean L, Bicakova-Rocher A, Kolopp M, Villaume C, Levi F, Debry G, et al. Circadian and ultradian rhythms in blood glucose and plasma insulin of healthy adults. Chronobiology International. 1988;5(3):227-36.

Merl V, Peters A, Oltmanns KM, Kern W, Hubold C, Hallschmid M, et al. Preserved circadian rhythm of serum insulin concentration at low plasma glucose during fasting in lean and overweight humans. Metabolism. 2004;53(11):1449-53. 
Mondini S, Guilleminault C. Abnormal breathing patterns during sleep in diabetes. Ann Neurol. 1985; 17(4):391-5.

Monnier L, Colette C, Owens DR. Glycemic variability: the third component of the dysglycemia in diabetes. Is it important? How to measure it? J Diabetes Sci Technol. 2008;2(6):1094-100.

Moreno CRC, Carvalho FA, Matuzaki LS, Prezotti S, Bighetti P, Lorenzi-Filho G. Association between the risk of obstructive sleep apnea and accidents in a truck driver population. Shiftwork International Newsletter. 2003;20(2):135.

Nathan DM, Kuenen J, Borg R, Zheng H, Schoenfeld D, Heine RJ, for the A1cDerived Average Glucose (ADAG) Study Group. Translating the hemoglobin A1c assay into estimated average glucose values. Diabetes Care. 2008;31(8):1-6.

Nishida S. Metabolic effects of melatonin on odative stress and dbetes mellitus. Endocrine 2005; 27(2):131-5.

Pallayova M, Donic V, Gresova S, Peregrim I, Tomori Z. Do differences in sleep architecture exist between persons with type 2 diabetes and nondiabetic controls? J Diabetes Sci Technol. 2010;4(2):344-52.

Paskaloglu K, Sener G, Ayanğolu-Dülger G. Melatonin treatment protects against diabetes-induced functional and biochemical changes in rat aorta and corpus cavernosum. Eur J Pharmacol. 2004;499(3):345-54.

Peschke E. Melatonin, endocrine pâncreas and diabetes. J Pineal Res. 2008;44:2640.

Pillar G, Schuscheim G, Weiss R, Malhotra A, McCowen KC, Shlitner A, et al. Interactions between hypoglycemia and sleep architecture in children with type 1 diabetes mellitus. J Pediatr. 2003;142(2):163-8.

Pires AC. Diabetes Melito tipo1, Hipoglicemia e Síndrome de morte súbita no leito. Sociedade Brasileira de Diabetes. Sociedade Brasileira de Diabetes (SBD). Available from: $\quad$ http://www.diabetes.org.br/colunistas-da-sbd/diabetes-em-evidencia/1219. [2011 Apr 18]. 
Punjabi NM, Shahar E, Redline S, Gottlieb DJ, Givelber R, Resnick HE. Sleepdisordered breathing, glucose intolerance, and insulin resistance: the sleep heart health study. American Journal of Epidemiology. 2004;160(6):521-30.

Radziuk J, Pye S. Diurnal rhythm in endogenous glucose production is a major contributor to fasting hyperglycaemia in type 2 diabetes. Suprachiasmatic deficit or limit cycle behaviour? Diabetologia. 2006;49(7):1619-28.

Resnick HE, Redline S, Shahar E, Gilpin A, Newman A, Walter R, et al. Diabetes and sleep disturbances. Diabetes Care. 2003;26:702-9.

Rios ER, Venâncio ET, Rocha NF, Woods DJ, Vasconcelos S, Macedo D, et al. Melatonin: pharmacological aspects and clinical trends. Int $\mathrm{J}$ Neurosci. 2010;120(9):583-90.

Rodríguez V, Mellado C, Alvarez E, De Diego JG, Blázquez E. Effect of pinealectomy on liver insulin and glucagon receptor concentrations in the rat. $J$ Pineal Res. 1989;6(1):77-88.

Roldan MB, Alonso M, Barrio R. Thyroid autoimmunity in children and adolescents with type 1 diabetes mellitus. Diabetes Nutr Metab. 1999;12:27-31.

Rotenberg L, Marques N, Menna-Barreto L. História e perspectivas da Cronobiologia. In: Marques N, Menna-Barreto L, organizadores. Cronobiologia: Principios e Aplicacoes. São Paulo: Edusp e Editora Fiocruz; 2003. p. 31-53.

Sacco S, Aquilini L, Ghezzi P, Pinza M, Guglielmotti A. Mechanism of the inhibitory effect of melatonin on tumor necrosis factor production in vivo and in vitro European Journal of Pharmacology. 1998;343(2-3):249-55.

Scheen AJ, Sturis J, Polonsky KS, Van Cauter E. Alterations in the ultradian oscillations of insulin secretion and plasma glucose in aging. Diabetologia. 1996;39:564-72.

Scheen AJ, Van Cauter E. The roles of time of day and sleep quality in modulating glucose regulation: clinical implications. Hormone Research. 1998;49:191-201.

Schmid SM, Hallschmid M, Jauch-Chara K, Wilms B, Lehnert H, Born J, Schultes B. Disturbed glucoregulatory response to food intake after moderate sleep restriction. Sleep 2011;34(3):371-7. 
Schultes B, Jauch-Chara K, Gais S, Hallschmid M, Reiprich E, Kern W, Oltmanns KM, Peters A, Fehm HL, Born J. Defective awakening response to nocturnal hypoglycemia in patients with type 1 diabetes mellitus. PLoS Med. 2007;4(2):e69.

Schütt M, Kern W, Krause U, Busch P, Dapp A, Grziwotz R, et al., DPV Initiative. Is the frequency of self-monitoring of blood glucose related to long-term metabolic control? Multicenter analysis including 24,500 patients from 191 centers in Germany and Austria. Exp Clin Endocrinol Diabetes. 2006; 114(7):384-8.

Seabra MLV e Cipolla-Neto J. Melatonina e sono. In: Tufik S, organizador. Medicina e biologia do sono. Barueri: Manole; 2008. p. 130-138.

Sicree RJ, Shaw J, Zimmet P. The Global Burden, Diabetes and Impaired Glucose Tolerance. IDF Diabetes Atlas fourth edition. Brussels: International Diabetes Federation; 2009. $105 \mathrm{p}$.

Siegelaar SE, Holleman F, Hoekstra JBL, DeVries JH. Glucose Variability; Does It Matter? Endocrine Reviews. 2010;31(2):171-82.

Simon C, Brandenberger G. Ultradian Oscillations of Insulin Secretion in Humans. Diabetes. 2002;51:S258-S61.

Simon C. Ultradian pulsatility of plasma glucose and insulin secretion rate: circadian and sleep modulation. Hormone Research. 1998;49:185-90.

Sociedade Brasileira de Diabetes. Diretrizes da Sociedade Brasileira de Diabetes 2009. 3a ed. Itapevi: A. Araujo Silva Farmacêutica; 2009. 400 p.

Spiegel K, Knutson K, Leproult R, Tasali E, Van Cauter E. Sleep loss: a novel risk factor for insulin resistance and Type 2 diabetes. J Appl Physiol. 2005;99(5):2008-19.

Spiegel K, Leproult R, Van Cauter E. Impact of sleep debt on metabolic and endocrine function. Lancet. 1999;354(9188):1435-39.

Stamatakis KA, Punjabi NM. Effects of sleep fragmentation on glucose metabolism in normal subjects. Chest. 2010;137(1):95-101. 
Tasali E, Leproult R, Ehrmann DA, Van Cauter E. Slow-wave sleep and the risk of type 2 diabetes in humans. Proc Natl Acad Sci U S A. 2008;105(3):1044-9.

The Diabetes Control and Complications Trial Research Group. The effect of intensive treatment of diabetes on the development and progression of long-term complications in insulin-dependent diabetes mellitus. $\mathrm{N}$ Engl $\mathrm{J}$ Med. 1993;329(14):977-86.

Trento M, Broglio F, Riganti F, Basile M, Borgo E, Kucich C, et al. Sleep abnormalities in type 2 diabetes may be associated with glycemic control. Acta Diabetol. 2008;45:225-9.

Van Cauter E, Polonsky KS, Scheen AJ. Roles of circadian rhythmicity and sleep in human glucose regulation. Endocrine Reviews. 1997;18(5):716-38.

Van Cauter E, Spiegel K, Tasali E, Leproult R. Metabolic consequences of sleep and sleep loss. Sleep Med. 2008;9:S23-S8.

Villa MP, Multari G, Montesano M, Pagani J, Cervoni M, Cerone E, et al. Sleep apnoea in children with diabetes mellitus: effect of glycaemic control. Diabetologia. 2000;43:696-702.

Wahi G, Zorzi A, Macnab A, Panagiotopoulos C. Prevalence of type 2 diabetes, obesity and the metabolic syndrome among Canadian First Nations children in a remote Pacific coast community. Paediatr Child Health. 2009;14(2):79-83.

Walker MP. Cognitive consequences of sleep and sleep loss. Sleep Med. 2008;9:S29-S34.

Winiarska K, Fraczyk T, Malinska D, Drozak J, Bryla J. Melatonin attenuates diabetes-induced oxidative stress in rabbits. J Pineal Res. 2006;40:168-76.

Yamamoto $\mathrm{H}$, Nagai K, Nakagawa $\mathrm{H}$. Role of SCN in daily rhythms of plasma glucose, ffa, insulin and glucagon. Chronobiology International. 1987;4(4):483-91.

Yavuz O, Cam M, Bukan N, Guven A, Silan F. Protective effect of melatonin on betacell damage in streptozotocin-induced diabetes in rats. Acta Histochem. 2003;105(3):261-6. 
Yeshayahu Y, Mahmud FH. Altered sleep patterns in adolescents with type 1 diabetes: implications for insulin regimen. Diabetes Care. 2010;33(11):e14. 


\section{APÊNDICE A}

Relatório médico para seleção ou exclusão de voluntários do grupo DM1

\section{$\underline{\text { Relatório Médico }}$}

Nome do(a) paciente:

Idade:

Altura:

Peso:

Tempo deDPe o diagnóstico do DM1:

Trabalha em turnos ou realiza trabalho noturno?

$\square \operatorname{sim}$

não

Possui algum distúrbio de sono?

$\square \operatorname{sim}$ não

Em caso positivo favor especificar:

Esquema de insulinização (incluir tipos de insulinas, doses e horários):

Toma algum medicamento além da insulina?

$\square \operatorname{sim}$ não

Em caso positivo favor especificar:

Possui algum outro distúrbio endócrino (hipotiroidismo, hipertiroidismo, acromegalia, etc.)? 
Em caso positivo favor especificar:

Data da última dosagem de hemoglobina glicada (A1c):

Resultado da última dosagem de hemoglobina glicada (A1c): $\%$

Data da última avaliação de fundo de olho:

Apresentou alguma alteração na retina?

$\square \operatorname{sim}$ não

Data da última dosagem de microalbuminúria:

Resultado:

Data da última dosagem de creatinina:

Resultado:

Data da última avaliação de sensibilidade com monofilamento:

Apresentou algum sinal de perda de sensibilidade?

$\square \operatorname{sim}$

$\square$ não

Possui alguma outra complicação decorrente do DM1?

$\square \operatorname{sim}$

não

Em caso positivo favor especificar:

Nome do(a) Médico(a):

CRM: - data de hoje: 


\section{APÊNDICE B}

Protocolo de triagem para avaliação de neuropatia e retinopatia

\section{Protocolo de Triagem para Deteccão de Neuropatia e Retinopatia}

Estão descritos abaixo os procedimentos não invasivos que serão utilizados a fim de verificar se os indivíduos portadores de diabetes mellitus do tipo 1, que estão se voluntariando para participar do estudo intitulado "Ciclo vigília-sono em portadores de diabetes mellitus tipo 1", não apresentam estas complicações. A presença de neuropatia ou retinopatia nestes indivíduos poderia nos levar a interpretar de forma inadequada os resultados obtidos no estudo.

1) Aferição da pulsação em repouso; e da pressão arterial com indivíduo deitado e 1 minuto após levantar. Instrumentos utilizados: estetoscópio e esfigmomanômetro. Considera-se sugestivo de algum nível de neuropatia autonômica quando a pulsação de repouso do indivíduo se apresenta acima de 100bmp, e/ou quando ao se levantar a pressão arterial diminui mais que $20 \mathrm{mmgHg} .{ }^{1,2}$

2) Teste de sensibilidade periférica com uso de monofilamento de 10 gramas. $O$ monofilamento flexível é pressionado contra diferentes pontos do pé do indivíduo. Considera-se a sensibilidade reduzida (evidência de neuropatia periférica) quando o indivíduo não expressa ter sentido um ou mais toques do monofilamento. ${ }^{1-4}$

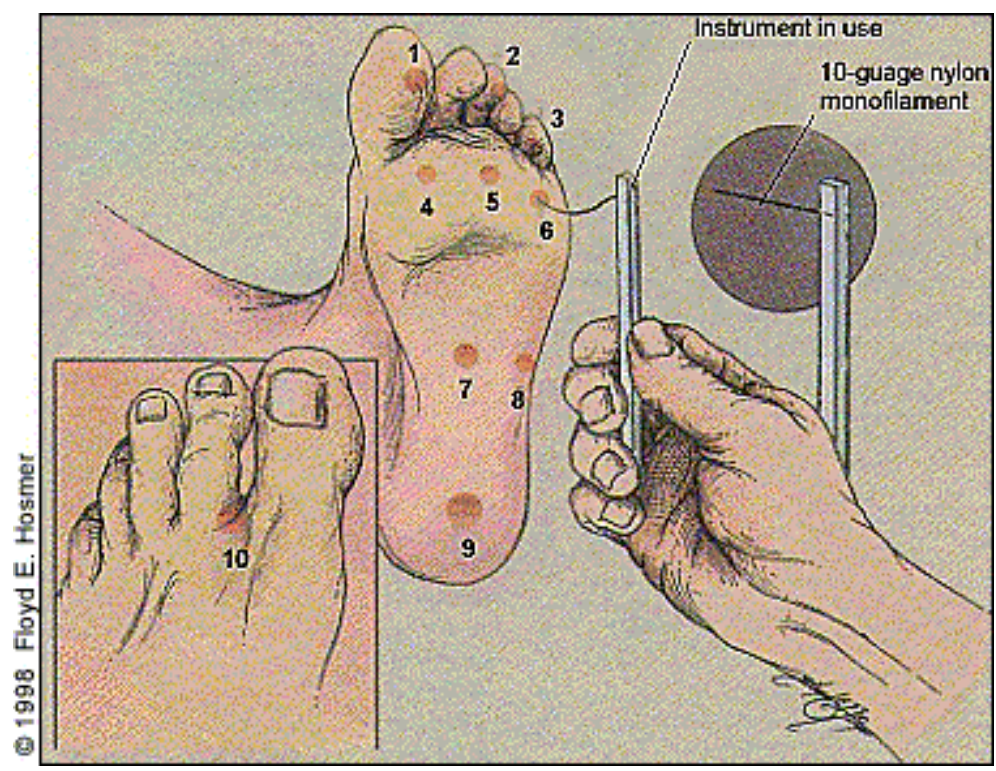


3) A avaliação de neuropatia periférica com uso do diapasão de $128 \mathrm{~Hz}$ é feita encostando-se o diapasão por vezes em vibração, e outras vezes não vibrando, sobre a parte óssea dorsal da falange distal de ambos hálux do indivíduo. Este deve relatar as vezes que percebe que o mesmo está vibrando. Caso o indivíduo não consiga identificar, por uma mais de uma vez, quando o diapasão está em vibração, considera-se que há redução na sensibilidade vibratória (evidência de neuropatia periférica). ${ }^{1-4}$

4) A avaliação simples da retina para detecção de retinopatia será realizada por oftalmologista, que, com uso de feixe de luz, identificará se há alterações superficiais na retina dos indivíduos. ${ }^{1,3}$

\section{Referências}

1. American Diabetes Association. Standards of Medical Care in Diabetes-2009. Diabetes Care 32:S13-S61, 2009.

2. Sociedade Brasileira de Diabetes. Diretrizes da Sociedade Brasileira de Diabetes 2009, 3를 edição, Itapevi, 2009. 400 p.

3. BOULTON, AJM; ARMSTRONG, DG; ALBERT, SF; et al. Comprehensive Foot Examination and Risk Assessment, A report of the Task Force of the Foot Care Interest Group of the American Diabetes Association, with endorsement by the American Association of Clinical Endocrinologists. Diabetes Care 31:1679-1685, 2008.

4. Gross, JL, Nehme, M. Detecção e tratamento das complicações crônicas do diabetes melito: Consenso da Sociedade Brasileira de Diabetes e Conselho Brasileiro de Oftalmologia. Rev. Assoc. Med. Bras. 45(3):279-284, 1999. 
Triagem para participação do estudo:

Ciclo VigíliaSono em Portadores de Diabetes Mellitus Tipo 1.

\section{Detecção de Neuropatia e Retinopatia}

Nome do voluntário:

Data da triagem:

O voluntário apresentou taquicardia de repouso (>100bmp), e queda na pressão sistólica $(>20 \mathrm{mmHg})$ ao levantar?

O voluntário apresentou alteração de sensibilidade periférica ao toque (monofilamento de 10g)? Especifique.

O voluntário apresentou alteração de sensibilidade periférica à vibração (diapasão de $128 \mathrm{~Hz})$ ? Especifique.

O voluntário apresentou alteração na retina? Especifique.

Nome e assinatura dos avaliadores: 


\section{APÊNDICE C}

Correlação entre dados do diário de sono e do Tempatilimi (actímetro)

\begin{tabular}{c|ccc|}
$\begin{array}{c}\text { Correlação entre Diário } \\
\text { de Sono e Actímetro }\end{array}$ & $\begin{array}{c}\text { Início do } \\
\text { sono / } \\
\text { repouso }\end{array}$ & $\begin{array}{c}\text { Fim do sono } \\
\text { / repouso }\end{array}$ & $\begin{array}{c}\text { Duração do } \\
\text { sono / } \\
\text { repouso }\end{array}$ \\
\hline Horário de deitar & $\begin{array}{c}r=0,9565 \\
p<0,0001\end{array}$ & - & - \\
Horário de levantar & - & $\begin{array}{c}r=0,9781 \\
p<0,0001\end{array}$ & - \\
Duração do sono & - & - & $r=0,6949$ \\
& & & $p<0,0001$
\end{tabular}

$\begin{array}{cccc}\begin{array}{c}\text { Wilcoxon e Teste T para } \\ \text { amostras dependentes } \\ \text { Diário de Sono e Actímetro }\end{array} & \begin{array}{c}\text { Início do } \\ \text { sono / } \\ \text { repouso }\end{array} & \begin{array}{c}\text { Fim do sono } \\ \text { / repouso }\end{array} & \begin{array}{c}\text { Duração do } \\ \text { sono / } \\ \text { repouso }\end{array} \\ \text { Horário de deitar } & \begin{array}{c}p<0,0001 \\ p<0,0001\end{array} & - & - \\ \text { Horário de levantar } & - & \begin{array}{c}p=0,9204 \\ p=0,4565\end{array} & - \\ \text { Duração do sono } & - & - & p<0,0001 \\ & & & p=0,0249\end{array}$




\begin{abstract}
ANEXO A
Termo de consentimento para realização dos procedimentos para triagem, avaliação de complicações
\end{abstract}

\title{
TERMO DE CONSENTIMENTO LIVRE E ESCLARECIDO
}

Triagem para participação do estudo: Ciclo Vigília/Sono em Portadores de Diabetes Mellitus Tipo 1.

Você está sendo convidado(a) a participar da triagem que antecede a participação no projeto de pesquisa acima citado. O documento abaixo contém todas as informações necessárias sobre tal triagem. Caso esteja dentro do perfil para participação do projeto de pesquisa, você será informado sobre todos os detalhes do protocolo de pesquisa e assinará outro termo de consentimento livre e esclarecido. Sua colaboração neste processo será de muita importância para nós, mas se desistir a qualquer momento, isso não causará nenhum prejuízo a você.

EU portador da

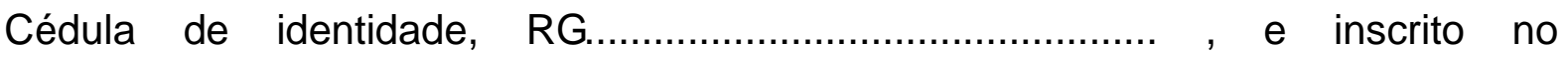
CPF/MF. nascido(a) em I abaixo assinado(a), concordo de livre e espontânea vontade em participar como voluntário(a) da triagem para o estudo "Ciclo Vigília/sono em Portadores de Diabetes Mellitus Tipo 1". Declaro que obtive todas as informações necessárias, bem como todos os eventuais esclarecimentos quanto às dúvidas por mim apresentadas.

Estou ciente que:

I. A participação nesta triagem não tem objetivo de me submeter a um tratamento, bem como não me acarretará qualquer despesa com relação aos procedimentos efetuados com o estudo;

II. Tenho a liberdade de desistir ou de interromper a colaboração neste estudo no momento em que desejar, sem necessidade de qualquer explicação;

III. A desistência não causará nenhum prejuízo à minha saúde ou bem estar físico;

IV. A minha participação acontecerá em 2 momentos. No primeiro deles eu me submeterei a procedimentos simples e não invasivos, que incluem: medição 
de pressão arterial, teste de sensibilidade periférica com uso de microfilamento e/ou diapasão; e feixe de luz para visualização da retina. Estes procedimentos têm por fim verificar a presença ou não de neuropatia autonômica, neuropatia periférica e retinopatia. No segundo momento eu serei solicitado a realizar um exame de sangue de rotina, hemoglobina glicada, onde normalmente realizo por orientação médica.

V. Os resultados obtidos durante esta triagem serão mantidos em sigilo, mas concordo que sejam divulgados em publicações científicas, deDPe que meus dados pessoais não sejam mencionados;

VI. Meu médico tomará conhecimento dos resultados, e caso eu desejar, poderei pessoalmente tomar conhecimento dos resultados, ao final desta triagem.

( ) Desejo conhecer os resultados desta triagem.

( ) Não desejo conhecer os resultados desta triagem.

São Paulo, de de

( ) Voluntário / ( ) Responsável

Testemunha 1 :Nome / RG / Telefone

Testemunha 2:Nome / RG / Telefone

Responsável pelo Projeto: Mark Thomaz Ugliara Barone

Telefones para contato: cel - (11) 82093569 e Laboratório - (11) 37171997

E-mail: mbarone@icb.usp.br 


\section{ANEXO B \\ Parecer da Comissão de Ética em Pesquisa com Seres Humanos do Instituto de Ciências Biomédicas da USP}

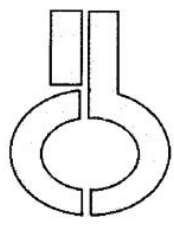

UNIVERSIDADE DE SÃO PAULO INSTITUTO DE CIÊNCIAS BIOMÉDICAS

Cidade Universitária "Armando de Salles Oliveira"

Av. Prof. Lineu Prestes, 2415 - cep. 05508-000 Săo Paulo, SP - Brasil

Telefone :(55) (11) 3091.7733 telefax : (55) (11) 3091-7438 e-mail: cep@ icb.usp.br

Prezado Senhor,

Atendendo sua solicitação, a Comissão de Ética em Pesquisas com Seres Humanos do $I C B$, em sua $91^{\circ}$ reunião realizada em 09.12 .08 , analisou o projeto de sua responsabilidade intitulado: "Ciclo vigília/sono em portadores de diabetes mellitus tipo I".

Informo a V.Sa. que, após análise e discussão, o referido projeto foi aprovado por esta Comissão.

Lembramos que cabe ao pesquisador elaborar e apresentar a este Comitê, relatórios anuais (parciais ou final), de acordo com a resolução 196/06 do Conselho Nacional da Saúde, item IX.2 letra c.

○ primeiro relatório deverá ser encaminhado à Secretaria deste CEP em 09 de dezembro de 2009.

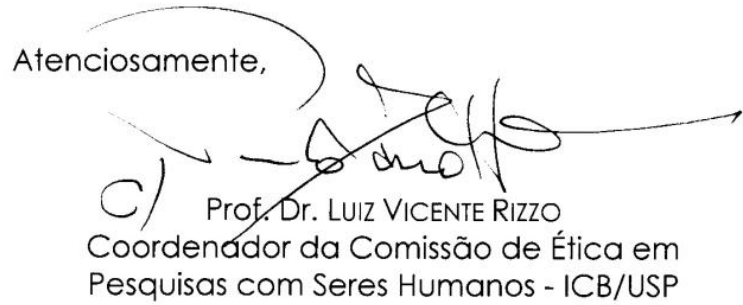

IImo. Sr.

MARK THOMAZ UGLIARA BARONE

Departamento de Fisiologia e Biofisica

Instituto de Ciências Biomédicas -USP

Comissão de Ética em Pesquisa com Seres Humanos do Instituto de Ciências Biomédicas I USP Aprovada pela Comissão Nacional de Ética em Pesquisa - CONEP, em 10 de fevereiro de 1998 


\section{ANEXO C}

Parecer da Comissão de Ética do Hospital das Clínicas da Faculdade de Medicina da Universidade de São Paulo

\section{Parecer da Comissão para Análise de Projetos de Pesquisa da Disciplina de Endocrinologia \\ Roteiro Proposto \\ É OBRIGATÓRIO O PREENCHIMENTO DE TODOS OS ITENS DO PARECER E DEVOLVER NO MÁXIMO EM 7(SETE) DIAS}

\section{IDENTIFICACÃO:}

Titulo do Projeto: “CICLO VIGÍLIA/SONO EM PORTADORES DE DIABETES MELLITUS TIPO 1".

Pesquisador(a) Responsável: Dr. MARIO KEHDI CARRA

Pesquisador(a) Executante: MARK THOMAZ UGLIARA BARONEa

Unidade Envolvida: Unidade de Diabetes da Disciplina de Endocrinologia da FMUSP e INCOR

Data: 02/01/2009 a 02/12/2010 - 23 meses

\section{OBJETIVOS:}

SUMÁRIO DO PROJETO: (Avaliar descrição e caracterização da amostra; critérios de inclusão e exclusão; adequação da metodologia; adequação das condiçães para realização do projeto).

Apoio financeiro: FAPESP

Valor:

Serviços da instituição necessários à execução do projeto (dosagens, compra, serviço de terceiros, etc.).A Instituição tem infra-estrutura que permite a realização do projeto em apreço.

RESOLUCÃO 196/96: Avaliar estrutura do Protocolo; justificava de uso de placebo; justificativa de suspensão terapêutica; análise de riscos e beneficios; retorno de beneficios para o sujeito e/ou para a comunidade; adequação do Termo de Consentimento e forma de obtê-lo inclusive dos outros centros, no caso de estudos multicêntricos (muito importante); informação adequada quanto ao financiamento (muito importante).

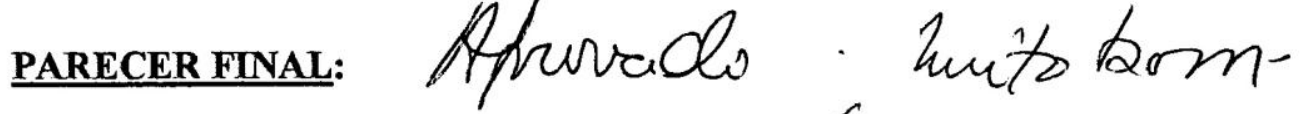

Encaminhar o pesquisador aos setores: Assinatura e carimbo Dr. Walter Bloise - 02/12/08

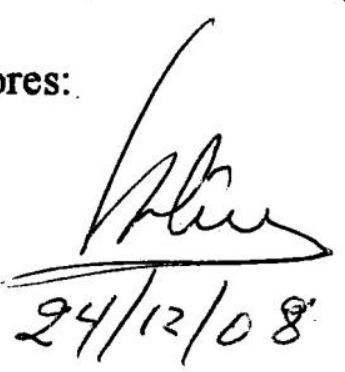




\section{ANEXO D}

Carta da Comissão Científica do Instituto do Coração da Faculdade de Medicina da

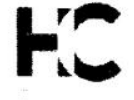

MEMO 0109/09
Universidade de São Paulo

São Paulo, 02 de março de 2009.

AO

Prof. Dr. Luiz Silveira Menna Barreto

A Comissão Científica na sessão 549/09/02 de 19/02/2009 tomou ciência de que o Laboratório do Sono/Incor estará participando como unidade executora , realizando 30 polissonografias do projeto de pesquisa Ciclo Vigília-Sono em Portadores de Diabetes Mellitus tipo 1.

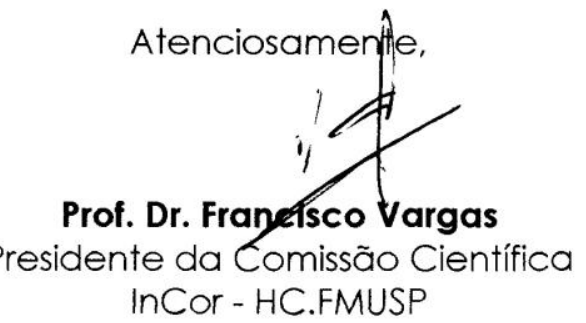




\section{ANEXO E \\ Carta da Associação de Diabetes Juvenil}

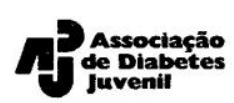

Rua Padre Antonio Tomas, 213

CEP 05003-010 - São Paulo - SP

Telefax (11) 36753266

0800-100627

Email - adi@adi.ora.b

Site : www.adi.org.br

São Paulo, 05 de novembro de 2008

À Comissão Científica do Instituto de Ciências Biomédicas da Universidade de São Paulo

Estou ciente do estudo intitulado "Ciclo vigíla-sono em portadores de diabetes mellitus tipo 1" que será executado pelo aluno de doutorado Mark Thomaz Ugliara Barone sob orientação do Prof. Dr. Luiz Silveira Menna Barreto do Instituto de Ciência Biomédica (ICB) da USP.

O estudo acima precisará contar com 20 indivíduos portadores de diabetes mellitus do tipo 1 . Nesse contexto, autorizo que esses indivíduos sejam recrutados sob minha supervisão na Associação de Diabetes Juvenil (ADJ).

Entendo ainda que a verba do projeto será solicitada à FAPESP, não cabendo à ADJ arcar com nenhuma despesa e nem onerar de nenhuma forma o pesquisador.

O recrutamento dos voluntários por mim indicados poderá ter início em 2009 , assim que houver aprovação do comitê de ética do Instituto de Ciências Biomédicas (ICB-USP).

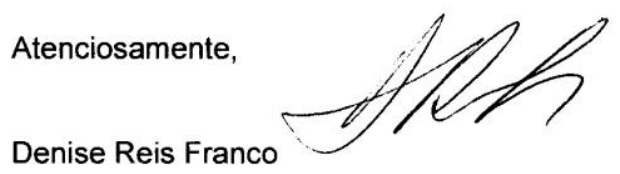

Médica endocrinologista

Coordenadora de Educação em Diabetes, ADJ 


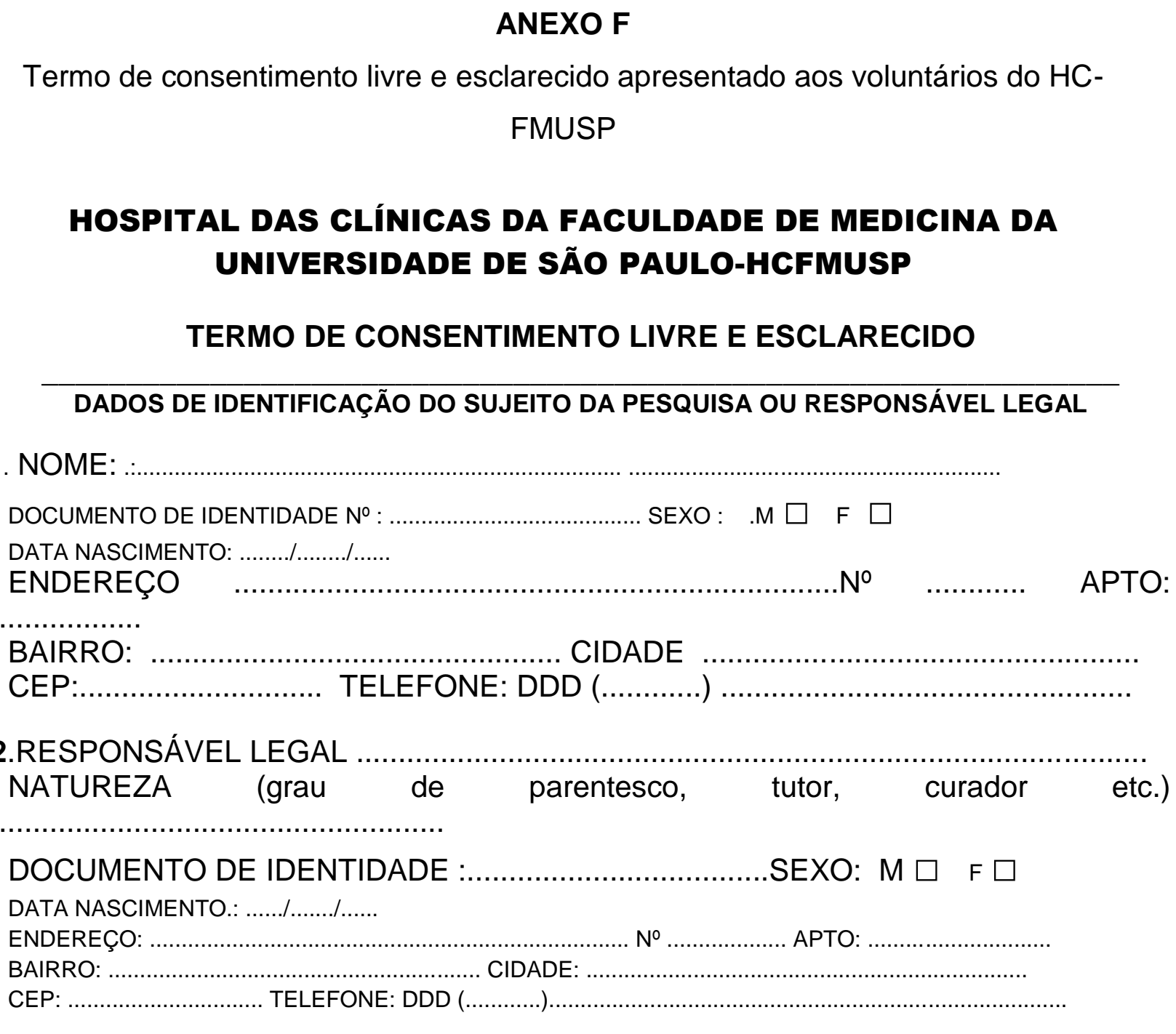

\section{DADOS SOBRE A PESQUISA}

1. TÍTULO DO PROTOCOLO DE PESQUISA Ciclo vigília/sono em portadores de diabetes mellitus tipo 1 PESQUISADOR : Mario Kehdi Carra CARGO/FUNÇÃO: médico INSCRIÇÃO CONSELHO REGIONAL № 36058 UNIDADE DO HCFMUSP: Clínica médica / endocrinologia

3. AVALIAÇÃO DO RISCO DA PESQUISA:

$\begin{array}{lll}\text { RISCO MÍNIMO } & \mathbf{x} & \text { RISCO MÉDIO } \\ \text { RISCO BAIXO } & \square & \text { RISCO MAIOR }\end{array}$

4.DURAÇÃO DA PESQUISA : Aproximadamente 23 meses.

HOSPITAL DAS CLÍNICAS DA FACULDADE DE MEDICINA DA UNIVERSIDADE DE SÃO PAULO-HCFMUSP 
Essas informações estão sendo fornecidas para sua participação voluntária neste estudo, que visa verificar como o controle do diabetes pode afetar o ciclo vigília/sono.

A maior parte dos procedimentos solicitados são procedimentos de rotina. $\mathrm{O}$ (a) $\operatorname{sr}(\mathrm{a})$ deverá seguir algumas orientações já que apesar de a maioria serem procedimentos de rotina, como ponta-de-dedo, coleta de urina, é importante que os horários sejam respeitados. Quanto às pontas-de-dedo, será solicitado que o (a) sr(a) realize, e anote no diário de glicemias que receberá, entre 6 e 9 testes por dia, durante 10 dias. Durante esse mesmo período o(a) sr(a) também deverá preencher um diário de sono com questões sobre sonolência, tempo de duração de sono e cochilos e avaliação da qualidade do sono; e ainda um aparelho semelhante a um relógio deverá ser usado e retirado apenas quando for tomar banho. $O(a) \operatorname{sr}(a)$ deverá coletar toda urina produzida urina durante 12 horas, uma noite, (se começar a coleta às $19 \mathrm{hs}$ de um dia, deve-se coletar urina até às $7 \mathrm{hs}$ da manhã seguinte). Após esses 10 dias nos reencontraremos e marcaremos um dia para colocar um aparelho, cujo sensor ficará em sua barriga, que medirá sua glicemia durante 3 a 5 dias seguidos, e uma noite em que o(a) sr(a) dormirá no Laboratório do Sono do Incor, quando terá seu sono monitorado em um exame chamado polissonografia. Ademais disso, o pesquisador pedirá ao seu médico o resultado de alguns dos seus exames de sangue de rotina, não precisando fazer exames de sangue além dos que já realiza.

A participação na pesquisa não traz riscos para a sua saúde. Os desconfortos que pode sentir são: eventual incômodo devido ao número maior de glicemias (ponta-de-dedo) que irá realizar durante os 10 dias; desconforto com algum dos aparelhos que irá utilizar (tempatilumi, o que parece um relógio, por 10 dias, e o CGMS que mede a glicemia por 3 a 5 dias); além da noite que durmirá no Incor que apesar de não haver nada que penetre a sua pele, haverá fios presos à sua pele durante toda a noite.

Apesar de não haver benefício direto para o participante, os resultados dessa pesquisa podem revelar novos conhecimentos sobre como o diabetes pode influir sobre o sono e a vigília de seus portadores. Assim, os conhecimentos obtidos com essa pesquisa talvez possam, no futuro, contribuir para que os portadores de diabetes tenham melhor qualidade de vida.

Os benefícios imediatos de sua participação são os resultados obtidos em todos os procedimentos e análises, que estarão à sua disposição, assim como de seu médico, o que eventualmente pode auxiliar no conhecimento mais detalhado do controle do seu diabetes e de dados sobre o seu sono.

Em qualquer etapa do estudo, você terá acesso aos profissionais responsáveis pela pesquisa para esclarecimento de eventuais dúvidas. O principal investigador é o Dr Mario Kehdi Carra, que pode ser encontrado no endereço ICHC - endocrinologia, telefone(s) (11) 3069 6293. Se você tiver alguma consideração ou dúvida sobre a ética da pesquisa, entre em contato com o Comitê de Ética em Pesquisa (CEP) - Rua Ovídio Pires de Campos, 225 - 5 andar - tel: 3069-6442 ramais 16, 17, 18 ou 20, FAX: 3069-6442 ramal 26 - E-mail: cappesq@hcnet.usp.br 
É garantida a liberdade da retirada de consentimento a qualquer momento e deixar de participar do estudo, sem qualquer prejuízo à continuidade de seu tratamento na Instituição.

As informações obtidas serão analisadas em conjunto com outros pacientes, não sendo divulgado a identificação de nenhum paciente.

$\mathrm{O}$ (a) sr(a) terá direito de ser mantido atualizado sobre os resultados parciais das pesquisas, ou de resultados que sejam do conhecimento dos pesquisadores.

Não há despesas pessoais para o participante em qualquer fase do estudo, incluindo exames e consultas. Também não há compensação financeira relacionada à sua participação. Se existir qualquer despesa adicional, ela será absorvida pelo orçamento da pesquisa.

O pesquisador se compromete a utilizar os dados e o material coletado somente para esta pesquisa.

Acredito ter sido suficientemente informado a respeito das informações que li ou que foram lidas para mim, descrevendo o estudo "Ciclo vigília/sono em portadores de diabetes mellitus tipo 1".

Eu discuti com o Dr. Mario Kehdi Carra sobre a minha decisão em participar nesse estudo. Ficaram claros para mim quais são os propósitos do estudo, os procedimentos a serem realizados, seus desconfortos e riscos, as garantias de confidencialidade e de esclarecimentos permanentes. Ficou claro também que minha participação é isenta de despesas e que tenho garantia do acesso a tratamento hospitalar quando necessário. Concordo voluntariamente em participar deste estudo e poderei retirar o meu consentimento a qualquer momento, antes ou durante o mesmo, sem penalidades ou prejuízo ou perda de qualquer benefício que eu possa ter adquirido, ou no meu atendimento neste Serviço.

Assinatura do paciente/representante legal Data

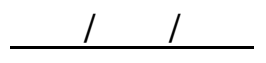

Assinatura da testemunha

Data

para casos de pacientes menores de 18 anos, analfabetos, semi-analfabetos ou portadores de deficiência auditiva ou visual.

(Somente para o responsável do projeto)

Declaro que obtive de forma apropriada e voluntária o Consentimento Livre e Esclarecido deste paciente ou representante legal para a participação neste estudo.

Assinatura do responsável pelo estudo

Data

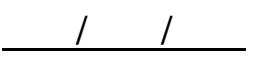




\begin{abstract}
ANEXO G
Termo de consentimento livre e esclarecido apresentando aos voluntários da ADJ e aos do grupo controle
\end{abstract}

\title{
TERMO DE CONSENTIMENTO LIVRE E ESCLARECIDO
}

ESTUDO: Ciclo VigíliaSono em Portadores de Diabetes Mellitus Tipo 1.

Você está sendo convidado(a) a participar do projeto de pesquisa acima citado. O documento abaixo contém todas as informações necessárias sobre a pesquisa que estamos fazendo. Sua colaboração neste estudo será de muita importância para nós, mas se desistir a qualquer momento, isso não causará nenhum prejuízo a você.

Eu,

portador da

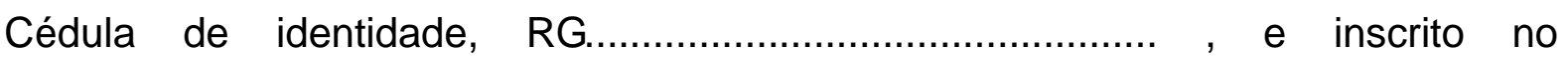
CPF/MF. nascido(a) em / I abaixo assinado(a), concordo de livre e espontânea vontade em participar como voluntário(a) do estudo "Ciclo Vigília/sono em Portadores de Diabetes Mellitus Tipo 1". Declaro que obtive todas as informações necessárias, bem como todos os eventuais esclarecimentos quanto às dúvidas por mim apresentadas.

Estou ciente que:

VII. A participação neste projeto não tem objetivo de me submeter a um tratamento, bem como não me acarretará qualquer ônus pecuniário com relação aos procedimentos efetuados com o estudo;

VIII. Tenho a liberdade de desistir ou de interromper a colaboração neste estudo no momento em que desejar, sem necessidade de qualquer explicação;

IX. A desistência não causará nenhum prejuízo à minha saúde ou bem estar físico;

X. A minha participação tem duração total de 15 dias e consiste em: responder a Escala de Sonolência de Epworth; preencher o diário de sono, diário de 
glicemia e usar o Tempatilumi no punho não dominante por 10 dias; usar o CGMS, medidor contínuo de glicose; e me submeter ao exame de polissonografia, dormindo por uma noite no laboratório pelo pesquisador indicado;

XI. Os resultados obtidos durante este ensaio serão mantidos em sigilo, mas concordo que sejam divulgados em publicações científicas, deDPe que meus dados pessoais não sejam mencionados;

XII. Meu médico tomará conhecimento dos resultados, e caso eu desejar, poderei pessoalmente tomar conhecimento dos resultados, ao final desta pesquisa.

( ) Desejo conhecer os resultados desta pesquisa.

( ) Não desejo conhecer os resultados desta pesquisa.

São Paulo, de de

( ) Voluntário / ( ) Responsável

Testemunha 1 :Nome / RG / Telefone

Testemunha 2:Nome / RG / Telefone

Responsável pelo Projeto: Mark Thomaz Ugliara Barone

Telefone para contato: cel - (11) 82093569 e Laboratório - (11) 37171997 
ANEXO H

Escala de sonolência de Epworth

Nome do voluntário:

Data:

\section{ESCALA DE SONOLÊNCIA DE EPWORTH}

Epworth Sleepiness Scale (Johns, 1991) - instruções traduzidas por Flávio Alóe

Qual é a probabilidade de você "cochilar" ou adormecer nas situações que serão apresentadas a seguir, em contraste com estar sentindo-se simplesmente cansado? Isso diz respeito ao seu modo de vida comum, nos tempos atuais. Ainda que você não tenha feito, ou passado por nenhuma dessas situações, tente calcular como poderiam tê-lo afetado.

Utilize a escala apresentada a seguir para escolher o número mais apropriado para cada situação:

$0=$ nenhuma chance de cochilar

$1=$ pequena chance de cochilar

$2=$ moderada chance de cochilar

$3=$ alta chance de cochilar

\begin{tabular}{|c|c|c|c|c|}
\hline & \multicolumn{4}{|c|}{$\begin{array}{l}\text { CHANCE DE } \\
\text { COCHILAR }\end{array}$} \\
\hline Sentado(a) e lendo & $\mathbf{0}$ & 1 & 2 & 3 \\
\hline Assistindo TV & $\mathbf{0}$ & 1 & 2 & 3 \\
\hline Sentado(a) em um lugar público (ex.: sala de espera, cinema, igreja, etc.) & $\mathbf{0}$ & 1 & 2 & 3 \\
\hline Como passageiro(a) de trem, carro ou ônibus andando 1 hora sem parar & $\mathbf{0}$ & 1 & 2 & 3 \\
\hline Deitando-se para descansar à tarde, quando as circunstâncias permitem & $\mathbf{0}$ & 1 & 2 & 3 \\
\hline Sentado(a) e conversando com alguém & $\mathbf{0}$ & 1 & 2 & 3 \\
\hline Sentado(a) calmamente após o almoço (sem álcool) & $\mathbf{0}$ & 1 & 2 & 3 \\
\hline $\begin{array}{l}\text { Dirigindo um carro, enquanto pára por alguns minutos ao pegar trânsito } \\
\text { intenso }\end{array}$ & 0 & 1 & 2 & 3 \\
\hline
\end{tabular}

Pontuação total: 


\section{ANEXO I}

Diário de Sono

\section{1a Parte - Responda ao despertar}

Data: - Dia da semana:

1. A que horas você foi dormir ontem? horas

2. Quanto tempo você demorou para pegar no sono?

Demorei

3. A que horas você acordou hoje? horas

4. Como você classifica seu sono desta noite?

Muito ruim Muito bom

5. Você acordou durante a noite? Se sim, quantas vezes?

( ) não ( ) sim vezes

6. Teve hipoglicemia ou hiperglicemia durante a noite?

( ) não ( ) hipoglicemia ( ) hiperglicemia

Quanto estava sua glicemia (caso tenha medido)? glicemia: $\mathrm{mg} / \mathrm{dl}$

7. Como você acordou?

( ) Alguém me chamou

( ) Espontaneamente (sozinho / sozinha)

( ) Com o despertador 
Outras observações que considere importantes (sono, variação da glicemia, humor, sintomas, atividade física, etc.):

\section{2- Parte - Responda antes de deitar}

8. Você sentiu sonolência durante o dia (manhã, tarde, noite)?

\section{Manhã}

nada muita

\section{Tarde}

nada muita

\section{$\underline{\text { Noite }}$}

nada

muita

9. Você dormiu / cochilou durante o dia?
( ) não
( ) $\operatorname{sim}$
Horário: duração:
Horário: duração:
Horário: duração:

Outras observações que considere importantes (sono, variação da glicemia, humor, sintomas, atividade física, etc.): 


\section{ANEXO J}

Tempatilumi

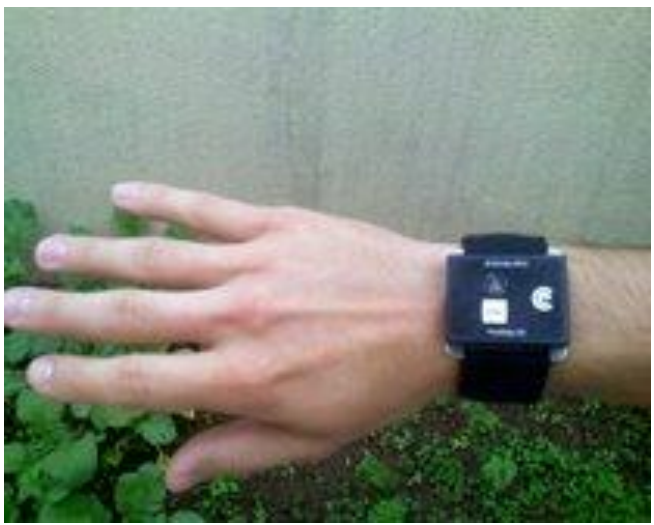

Usado no punho não dominante.

O voluntário é instruído a apertar o botão de eventos quando retira o aparelho e novamente quando volta a colocá-lo, a fim de evitar que as retiradas sejam confundidas com repouso. 
ANEXO $\mathrm{K}$

Diário de Glicemia

\begin{tabular}{|c|c|c|c|c|}
\hline Dias de estudo & \multicolumn{2}{|l|}{$1^{\circ}$} & \multicolumn{2}{l|}{$2^{\circ}$} \\
\hline & Data $=>$ & $/$ & Data $=>$ & $/$ \\
\hline Ao despertar & Hora & Glicemias & Hora & Glicemias \\
\hline Meio da manhã & $:$ & & $:$ & \\
\hline Antes do Almoço & $:$ & & $:$ & \\
\hline Meio da tarde & $:$ & & $:$ & \\
\hline \multirow{2}{*}{ Antes do jantar } & $:$ & & $:$ & \\
\hline Antes de dormir & $:$ & & $:$ & \\
\hline \multirow{2}{*}{ Outros Horários } & $:$ & & $:$ & \\
\cline { 2 - 5 } & $:$ & & & \\
\cline { 2 - 5 } & & & & \\
\hline
\end{tabular}

